\title{
SUBTASK 1.7 - EVALUATION OF KEY FACTORS AFFECTING SUCCESSFUL OIL PRODUCTION IN THE BAKKEN FORMATION, NORTH DAKOTA - PHASE II
}

Final Report

(for the period of May 1, 2010, through October 31, 2011)

Prepared for:

AAD Document Control

National Energy Technology Laboratory

U.S. Department of Energy

PO Box 10940, MS 921-107

Pittsburgh, PA 15236-0940

Cooperative Agreement: DE-FC26-08NT43291

Technical Monitor: John Terneus

Prepared by:

Darren D. Schmidt Steven A. Smith James A. Sorensen Damion J. Knudsen John A. Harju Edward N. Steadman

Energy \& Environmental Research Center University of North Dakota 15 North 23rd Street, Stop 9018

Grand Forks, ND 58202-9018 


\section{EERC DISCLAIMER}

LEGAL NOTICE This research report was prepared by the Energy \& Environmental Research Center (EERC), an agency of the University of North Dakota, as an account of work sponsored by the U.S. Department of Energy National Energy Technology Laboratory. Because of the research nature of the work performed, neither the EERC nor any of its employees makes any warranty, express or implied, or assumes any legal liability or responsibility for the accuracy, completeness, or usefulness of any information, apparatus, product, or process disclosed or represents that its use would not infringe privately owned rights. Reference herein to any specific commercial product, process, or service by trade name, trademark, manufacturer, or otherwise does not necessarily constitute or imply its endorsement or recommendation by the EERC.

\section{DISCLAIMER}

This report was prepared as an account of work sponsored by an agency of the United States Government. Neither the United States Government, nor any agency thereof, nor any of their employees, makes any warranty, express or implied, or assumes any legal liability or responsibility for the accuracy, completeness, or usefulness of any information, apparatus, product, or process disclosed, or represents that its use would not infringe privately owned rights. Reference herein to any specific commercial product, process, or service by trade name, trademark, manufacturer, or otherwise does not necessarily constitute or imply its endorsement, recommendation, or favoring by the United States Government or any agency thereof. The views and opinions of authors expressed herein do not necessarily state or reflect those of the United States Government or any agency thereof.

\section{ACKNOWLEDGMENTS}

The authors would like to acknowledge the hard work and dedication of several individuals and organizations, without whose help and support the research described in this report would not have been possible. We want to extend special thanks to the following people at the U.S. Department of Energy's National Energy Technology Laboratory (NETL) for their encouragement and guidance in the conceptualization of this project: Mr. John Duda, Director of the Strategic Center for Natural Gas and Oil; Mr. James Ammer, Division Director of the Natural Gas \& Oil Project Management Division at NETL; and Mr. John Terneus, NETL Project Manager. We also express our gratitude to the following people at the North Dakota Department of Mineral Resources: Mr. Lynn Helms, Director of the North Dakota Department of Mineral Resources, for his invaluable guidance, insight, and critique of some of the critical elements of this research program at every stage of its progress; Mr. Ed Murphy, North Dakota State Geologist, for his unwavering support and commitment to ensuring the technical success of this project; and Dr. Julie LeFever, Director of the North Dakota Core Library, and Mr. Kent Hollands of the North Dakota Geological Survey Core Library for their guidance and assistance in selecting and providing the EERC with the physical samples used to conduct the petrographical and geomechanical analytical activities. The authors also appreciate the efforts of 
Mr. Ron Ness of the North Dakota Petroleum Council, Mr. Wayne Biberdorf of Hess (retired), and Mr. David Brimberry and Mr. Russ Buettner of Marathon Oil Company for providing an industry perspective and support to this project: The authors thank the following members of the EERC technical staff for their critical contributions to this project; Mr. Jordan Bremer, Mr. Chris Beddoe, Mr. Erick Zacher, Mr. David Westerman, Mr. Blaise Mibeck, Mr. Corey Lindeman, and Mr. Ben Huffman for providing technical support to the laboratory analytical activities; Mr. Saurabh Chimote and Mr. Wes Peck for their efforts in creating the Web-based Bakken Decision Support System; and Mr. Terry Bailey for his insight, wisdom, dedication, and selfless contributions that have helped the technical team understand and illuminate the geologic complexities of the Bakken. Finally, the authors recognize the tremendous efforts of Ms. Carol Schimetz, Ms. Heather Johnson, Ms. Joyce Riske, Mr. Ray Pikarski, and Ms. Jane Russell for their invaluable support in the preparation and finalization of this report. 


\title{
SUBTASK 1.7 - EVALUATION OF KEY FACTORS AFFECTING SUCCESSFUL OIL PRODUCTION IN THE BAKKEN FORMATION, NORTH DAKOTA - PHASE II
}

\begin{abstract}
Production from the Bakken and Three Forks Formations continues to trend upward as forecasts predict significant production of oil from unconventional resources nationwide. As the U.S. Geological Survey reevaluates the 3.65 billion bbl technically recoverable estimate of 2008 , technological advancements continue to unlock greater unconventional oil resources, and new discoveries continue within North Dakota. It is expected that the play will continue to expand to the southwest, newly develop in the northeastern and northwestern corners of the basin in North Dakota, and fully develop in between. Although not all wells are economical, the economic success rate has been near $75 \%$ with more than $90 \%$ of wells finding oil. Currently, only about $15 \%$ of the play has been drilled, and recovery rates are less than $5 \%$, providing a significant future of wells to be drilled and untouched hydrocarbons to be pursued through improved stimulation practices or enhanced oil recovery.

This study provides the technical characterizations that are necessary to improve knowledge, provide characterization, validate generalizations, and provide insight relative to hydrocarbon recovery in the Bakken and Three Forks Formations. Oil-saturated rock charged from the Bakken shales and prospective Three Forks can be produced given appropriate stimulation treatments. Highly concentrated fracture stimulations with ceramic- and sand-based proppants appear to be providing the best success for areas outside the Parshall and Sanish Fields. Targeting of specific lithologies can influence production from both natural and induced fracture conductivity. Porosity and permeability are low, but various lithofacies units within the formation are highly saturated and, when targeted with appropriate technology, release highly economical quantities of hydrocarbons.
\end{abstract}

This subtask was funded through the Energy \& Environmental Research Center-U.S. Department of Energy Joint Program on Research and Development for Fossil Energy-Related Resources Cooperative Agreement No. DE-FC26-08NT43291. 


\section{TABLE OF CONTENTS}

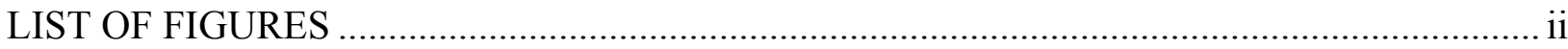

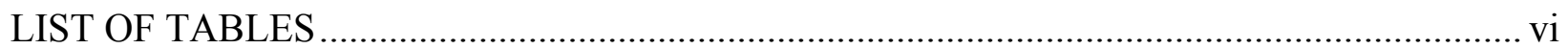

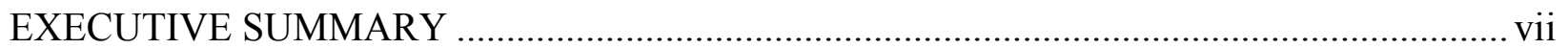

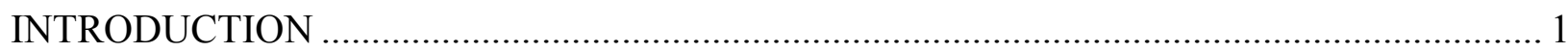

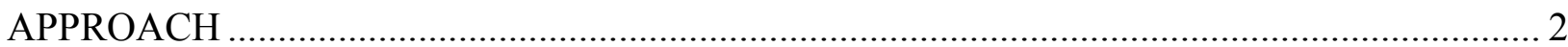

Industry Advisory Board ....................................................................................... 3

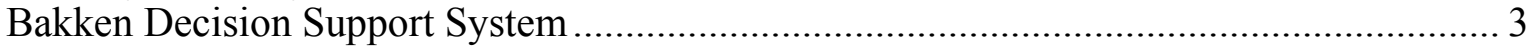

EXPERIMENTAL METHODS........................................................................................

Geomechanical Properties and Hydraulic Fracture Stimulation and Design ......................... 7

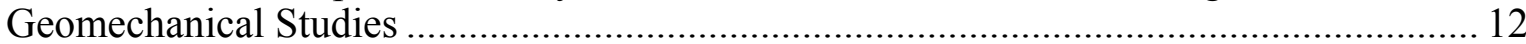

Selection of Intervals for Characterization ............................................................. 12

Geomechanical Experimental Methods ............................................................. 14

Geochemical and Petrographic Studies....................................................................... 15

Geochemical Studies - Experimental Methods ........................................................ 15

Petrographic Studies - Experimental Methods......................................................... 16

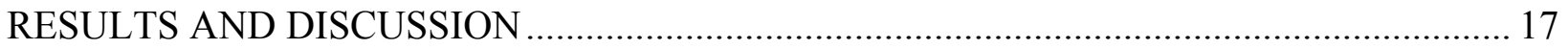

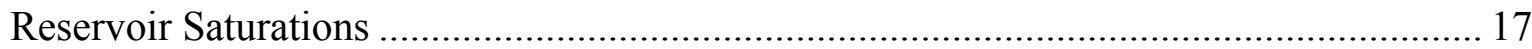

Reservoir Saturation Results and Discussion ................................................................... 24

Production Analysis of Middle Bakken Lithofacies in Dunn County ................................ 26

Completion and Stimulation Analysis for Wells in the Bakken Formation......................... 32

Database Description ........................................................................................ 32

Multistage Hydraulic Fracturing.......................................................................... 34

Diesel Gel and Water-Based Gel Hydraulic Fracture Fluids.................................. 34

Well Completions and Stimulations ………………………................................... 37

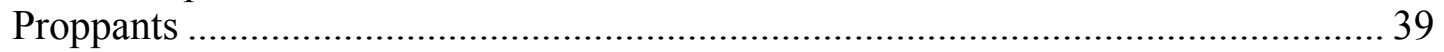

Proppant Concentrations................................................................................... 43

Summary of Analysis of Completion and Stimulation Database …………………... 44

Relationship Between Rock Fabric and Geomechanical Properties .................................... 45

Petrographic Studies ………………………………….................................... 46

Geomechanical Results..................................................................................... 55

Summary of Geomechanical Key Results .............................................................. 62

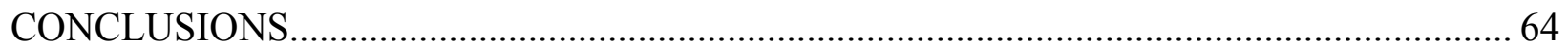

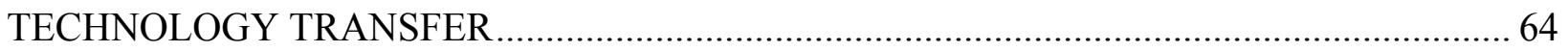

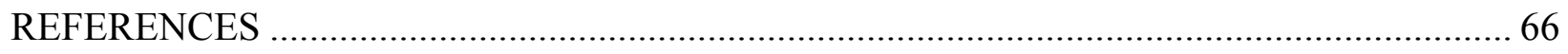

GEOMECHANICAL TESTING TECHNIQUES ......................................................... 


\section{LIST OF FIGURES}

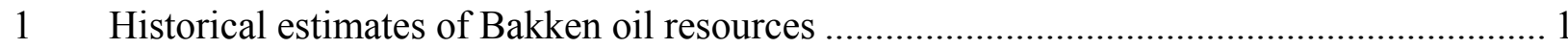

2 Geographical extent of the Bakken Formation within the Williston Basin ......................... 2

3 Home page for the BDSS, www.undeerc.org/bakken/................................................... 5

4 Example of the decision support GIS highlighting mapping tools and well information..... 6

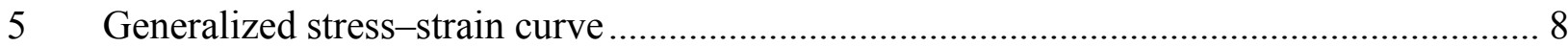

$6 \quad$ Influence of mechanical properties relative to calculated fracture width for a fixed fracture height and net pressure....................................................................................... 9

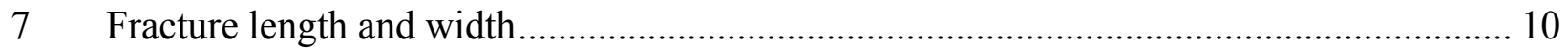

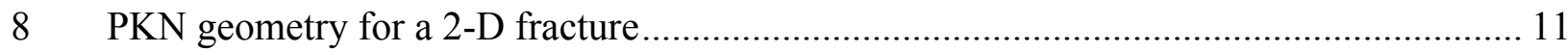

9 Stratigraphic column illustrating the three prominent layers of the Bakken Formation

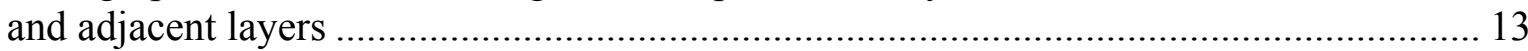

10 Location of wells sampled for geomechanical testing .................................................. 14

11 First 6 months of cumulative oil production for Sanish and Parshall Fields in

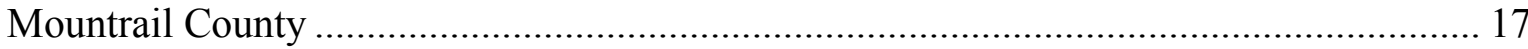

12 First 6 months of cumulative oil production for Dunn County near the Heart River fault. 18

13 A three-dimensional contour of the hydrogen index wall of the upper Bakken shale and its relation to Sanish and Parshall Fields .................................................................... 19

14 Pressure anomaly of Parshall Field and multitrapping mechanisms ................................. 20

15 Areal distribution of pore fluid gradients in the Bakken Formation ................................... 20

16 Map of average water saturations from well logs produced by Simenson........................... 21

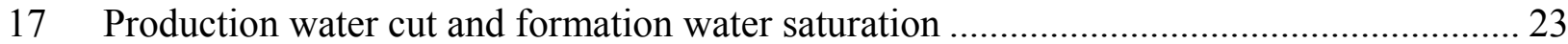

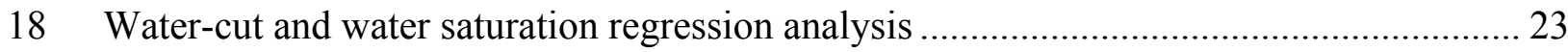

19 Data for 15 months of cumulative oil production and calculated formation water saturation 


\section{LIST OF FIGURES (continued)}

20 Regression analysis of production versus formation saturation......................................... 26

21 Typical well path in relation to upper and lower Bakken shales for early horizontal completions in Dunn County ........................................................................................... 27

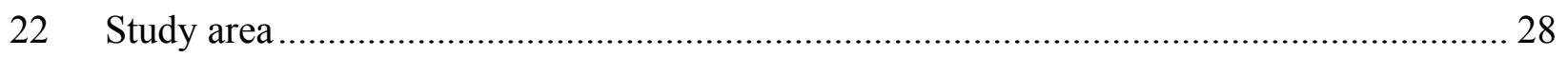

23 Lithologic description of the Bakken Formation from core showing relation to well log

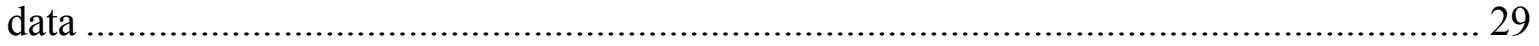

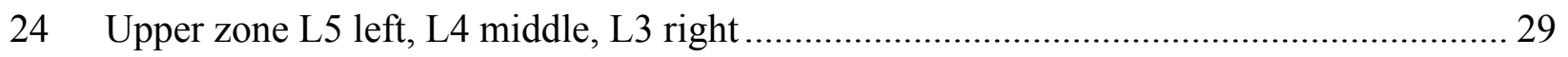

25 Central basin facies middle zone L2 left and lower zone (bottom of L2) and L1 right...... 30

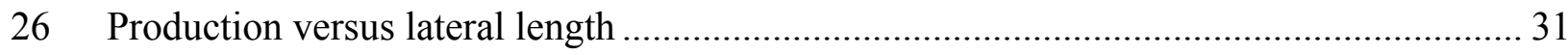

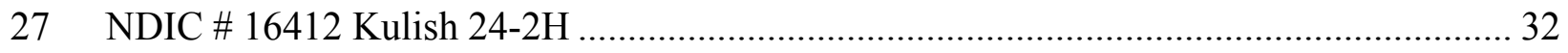

28 Number of hydraulic fracture stages for each well and 6-month cumulative production over time in the Bakken Formation .................................................................................... 35

29 Number of stages hydraulically fractured in a well versus 6-month cumulative

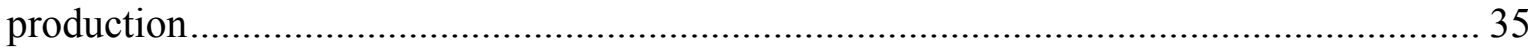

30 Cumulative (6-month) production comparison of wells stimulated with gelled diesel

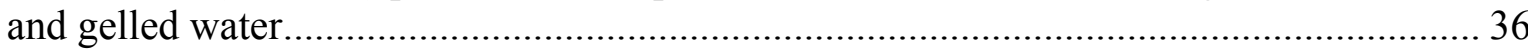

31 Comparison of production from wells using sliding sleeves, plug and perf, and combination stimulation methods ................................................................................. 38

32 Production per linear foot for short and long laterals in Mountrail County....................... 39

33 Production per linear foot relative to the spacing of isolated hydraulical fracture zones

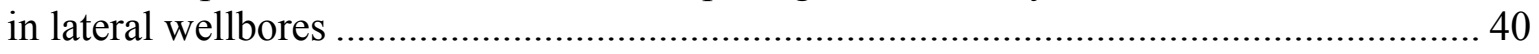

34 Performance of ceramic and sand proppants in Dunn County, 6-month cumulative production

35 Performance of ceramic and sand proppants in Williams County, 6-month cumulative production. 


\section{LIST OF FIGURES (continued)}

36 Performance of ceramic and sand proppants in Mountrail County, 6-month cumulative production.

37 Cumulative 6-month production of wells stimulated with various sizes of sand in Mountrail County

38 Cumulative 6-month production for wells stimulated with various sizes of ceramics and sand in McKenzie and Williams Counties

39 Proppant concentration and 6-month cumulative oil production ....................................... 44

40 Multistage completions and 6-month cumulative production for Dunn County wells ....... 45

41 Photographs of slabbed core samples representing the upper Bakken shale, middle Bakken, and Three Forks Formations

42 Location of wells from which thin sections were analyzed ........................................... 47

43 Generalized depositional model for the Bakken system …........................................... 50

44 Photomicrograph of the middle Bakken showing tight, argillaceous, fine-grained dolomite with floating silt grains 50

45 Thin-section photomicrograph of the Three Forks Formation showing chaotically bedded organic clays, microsparitic dolomite, and floating silt grains

46 Thin-section photomicrograph of Sample 00531 showing a partially healed microfracture

47 Thin-section photomicrograph of Sample 00638 showing a hydrocarbon-filled, partially cement-filled pore

48 Thin-section photomicrograph of Sample 00625 showing heavy dolomite cement growth through a very fine sand/siltstone matrix ............................................................. 52

49 Examples of the scheme for classification of thin-section samples .....................................54

50 Chart showing the relationship between depth and measured peak strength for all samples in the study area

Continued... 


\section{LIST OF FIGURES (continued)}

51 Chart showing the relationship between depth and measured peak strength for all samples tested

52 Chart showing the relationship of peak strength and Young's modulus for the middle Bakken and Three Forks Formations

53 Chart showing the relationship of depth to Young's modulus in vertically sampled wells

54 Charts comparing peak strength to depth for vertically sampled wells in the Bakken and Three Forks Formations

55 Young's modulus plotted against depth and comparing values with respect to the different classifications of bedding structure

56 Peak strength values plotted against depth and comparing values with respect to the different classifications of bedding structure

57 Map illustrating generalized interpretation of the distribution of Young's modulus values for the middle Bakken

58 Young's modulus for Three Forks samples plotted against depth and comparing values with respect to the different classifications of bedding structure

59 Peak strength values for Three Forks samples plotted against depth and comparing values with respect to the different classifications of bedding structure 


\section{LIST OF TABLES}

1 Mechanical Properties of Berea Sandstone Relative to Confining Pressure Conditions .... 15

2 Cementation Exponent Utilized for $\mathrm{S}_{\mathrm{w}}$ Calculations by Simenson.............................. 21

$3 \quad$ Archie Variable Statistical Results ......................................................................... 22

4 Average Production - Cumulative 6-month and Number of Wells in Data Grouping ....... 30

5 Characterization of Completion and Stimulation Database ....................................... 33

6 Results of Petrographic Analysis for Bakken Thin-Section Samples ............................ 48

7 Data Derived from Mechanical Testing of the Middle Bakken and Three Forks

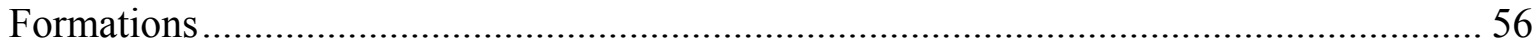

8 Display of Sample and Mechanical Data for the Three Wells from Which Samples from Multiple Vertical Zones Were Tested for Mechanical Properties 


\section{SUBTASK 1.7 - EVALUATION OF KEY FACTORS AFFECTING SUCCESSFUL OIL PRODUCTION IN THE BAKKEN FORMATION, NORTH DAKOTA - PHASE II}

\section{EXECUTIVE SUMMARY}

Unconventional oil sources such as the Bakken and Three Forks Formations represent a significant frontier for domestic energy development. The North Dakota Department of Mineral Resources predicts that oil production from the Bakken and Three Forks Formations will grow from the current 444,000 barrels a day to more than 700,000 barrels a day in the next 4 to 7 years. The two formations have produced more than 300 million barrels to date. In North Dakota alone, 2010 production exceeded 85 million barrels. However, while production is prolific, many questions remain as to how the resource can be more fully and efficiently developed.

Since October 2008, the Energy \& Environmental Research Center (EERC) has conducted a multidisciplinary research program in two phases to identify key attributes of successful Bakken wells and provide technically based guidance to stakeholders regarding future exploitation efforts. The EERC's Bakken research program has taken a five-pronged approach to evaluate and compare key attributes of the Bakken play: geology, geochemistry, petrography, geomechanics, and engineering. Phase I work focused on aspects of Mountrail and Dunn Counties and indicated that geological factors and engineering practices both played critical roles in determining the likelihood of success for any given Bakken well. The Phase II efforts have expanded on the Phase I work, looking more broadly across the North Dakota portion of the Bakken play. The results of the Phase II work center on well completions, productivity, and geologic factors indicative of productivity, such as geochemistry-related oil saturation, geomechanical properties related to the design of hydraulic fractures, and petrography for characterization of the rock fabric.

The key findings of the Phase II work are as follows:

1. Production in the Bakken and Three Forks Formations is undoubtedly benefiting from multistage hydraulic fracturing. Completion data collected from over 700 wells have clearly enumerated the engineering aspects of the play and suggest that there is room to further improve stimulation treatments with quality proppants and shorter treatment spacings along the lateral wellbore.

2. Water and oil saturation data coupled with water-cut data appear to be useful in identifying and evaluating productive and nonproductive areas along the eastern edge of the Bakken play. The correlation appears to be less applicable to production in the western portion of North Dakota, although more saturation data are necessary to fully evaluate this concept.

3. The majority of identifiable porosity in thin-section samples was in partially healed microfractures or in residual hydrocarbon-filled accumulations. 
4. Pore structures in thin sections were observed to be highly disconnected while intragranular permeability was highly compacted and cemented. This supports the observation that productivity has historically been attributed to natural and/or induced fractures.

5. Areas of North Dakota that have highly productive lithofacies within the middle Bakken tend to comprise geomechanically weaker rocks. Brittle rocks with high Young's modulus tend to propagate longer fractures.

6. Strength of middle Bakken rocks appears to be related to microstructure and facies. Structureless and weakly laminated samples tended to display higher peak strength, whereas strongly laminated or chaotically bedded samples were weaker.

7. Geomechanical properties in the Three Forks vary widely because of the highly laminated nature of the rock. When not highly laminated, Three Forks rocks can have higher strengths than middle Bakken rocks.

8. With respect to peak strength in the Bakken, sample data consistently fall in the 45,000-psi area, although the actual range was from 18,000 to 58,000 psi. Depth was not a significant factor affecting mechanical strength, although deviations from the norm appear to be tied to microstructure and/or facies.

9. Examination of data from horizontal wells in which the wellbore treatments have targeted softer rocks suggests that proppant placement in the near wellbore requires critical attention to maintain a good conductivity of fluids from the formation.

Technological advancements, particularly with respect to hydraulic fracturing, continue to unlock greater tight oil resources, and expansion of the Bakken-Three Forks play in North Dakota continues to develop. It is expected that new wells will continue to be drilled in Mountrail and Dunn Counties, which have been the focal points of activity for the past few years. Drilling will likely expand to the southwest, northwest, and north-central parts of North Dakota. While not all wells drilled in recent years have been economical, the success rate has been near $75 \%$, with more than $90 \%$ of the wells finding oil. Currently, only about $15 \%$ of the known play has been drilled and current recovery rates are typically less than $5 \%$. With the size of the recoverable resource being in the range of several billions of barrels, these circumstances indicate that there will continue to be opportunities to drill wells and pursue untouched hydrocarbons through improved stimulation practices or enhanced oil recovery operations.

This subtask was funded through the EERC-U.S. Department of Energy Joint Program on Research and Development for Fossil Energy-Related Resources Cooperative Agreement No. DE-FC26-08NT43291. 


\section{SUBTASK 1.7 - EVALUATION OF KEY FACTORS AFFECTING SUCCESSFUL OIL PRODUCTION IN THE BAKKEN FORMATION, NORTH DAKOTA - PHASE II}

\section{INTRODUCTION}

The Bakken Formation is known to be an important source rock for oil in the Williston Basin. Total organic carbon (TOC) within the shales may be as high as $40 \%$, with estimates of total oil in place across the entire Bakken Formation ranging from 10 to 500 billion barrels (Figure 1). While the hydrocarbon resource within the Bakken Formation is tremendous, the Bakken is considered to be an unconventional tight oil play because it is characterized by very low porosity and permeability. Despite its unconventional nature, the significance of oil production from the Bakken Formation in North Dakota and the importance of gaining a greater understanding of the technical issues facing its further development can be demonstrated by the recent growth in exploration and production $(\mathrm{E} \& \mathrm{P})$ activity.

The Bakken and underlying Three Forks Formations are present throughout a significant portion of the northern Williston Basin (Figure 2) and are productive in numerous reservoirs throughout eastern Montana, western North Dakota, southeastern Saskatchewan, and southwestern Manitoba. Production from these reservoirs has relied upon the use of multistage hydraulic fracturing to allow formation fluids to flow to producing oil wells. These techniques have recently become better understood and have continued to contribute to successful initial production rates throughout the basin. However, variable success is still occurring, depending on field development, drilling, and completion approaches applied to a specific area. While variability within a play is nothing unusual in the petroleum industry, the Bakken play is noteworthy because of the wide variety of approaches and technologies that have been applied to create sustainable long-term productivity.

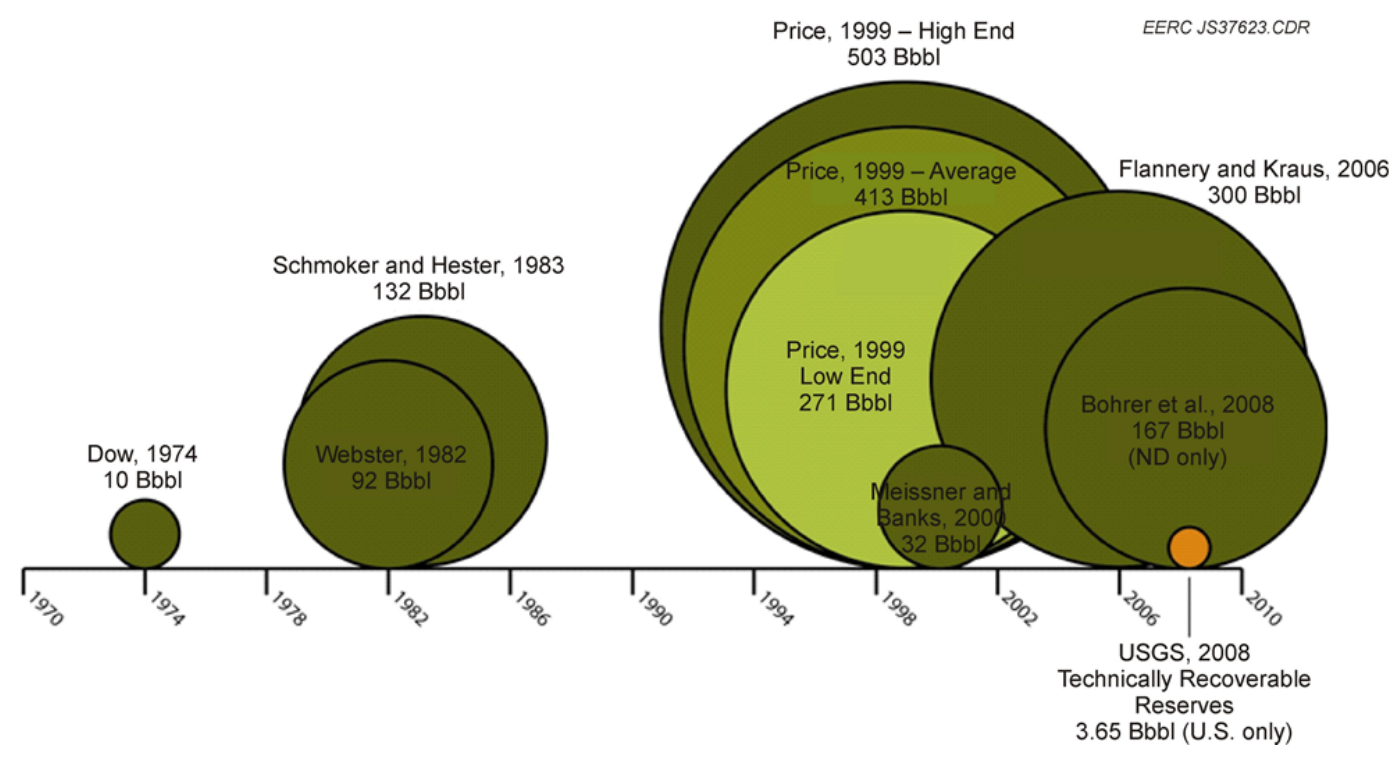

Figure 1. Historical estimates of Bakken oil resources. 


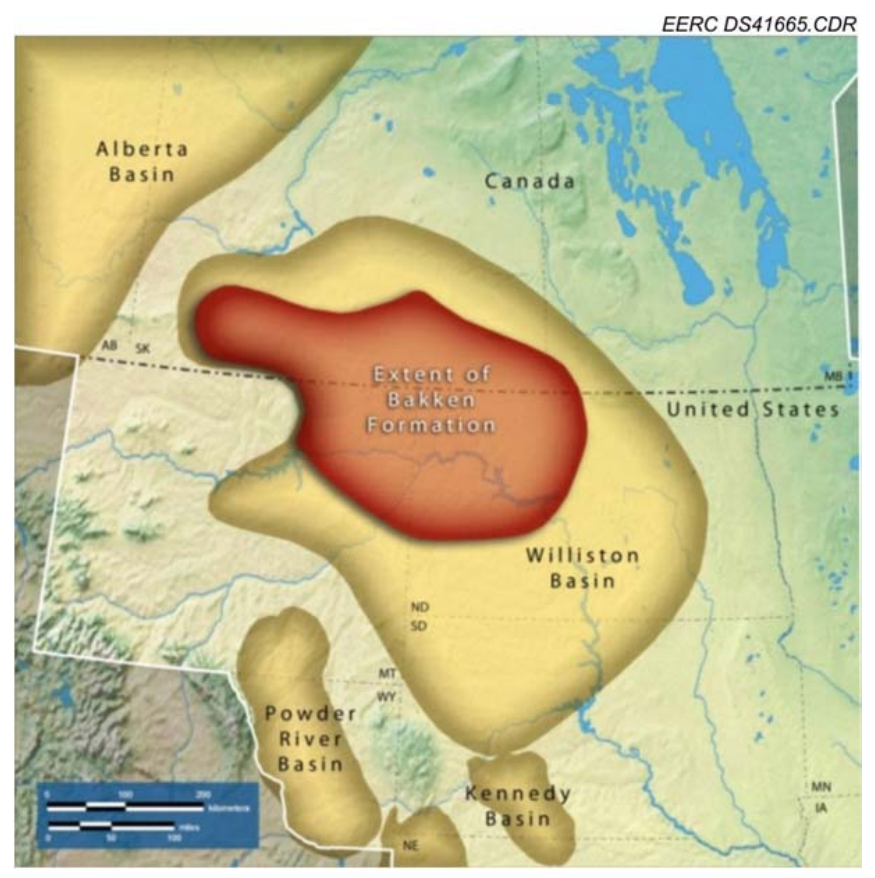

Figure 2. Geographical extent of the Bakken Formation within the Williston Basin.

\section{APPROACH}

Since October 2008, the Energy \& Environmental Research Center (EERC) has conducted a multidisciplinary research program to identify key attributes of successful Bakken oil wells and provide technically based guidance to stakeholders regarding future exploitation efforts. The EERC's Bakken research program was conducted as part of the ongoing EERC-U.S. Department of Energy (DOE) Joint Program on Research and Development for Fossil Energy-Related Resources Cooperative Agreement. The program has taken a five-pronged approach to evaluate and compare key attributes of the Bakken petroleum system, which includes all members of the Bakken Formation and the underlying Three Forks Formation. In broad terms, the five prongs of the research program are geology, geochemistry, petrographics, geomechanics, and engineering. Aspects of each of these areas have been evaluated and compared between different productive areas of the Bakken play. Phase I of the EERC's Bakken research program was completed in March 2010, and the results of the Phase I activities are presented and discussed in Sorensen and others (2010).

To address and expand upon many of the key results and new questions generated by the Phase I activities, the EERC conducted Phase II of the Bakken research program from April 2010 until October 2011. One of the major changes in the program was the expansion of the scope to include examinations of aspects of the Three Forks Formation, which has grown in prominence as a major producing tight oil play in its own right. The Phase II project work plan comprised four activities: Activity 1 - Bakken Decision Support System, Activity 2 Geomechanical Studies, Activity 3 - Geochemical and Petrographic Studies, and Activity 4 Industry Advisory Board and Technology Transfer. While the activities were organized, managed, and conducted according to this structure, this final report for Phase II has been 
organized to present the experimental methods and results of the project activities in terms of the key focal areas that are critical to understanding successful exploitation of the Bakken and Three Forks Formations. Those key focal areas are the physical characteristics of the reservoir system as represented by its geomechanical, geochemical, and petrographic properties, as well as the nature of completion and stimulation technologies that are applied to the reservoir. The concepts, methods, results, and subsequent discussion have been presented in this report to provide stakeholders with a more holistic interpretation of the various data sets with an eye toward illustrating potential important relationships between attributes.

\section{Industry Advisory Board}

An industry advisory board was established to provide insight and guidance regarding project activity and to help target results given changing circumstances, market influences, and perceived industry needs. Various members from industry were consulted over the course of the project, both formally and informally. Three formal industry advisory board meetings were held over the course of the project. Members included the North Dakota Department of Mineral Resources (NDDMR), the North Dakota Petroleum Council, the North Dakota Geological Survey (NDGS), and WB Consulting. Meetings were held on the following dates: December 1, 2010, Bismarck, North Dakota; May 31, 2011, Denver, Colorado; and September, 21, 2011, Medora, North Dakota. Industry participants who have attended and provided input have included the following: Murex, Neset Consulting, Baytex, Hess Corporation, Marathon, Enbridge, and United Energy Trading.

\section{Bakken Decision Support System (BDSS)}

The BDSS was further developed under Phase II as a Web-based information and research tool to support the application of key data toward improving oil and gas production from the Bakken. The BDSS includes information and links to geologic descriptions, developmental history, oil production, and reserve estimate information for both the Bakken Formation and the Three Forks Formation. The primary feature of the BDSS is an interactive geographical database of wells that allows the user to compare and analyze relevant information, including production and completion information for all publically available data. Analytical tools have been developed within the BDSS to support the evaluation and interpretation of the data. Analytical tools within the database include, but are not necessarily limited to, advanced search capabilities, export-to-spreadsheet capabilities, map layers of key geological characteristics (e.g., lithofacies, clay content, clastic versus carbonate), and the ability to link data with selected relevant modeling software. Specific elements of the BDSS include the following:

- Maps of key geological properties (e.g., thickness, lithology, structure, depositional environment, organic carbon)

- Development history of the Bakken and Three Forks plays

- Oil production data as periodically reported to the NDDMR

- Completion and stimulation information and data 
- Interactive map associated with the database

- Downloadable data sets

- Downloadable reports and papers by other researchers working on the Bakken and Three Forks oil plays

- Links to other Web sites and relevant publicly available technical articles focused on Bakken and/or Three Forks information

- Technology transfer products developed over the course of this project

Production data from wells drilled into the Three Forks Formation are included in the BDSS. The BDSS is user-friendly and enables comparison of geologic and production data. All content on the BDSS is publicly available, and production data can be downloaded with a subscription from the NDDMR.

The BDSS was developed by the EERC's research information systems group, geologic research staff, and outreach coordinators to develop a quality interactive publically available product. The home page shown in Figure 3 illustrates the Web 2.0 format and the three key interactive features, including downloadable resources, decision support, and up-to-date news stories. Other resources provided on the Web site include:

1. Bakken Formation geology, production, and history.

2. Descriptions of completion and well stimulation technologies.

3. National Energy Technology Laboratory (NETL)-sponsored research studies.

4. A resource toolbox providing links to various geologic maps and studies.

The interactive features of the Web site provide valuable information for site visitors. The downloadable resources include direct links to pertinent publications, a bibliography of over 240 citations, and a downloadable file of the latest updated monthly production data from Bakken and Three Forks wells. The decision support is a geographic information system-(GIS)based tool that can be used to visualize geographic information relative to wells, production, and geologic data for the North Dakota portion of the Williston Basin. The GIS tools provide the following functionality:

- Overview - adds an overview map to the Viewer application user interface

- Bookmark - spatial bookmarks for quick navigation

- Draw - quick drawing (i.e., redlining)

- Navigation - provides a comprehensive set of map navigation controls in the Viewer

- Legend - displays legend of active layers

- Layer list - displays the operational data in the Viewer application

- Print - simple printing of the Viewer display

- Identify - identify active layers on a map 


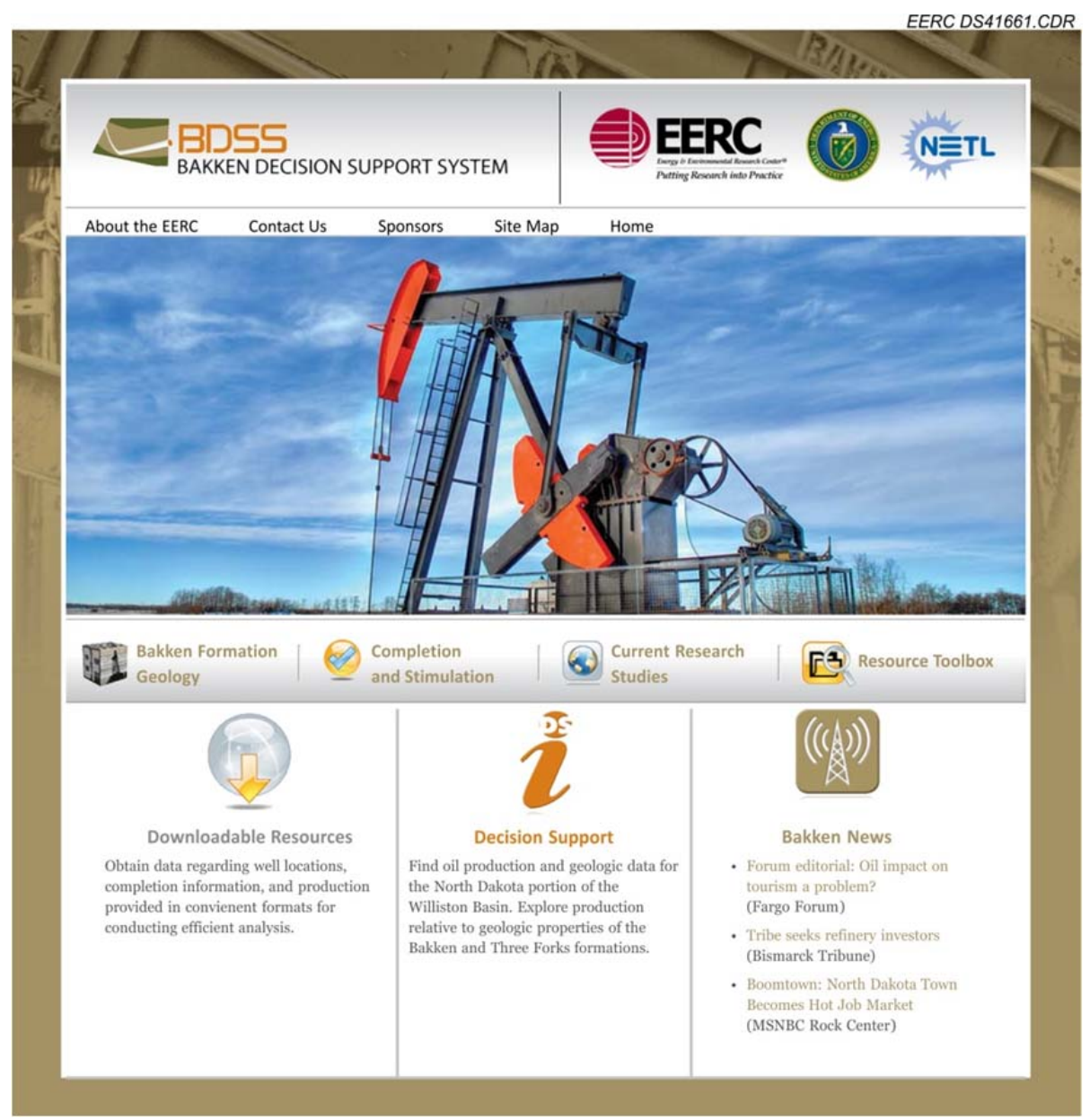

Figure 3. Home page for the BDSS, www.undeerc.org/bakken/.

- Coordinate - displays x,y coordinate values to appear in the application's user interface

- Elevation - allows creation of an elevation on the map between two points

- Map switcher - allows switching between different base maps

- Help - text-based help and examples

An example of the GIS is provided in Figure 4 to indicate the functionality for the display of well locations, production data, and various mapping tools. Layers that are built into the Web site include geologic data obtained from the NDGS. The GIS tool provides the ability to overlay wells with the following:

\section{- North Dakota oil field boundaries}

- Cumulative oil production contours

- Major geologic structural features such as the Nesson Anticline

- Structural isopach maps of the total Bakken, upper member of Bakken shale, middle member of Bakken, lower member of Bakken shale, and Three Forks 


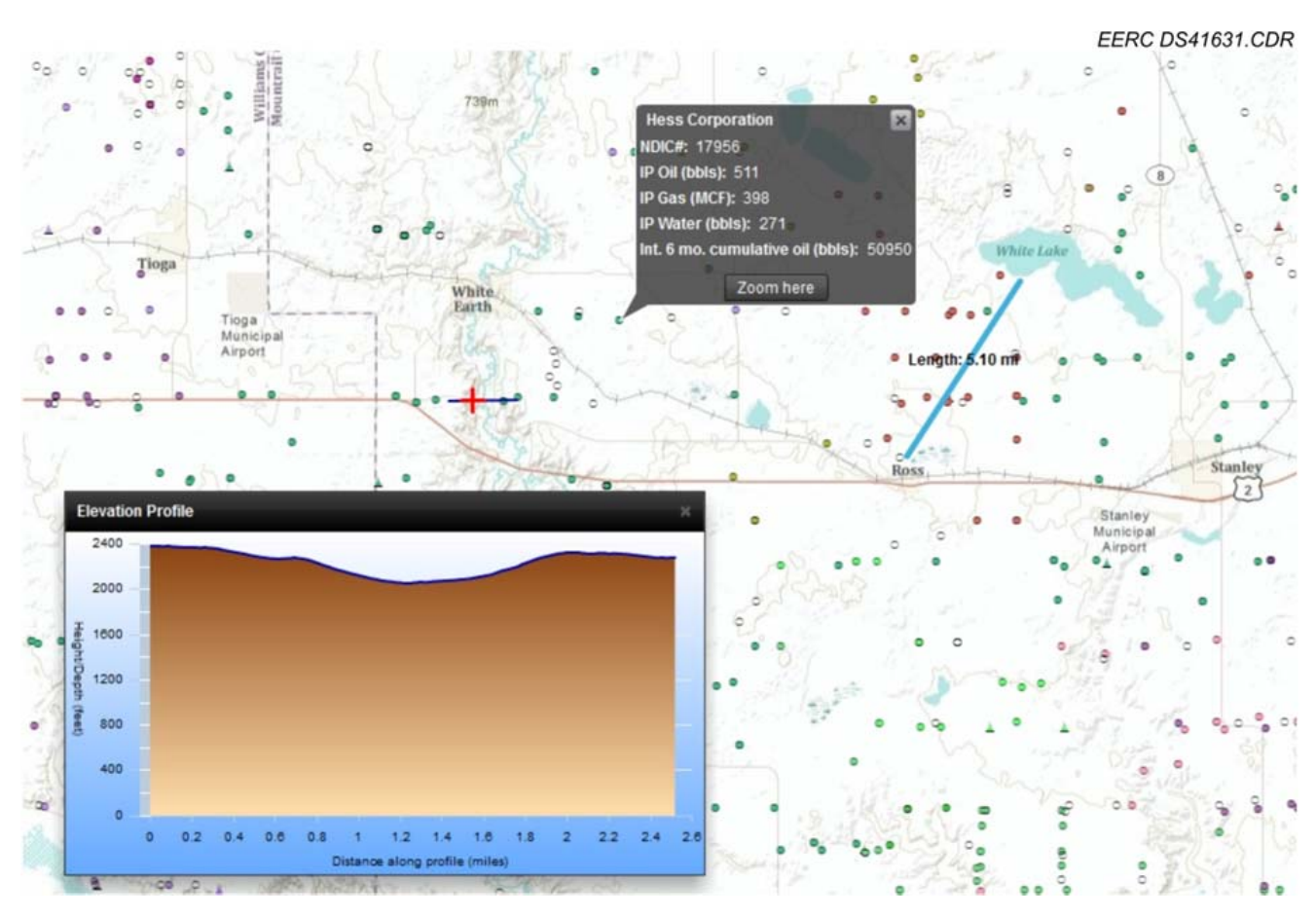

Figure 4. Example of the decision support GIS highlighting mapping tools and well information.

- Geochemical data for the Bakken shales such as the TOC, hydrogen index, and thermal maturity

Additionally, users have the functionality to turn the above layers on and off, while highlighting the display of North Dakota counties, confidential and permitted wells, and a legend for operators of Bakken and Three Forks wells. Recent news stories are updated daily and sourced from local articles through the North Dakota Petroleum Council.

The BDSS was constructed with high-quality tools, including Adobe Flex Builder 4, an Environmental Research Systems Institute (ERSI) structured query language (SQL) server geodatabase, and the ESRI software development kit for Flex. These recent technologies allow the site to function quickly and crisply.

The Bakken Web site was released June 30, 2011, and has received over 2545 visits with 6997 page views. Users are normally viewing more than 2 pages each visit. Internet traffic is primarily from within the United States. The EERC will be seeking future industry support to keep the Web site functional and up to date. A procedure has been established with the NDDMR to provide updated production data. A Fossil Energy Techline Web article was published by NETL on July 19, 2011, announcing the release of the Web site. 


\section{EXPERIMENTAL METHODS}

\section{Geomechanical Properties and Hydraulic Fracture Stimulation and Design}

Because hydraulic fracture stimulation is critical to the success of Bakken and Three Forks production, it is necessary to understand the mechanical properties of these rock units and to fully understand their role in the success of this play. Mechanical properties dictate the size, frequency, pattern, and orientation of fracture networks (natural and artificial) at both the microand macroscale. As such, the EERC has conducted a series of mechanical tests performed on selected core material from the Bakken and Three Forks Formations. Specifically, multistage triaxial testing was conducted to derive the peak strength characteristics of these formations. The overall goal of the testing program is to characterize the geomechanical properties of the Bakken and Three Forks Formations in the North Dakota portion of the Williston Basin.

Geomechanical property data is an essential element in the design of hydraulic fracture stimulation necessary for the economic production of oil from the Bakken and Three Forks Formations. The Bakken and Three Forks Formations are characterized by organic shales that provide a source of hydrocarbons for adjacent, less organically rich rocks characterized by low permeability and porosity. The shales are oil-prone because of their relatively lower thermal maturity when compared to gas-prone shales. Because of the limited permeability of the formations, the Bakken and Three Forks can be classified as tight oil plays. Hydraulic fracturing technology is essential for producing hydrocarbons from tight oil formations. Hydraulic fracturing is the process of pumping a fluid into a wellbore at an injection rate that is too great for the formation to accept under normal flow conditions. As the resistance to flow in the formation increases, the pressure of the wellbore eventually exceeds the breakdown pressure of the formation. Once the formation "breaks down," a fracture is formed, and the injected fluid begins moving down the fracture. The fracture is normally formed at the wellbore in two directions that propagate 180 degrees from one another. Deviations from this ideal shape occur when the formation is naturally fractured or cleated, in which case, multiple fractures can be created and propagate. Although there are many considerations for proper fracture design, geomechanical properties are a measurable component to hydraulic fracture calculations.

Hydraulic fracturing involves fracture mechanics, solid mechanics, fluid mechanics, and thermal mechanics. Proper hydraulic fracture design is facilitated by theoretical modeling. Modeling is conducted to optimize economics, design a pump schedule, simulate the fracture geometry, estimate proppant placement, and guide fracture treatment evaluation. Early work on fracture modeling was reported by Sneddon and Elliot (1946). They proved that for a fracture of fixed height and infinite extent, the maximum width relative to net pressure is as follows.

$$
w=\frac{\left(1-v^{2}\right) 2 P_{n e t} H}{E}
$$

In rock mechanics, Young's modulus (E) and Poisson's ratio (v) are mechanical properties obtained from standard testing of rock cores. Young's modulus is defined by stress divided by strain and is obtained from the slope of the elastic portion of the stress-strain curve for a given test specimen (Figure 5). 


$$
E=\frac{\text { stress }}{\text { strain }}=\frac{\sigma}{\epsilon}
$$

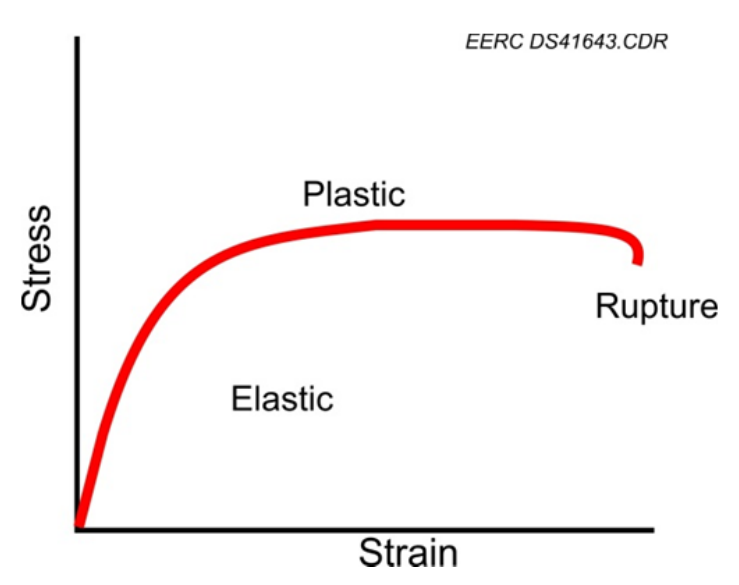

Figure 5. Generalized stress-strain curve.

Stress is the measure of force per unit area normally expressed as pounds per square inch (psi). Stress is the result of the overburden load on a rock formation or, in terms of standard rock mechanics testing, the load divided by the cross-sectional area of the test specimen. Strain is a measure of deflection as the result of an applied stress. Strain is equivalent to the change in length divided by the original length and is expressed as (in./in.).

Generally, Young's modulus is an elastic constant that provides a relative measure of the stiffness of a material. Additional elastic constants which can be related to Young's modulus for homogeneous isotropic materials include the bulk modulus $(\mathrm{K})$ and shear modulus $(\mathrm{G})$. The definitions and relationships are provided in equations below.

$$
\begin{gathered}
\text { Bulk Modulus: } K=-V \frac{\partial P}{\partial V} \\
\text { Shear Modulus: } G=\frac{\text { shear stress }}{\text { shear strain }} \\
E=2 G(1+v) \\
E=3 K(1-2 v)
\end{gathered}
$$

Poisson's ratio is the measure of transverse strain (horizontal) to axial strain (vertical) for a given material. The range of Poisson's ratio for most materials is 0 to 0.5 . Materials such as rubber have a ratio near 0.5 and a material such as cork near 0. Rocks typical for the Bakken Formation can range from 0.24 to 0.32 (North Dakota Industrial Commission [NDIC], 2006). In comparison, steel has a Poisson's ratio of 0.3 . 
Given the relationship of net pressure and calculated fracture width, the influence of mechanical properties can be significant in fracture design. Relative to the calculation of fracture width modeled by Sneddon and Elliot, it can be determined that the higher the Young's modulus, or "stiffness" of the rock, the smaller the resulting fracture width. Figure 6 provides an example of fracture width calculated for varying Young's modulus and Poisson's ratio given fixed fracture height and net pressure. Considering the potential variability of mechanical properties for rock layers within the Bakken Formation, a Poisson's ratio over the range of 0.24-0.32 would have less of an impact on the calculated fracture width versus Young's modulus. Young's modulus in the Bakken Formation can vary from 3,500,000 to 9,500,000 psi (NDIC, 2006), affecting the fracture width over a range of 0.13 " to 0.38 " (over a factor of 2). A high Young's modulus tends to produce narrow fractures relative to low Young's modulus, which results in wider fractures (Holditch, 2007).

In order to understand the relative effect of fracture width on the magnitude of oil production, the concept of dimensionless fracture conductivity is as follows where $\mathrm{k}=$ formation permeability and $\mathrm{k}_{\mathrm{f}}=$ permeability of the fracture (see Figure 7).

Formation and fracture permeability perform in series. Given a tight formation such as the Bakken, the overall well performance will be limited to the permeability of fluids into the fracture combined with the fracture permeability. If $\mathrm{F}_{\mathrm{CD}}$ is low, the well performance is constrained by the fracture conductivity; therefore, increasing fracture width would improve well performance where an increase of fracture length would not. Conversely, if $\mathrm{F}_{\mathrm{CD}}$ is high, the fracture is highly conductive relative to the formation, and an increase in length would be

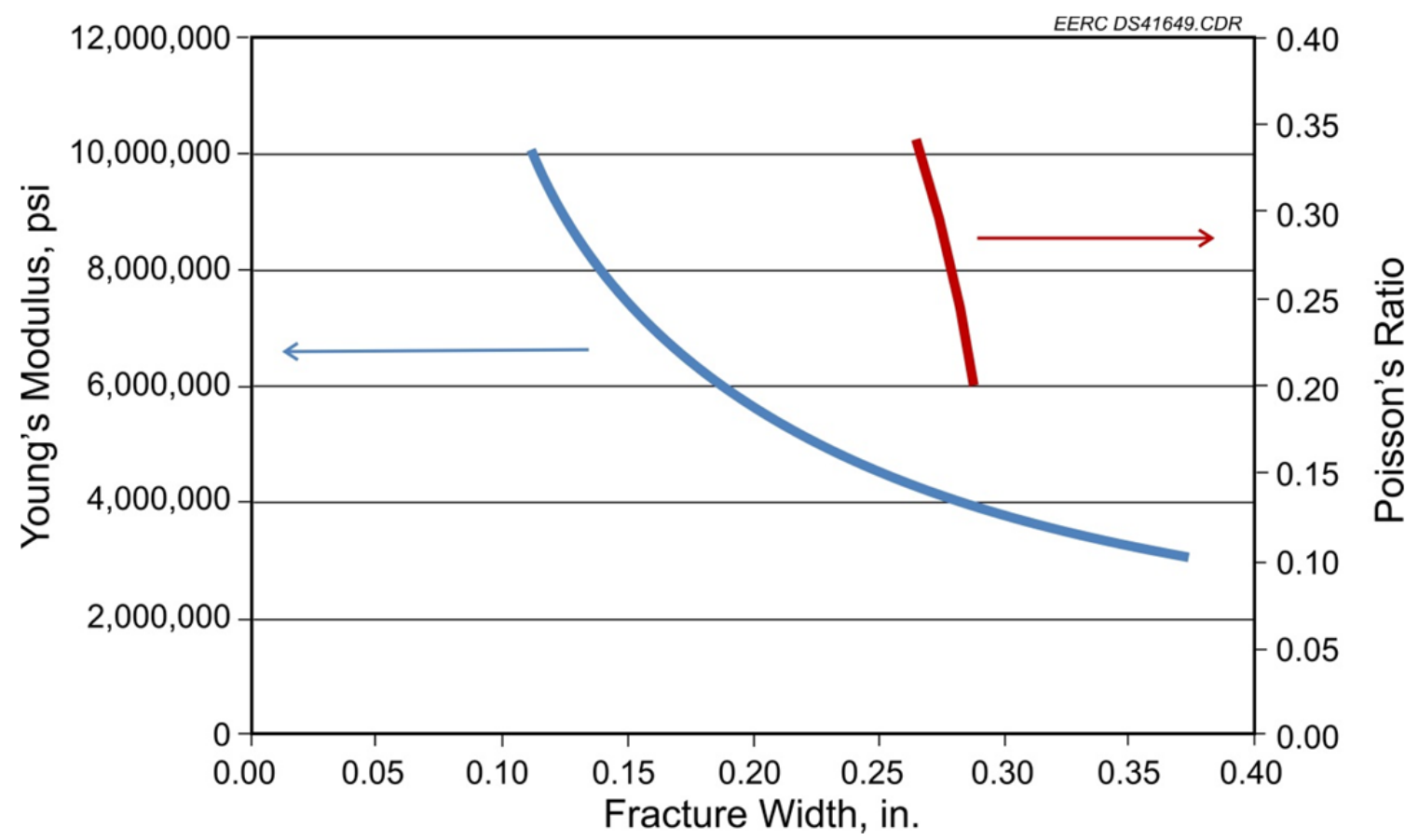

Figure 6. Influence of mechanical properties relative to calculated fracture width for a fixed fracture height and net pressure. 


$$
F_{C D}=\frac{k_{f} w}{k_{f} w}
$$
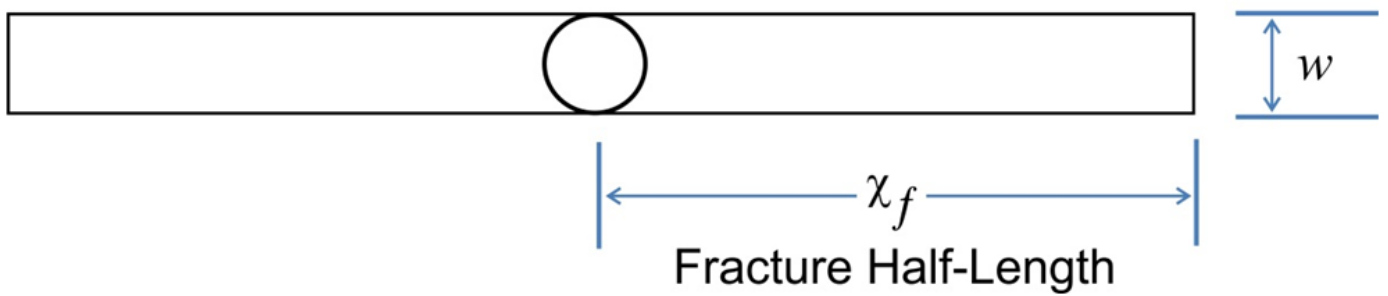

Figure 7. Fracture length and width.

beneficial while improving conductivity via width or fracture permeability would not. The effective wellbore radius, a concept developed by Prats (1961), is used to describe the apparent increase in wellbore radius as the result of a fracture in which a fractured well will appear to have a larger diameter than the true diameter. The concept has been used to prove the varied behavior of fracture stimulation in high- to moderately permeable reservoirs versus tight formations such as the Bakken. The relationship provides that achieving a fracture conductivity of 2.3 results in a relationship where the effective wellbore radius is equal to one-half the fracture length and is equivalent to expanding the wellbore of the well (Jones and Britt, 2009). Therefore, in permeable reservoirs, a dimensionless fracture conductivity of 2.3 maximizes the performance, and extension of fracture length is equivalent to increasing the wellbore diameter. In contrast, flow to the wellbore is limited in tight formations, and therefore, the fracture conductivity could be viewed as infinite, where fracture length becomes the most critical parameter to well productivity. Understanding the dimensionless fracture conductivity is important to fracture design.

The most time-consuming part of fracture design is developing complete and accurate data. Data that can be controlled by the engineer include the following:

- Well completion details

- Treatment volume

- Pad volume (fluid pumped early in the treatment with no proppant)

- Injection rate

- Fracture fluid density and viscosity

- Fluid loss additives

- Propping agent type and volume

The following are data that must be measured or estimated and cannot be controlled by the engineer:

- Formation depth and thickness

- Permeability and porosity

- In situ stresses in pay zone and surrounding layers 
- Formation modulus (Young's modulus or elastic modulus)

- Poisson's ratio

- Reservoir pressure

- Formation compressibility

Operating companies run downhole geophysical logs, cut cores, and conduct well tests to determine the properties of reservoir layers. It is not practical to collect such data on every well; therefore, data from a few wells are correlated to log parameters, so logging of subsequent wells can be used to compile accurate data sets. Fracture treatment design is typically done by entering data sets into a pseudo-three-dimensional (P3-D) model. Fracture growth can be estimated relative to the various layers of reservoir rock. Brittle rock will propagate fractures in the direction of the largest principal stress, and the growth of fractures can be limited by more plastic rocks such as shales. Generally design of fractures using P3-D models can be more easily explained by a simplified 2-D fracture model.

The 2-D fracture model known as the Perkins-Kern-Nordgren (PKN) geometry is normally used when the fracture length is much greater than the fracture height, which would be expected in deep formations such as the Bakken Formation. In addition, the fracture height is assumed to be constrained by the pay interval bounded by rocks of low Young's modulus. Generally, models are used to make engineering decisions rather than calculate the precise values for fracture dimensions. Fracture designs are compared to actual field results to successfully calibrate for future fracture stimulation design. The PKN model involves estimating fracture height to calculate fracture length and width. Predictions can be made if in situ stress, Young's modulus, formation permeability, and leakoff coefficient are reasonably known. A description of the PKN fracture geometry is provided in Figure 8. A classical solution in elastic theory predicts

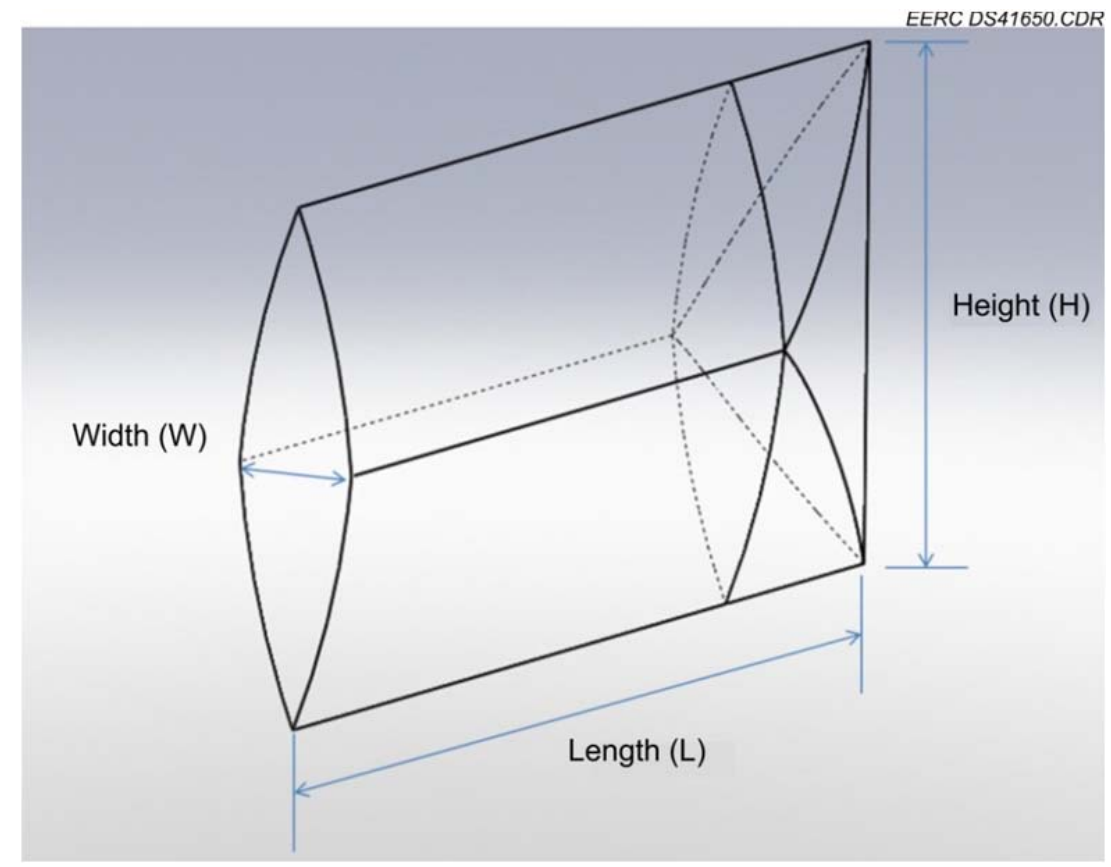

Figure 8. PKN geometry for a 2-D fracture. 
that for deformation between two parallel plates where there is a pressurized slit through the slab, the slit will deform into the shape of an ellipse. The ellipse will have a major axis equal to the slit half-length (height), a minor axis proportional to the pressure, and slit length inversely proportional to the elastic modulus.

The following two equations are solved simultaneously to derive a model for fracture width (Equation 3). Equation 7 is used to compute the pressure distribution down the fracture for any given combination of injection rate, fracture fluid viscosity, fracture height, and fracture width.

$$
\frac{\partial \Delta p}{\partial x}=\frac{64}{\pi}-\frac{Q u}{H w^{3}}
$$

$\partial \Delta \mathrm{p}=$ change in net pressure of the fracture

$\partial \mathrm{x}=$ incremental distance down the fracture length

$\mathrm{Q}=$ injection rate

$\mathrm{u}=$ viscosity

$\mathrm{H}=$ fracture height

$\mathrm{w}=$ fracture width

$\mathrm{L}=$ fracture half length

$v=$ Poisson's ratio

$\mathrm{G}=$ Shear modulus $G=\frac{E}{2(1+v)}$

$\mathrm{E}=$ Young's modulus

$\mathrm{w}_{\mathrm{w}}=$ Fracture width at borehole

The fracture mechanics equation provides a relationship between a given pressure distribution and fracture dimensions based on rock mechanics theory (Equation 8).

$$
\begin{gathered}
w_{(x, t)}=\frac{(1-v) H \Delta p_{(x, t)}}{G} \text { or } w=\frac{\left(1-v^{2}\right) 2 P_{n e t} H}{E} \\
w_{(o, t)}=2.52\left(\frac{(1-v) Q \mu L}{G}\right)^{1 / 4} \text { or } w_{(x)}=3\left(\frac{\left(1-v^{2}\right) Q \mu(L-x)}{E}\right)^{1 / 4} \\
\text { Oil field units: } \frac{b b l}{\min }, \text { in }, c p, p s i w_{w}=0.38\left(\frac{\left(1-v^{2}\right) Q \mu L}{E}\right)^{1 / 4}
\end{gathered}
$$

\section{Geomechanical Studies}

\section{Selection of Intervals for Characterization}

With respect to stratigraphy, the Devonian-Mississippian-age Bakken Formation in the Williston Basin typically comprises three members: the upper, middle, and lower Bakken (Figure 9). Lithologically, the Upper and Lower Members of the Bakken are dominated by shales 


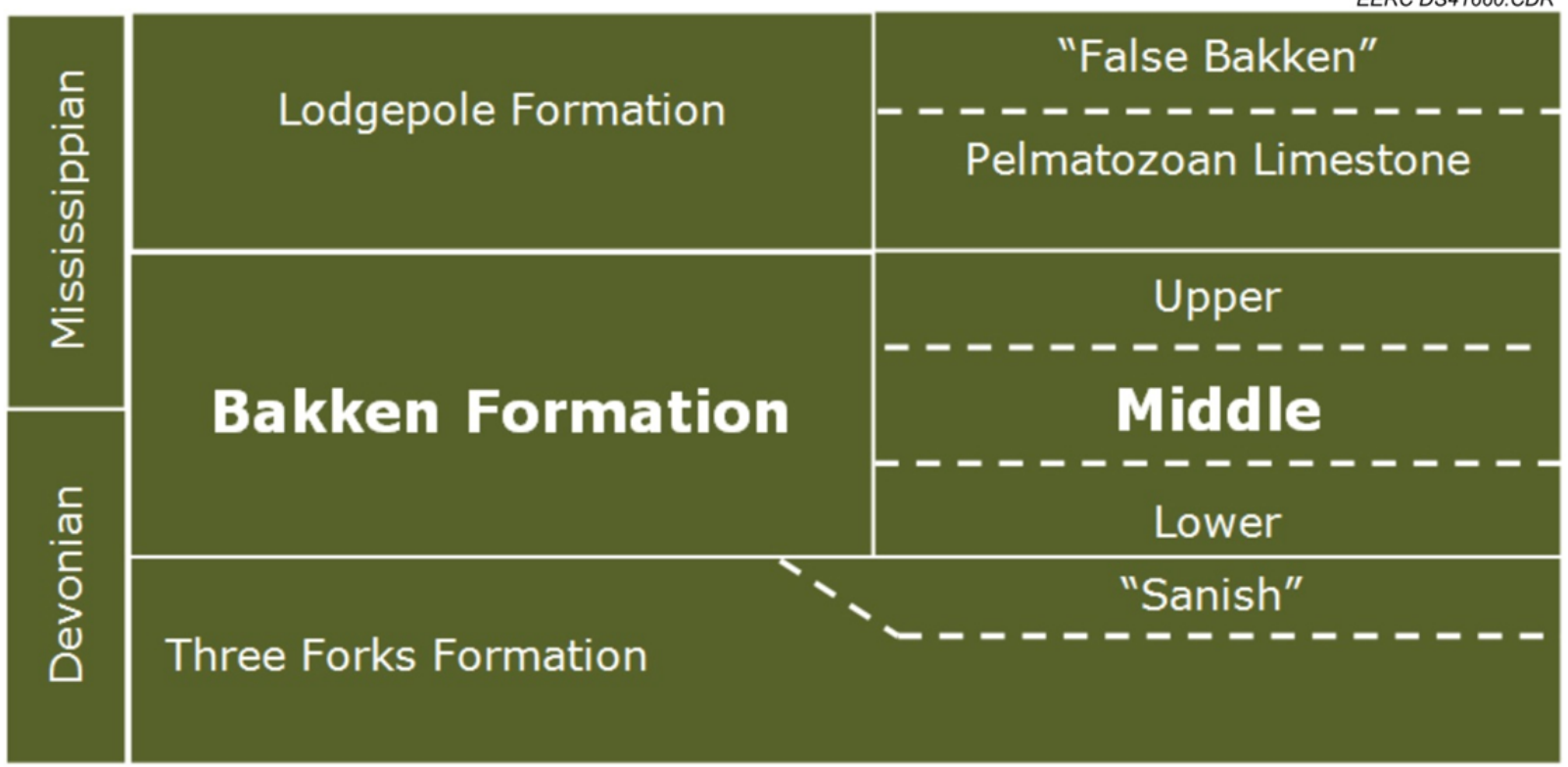

Figure 9. Stratigraphic column illustrating the three prominent layers of the Bakken Formation and adjacent layers.

rich in organic carbon that act as the source rock for oil within the Middle Member of the Bakken. The lithology of the Middle Member varies widely from clastics (including shales, silts, and sandstones) to carbonates (primarily dolomites), with five distinct lithofacies being identified in the North Dakota portion of the Williston Basin. In general, all of these rocks are characterized by low porosity and permeability. With respect to structure, the Williston Basin is characterized by relatively few and subtle structural features.

The core library of the NDDMR NDGS maintains a collection of cores collected from oil and gas wells drilled in North Dakota. An inventory of cores cataloged as Bakken or Three Forks or from a similar Mississippian-Devonian record was reviewed. Approximately 164 cores were identified from over 2000 wells that have been completed in the Bakken/Three Forks intervals. The selection of cores for geomechanical study included mapping areal extent of available core and attempting to obtain reasonable coverage on a county basis. The down selection process included reviewing individual core photos to determine if appropriate intervals of either the Bakken or Three Forks are present. The middle Bakken lithofacies existing 10-20 ft below the upper Bakken shale and the Three Forks located immediately below the lower Bakken shale make up the vast majority of horizontal well completion targets based on a review of well file data and information supplied by operators. In all, 39 wells were sampled, resulting in a total of 79 plugs from the middle Bakken and Three Forks Formations (Figure 10). Forty-eight plugs were used for destructive geomechanical testing and the remainder were used for petrographic analysis. Vertical sampling of three wells included all the lithologies of the middle Bakken and $50 \mathrm{ft}$ of the Three Forks Formation below the lower Bakken shale. The core plugs taken for testing were all vertical plugs, oriented with the plug axis parallel to the core axis. 


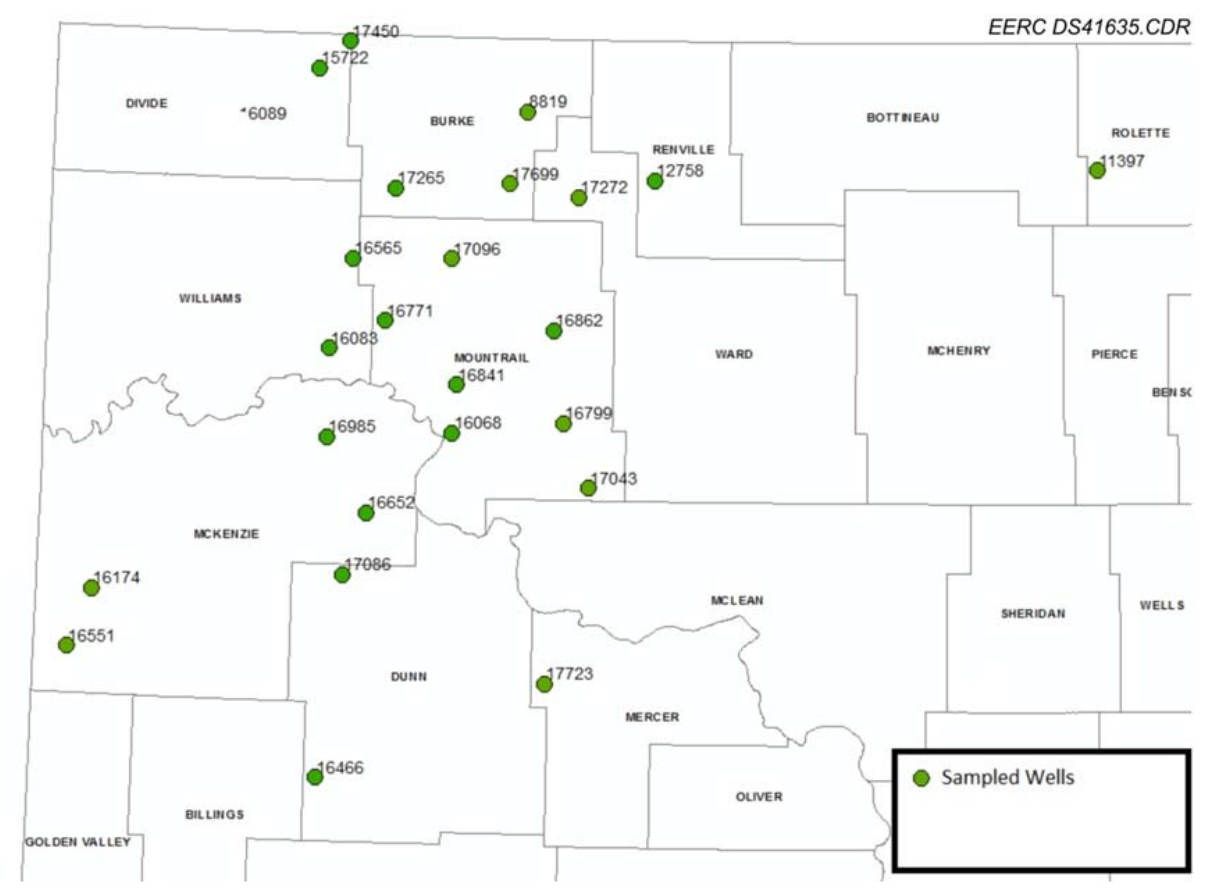

Figure 10. Location of wells sampled for geomechanical testing.

\section{Geomechanical Experimental Methods}

Rock mechanics is the study of rock deformation and fracture. Standard laboratory tests are used to describe properties such as Young's modulus and Poisson's ratio. Farmer (1968) stated that it is important to remember that the properties of rocks obtained under laboratory test conditions are related to the test conditions. This is highlighted in the ASTM International (ASTM) standard D7012-10 "Standard Test Method for Compressive Strength and Elastic Moduli of Intact Rock Core Specimens under Varying States of Stress and Temperatures," where data for Young's modulus and Poisson's ratio for Berea sandstone under unconfined (uniaxial) testing versus confined (triaxial) testing is provided. A more complete set of data was compiled by New England Research (2011) where 16 specimens of Berea sandstone were tested. The average results for these tests are provided in Table 1 and illustrate that the axial failure strength is greater for rocks under confined conditions. Furthermore, these rocks will undergo greater plastic deformation-hence the lower Poisson's ratio (greater transverse versus axial strain) with greater confining pressure. What may not be obvious is the greater stiffness of the rock with increasing confining pressure within the elastic range in which Young's modulus is determined. The implication of this is that static testing of core should be performed near actual in situ confining pressures to adequately determine Young's modulus relative to hydraulic fracturing design.

The standard test for determination of Young's modulus for hydraulic fracture design is the triaxial compression test. The ASTM and the International Society of Rock Mechanics (ISRM) 
Table 1. Mechanical Properties of Berea Sandstone Relative to Confining Pressure Conditions (New England Research, 2011)

\begin{tabular}{lcc}
\hline Confining Pressure, psi & Young's Modulus, $10^{6}$ psi & Poisson's Ratio \\
\hline 0 & 2.2 & 0.37 \\
1450 & 3.0 & 0.29 \\
3626 & 3.3 & 0.24 \\
5802 & 3.4 & 0.19 \\
\hline
\end{tabular}

provide standards. The ASTM reference is D7012-10 and the ISRM reference is "Suggested Method for Determining the Strength of Rock Materials in Triaxial Compression." Where the ASTM standard refers to other supporting standards, the ISRM is comprehensively inclusive. The standards are similar, and salient aspects are presented in Appendix A.

In all, 48 samples were subjected to destructive triaxial testing. Each sample was tested resulting in the following information:

- Sample description

- Bulk volume

- Porosity

- Young's modulus at each confining pressure

- Poisson's ratio at each confining pressure

- Axial stress vs. strain

- Axial stress vs. volumetric strain

- Axial stress vs. confining pressure:

- Peak strength envelope

- Residual strength envelope

- Mohr-Coulomb failure criterion:

- Apparent internal friction angle

- Shear stress intercept (cohesion)

\section{Geochemical and Petrographic Studies}

\section{Geochemical Studies - Experimental Methods}

Understanding the geochemical properties of a formation includes determining the relative saturation of the different fluid phases that may exist within the rock. The rocks of the Bakken Formation in North Dakota are considered to be either water saturated or oil saturated. Water saturation is the fraction or percentage of the pore volume that is occupied by formation water, while oil saturation is the percentage occupied by oil. Under Phase II, EERC efforts to assess the potential relationships between fluid saturation properties of the Bakken and oil productivity were focused on the evaluation of water saturation data, oil saturation, and production data to determine if there might be a correlation between water saturations calculated from well logs and oil production. While extensive well-by-well data are available for oil and water production over time in North Dakota, resistivity logs that can be used to calculate 
formation saturation are substantially less available. With this in mind, activities were conducted to determine if production water cut may serve as a reasonably proxy for log-derived water saturation. These activities included mining the NDIC oil well database for relevant logs, fluid saturation, and core data and using geostatistical analysis techniques to develop maps depicting water saturation, production water cut, and oil production.

\section{Petrographic Studies - Experimental Methods}

EERC petrographic assessment efforts were focused on the creation and analysis of thin sections of the reservoir zones within the Bakken and Three Forks Formations. These data are generally used to improve the basic understanding of rock properties contributing to the ultimate productivity of the reservoir. In addition, results of this study provide guidance in the assessment of future opportunities, including applications to geologic modeling, investigations of unswept oil, and identification of enhanced recovery options. The following petrographic analysis was performed, at least in part, to supplement geomechanical testing performed in Activity 2. In this way, it can be thought of as a worst-case scenario that underestimates the presence of natural fractures.

This assessment focuses on petrophysical classification and description of the middle Bakken and Three Forks Formations. Together with mechanical and petrophysical characterization, an increased understanding may be gained regarding the complex interactions of how mineralogy, depositional energy, existing fracture networks, and location of residual hydrocarbons affect mechanical strength and, inevitably, production.

Thirty-one intervals were selected from fourteen wells (NDIC 12785, 15722, 16068, 16083, 16466, 16565, 16652, 16771, 16841, 16862, 16985, 17086, 17265 and 17450) for analysis representing a variety of rock fabrics ranging from carbonate mudstone and shale to fine sand/ooid mixtures.

Specific analyses included the following:

- General description of thin-section attributes

- Identification and estimation of mineralogical assemblages

- Porosity prevalence and type

- Mineral cement identification

- Description of microstructure

- Photomicrographs at $40 \times$ and $100 \times$ magnifications

- Assignment of petrographic class according to observed transportational energy

- Estimation of depositional environment 


\section{RESULTS AND DISCUSSION}

\section{Reservoir Saturations}

Previous work under Phase I considered geological properties such as thickness, structure, and organic content of shales to understand production in Mountrail and Dunn Counties in the Bakken Formation in North Dakota. Conclusions highlighted greater TOC content of the shales and greater thicknesses which contribute to pore pressure-related fracturing. Also noticeable was the presence of various structural elements contributing to areas of higher production. The relative magnitude of production for these areas is shown in Figures 11 and 12. A recent understanding for the high cumulative production from the Parshall Field in Mountrail County has been described by Grau and others (2011). It is generally understood that thermally mature areas of the Bakken Formation are overpressured because of oil generation and expulsion into the middle Bakken from the diagenesis of the thick, highly organic Bakken shales. The pressure gradient in the Parshall Field of $0.73 \mathrm{psi} / \mathrm{ft}$ is unusual when compared to the west in the Sanish Field, where the average pressure gradient is $0.55 \mathrm{psi} / \mathrm{ft}$. Additionally, it is unusual that the location of the Parshall Field is a considerable distance into a thermally immature area of the Bakken, as illustrated in Figure 13 (Jarvie and others, 2011). A multivariable trapping scenario has been proposed as shown in Figure 14 by Grau and others (2011). The upper boundary is the regionally thick, impermeable Lodgepole Formation. Lineaments trending northeast—-southwest
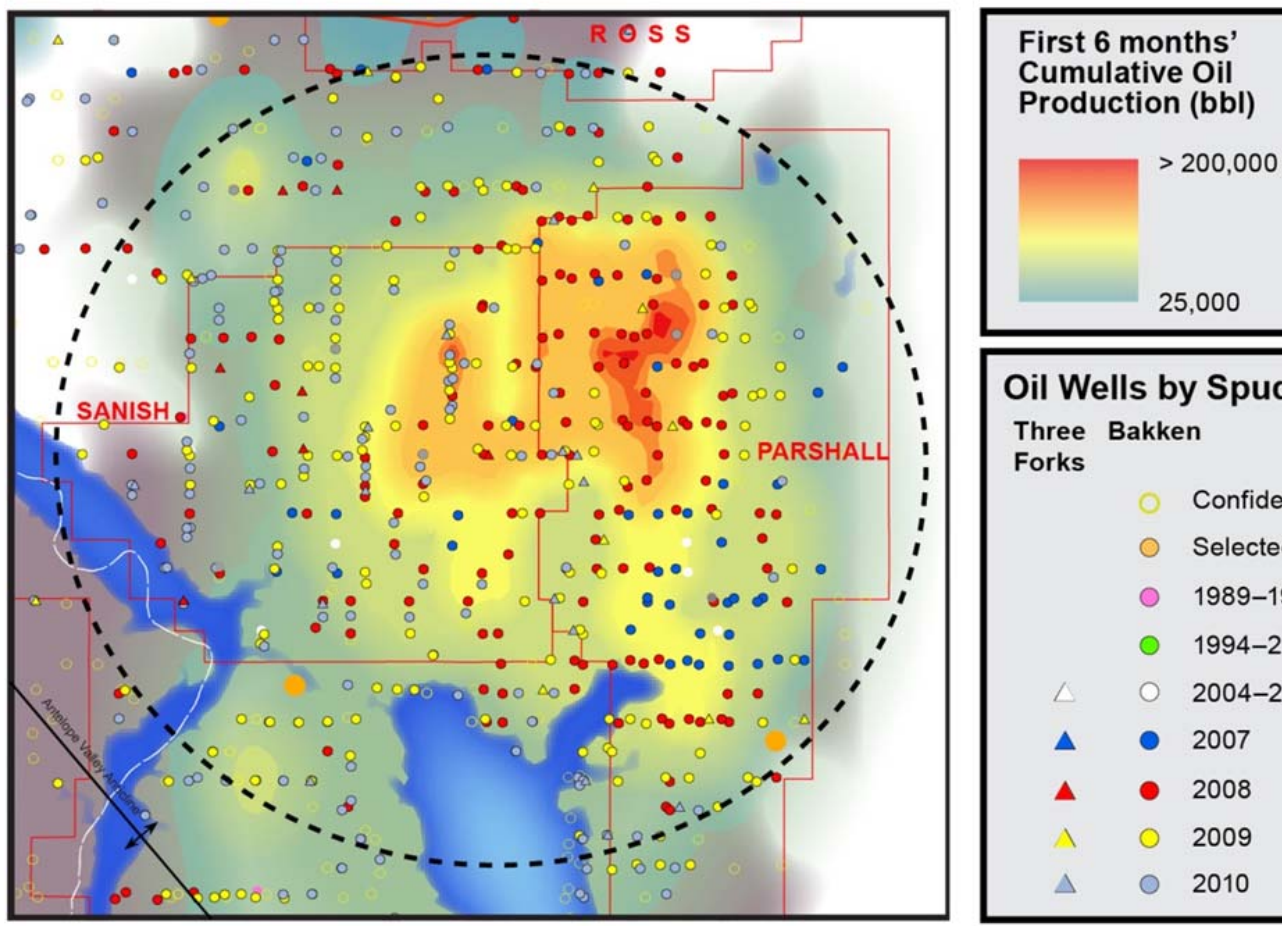

EERCDS41717.A

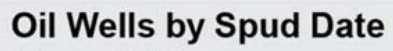

Three Bakken

Forks

Confidential and Permitted

- Selected Pre-1989

- 1989-1993

○ 1994-2003

- 2004-2006

- 2007

× 2008

- 2009

$\triangle \quad 2010$

Figure 11. First 6 months of cumulative oil production for Sanish and Parshall Fields in Mountrail County. 

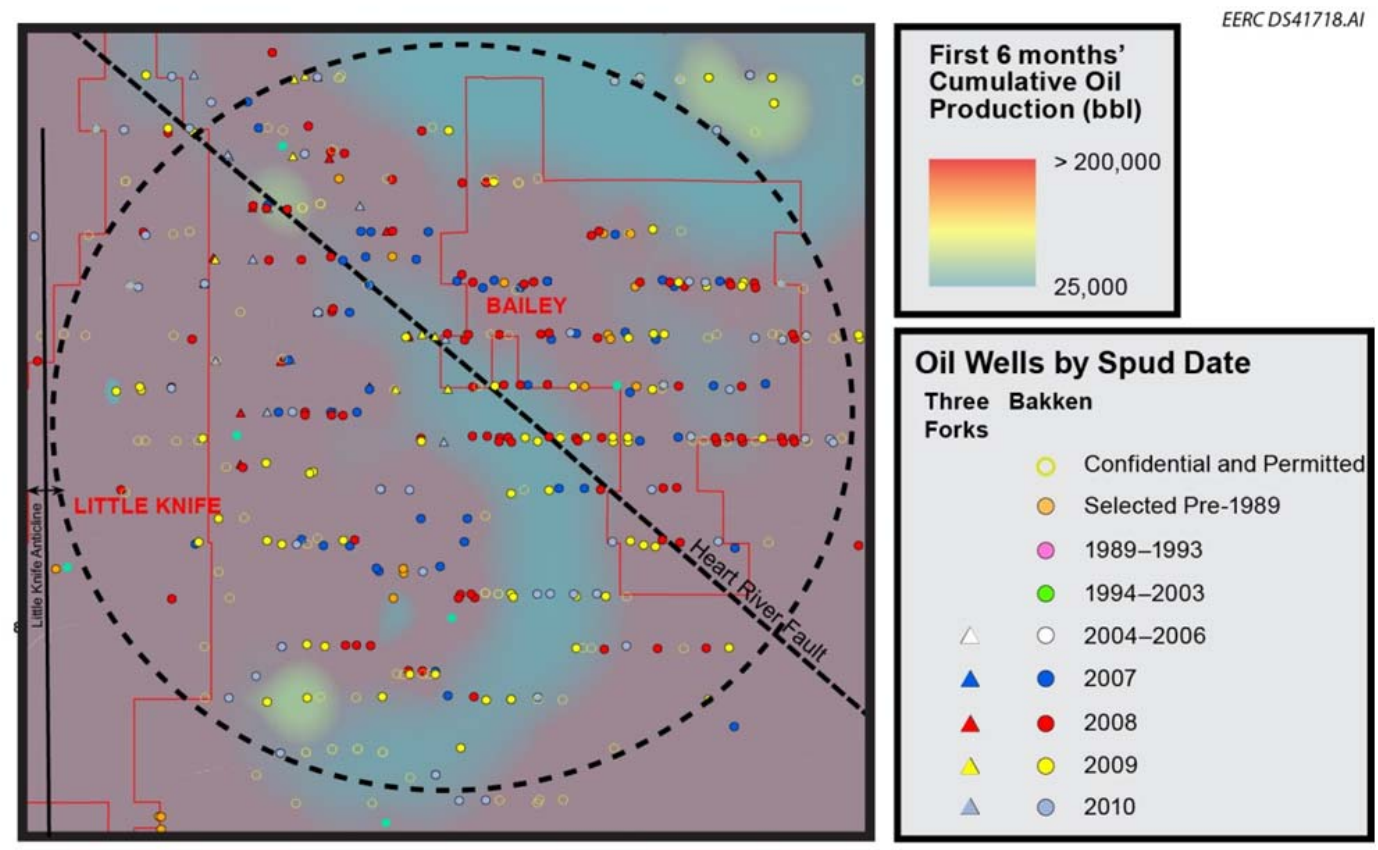

Figure 12. First 6 months of cumulative oil production for Dunn County near the Heart River fault.

are thought to act as lateral seals as evidenced by significant pressure differences encountered during the drilling of horizontal wells. The eastern updip boundary is the thermally immature upper Bakken shale. Immature kerogen-rich shale limits the migration of downdip fluids resulting from less matrix and fracture permeability.

Previous investigations suggest that water saturations calculated from well logs of the middle Bakken may reasonably predict cumulative oil production. The discovery of the Elm Coulee Field in Montana and the discovery of the Parshall Field in North Dakota can be attributed to the recognition of the relationship between high resistivity and oil saturation in the middle member of the Bakken Formation (Johnson, 2011). It has also been recognized that saturations may coincide with overpressuring in the Bakken (Johnson, 2010). A first attempt to map pressure gradients in the Bakken was completed by Meissner (1984) (Figure 15). Although high fluid pressures in rock typically produce low resistivity measurements on well logs, high hydrocarbon saturations in the Bakken result in high resistivity measurements. Understanding that the high oil saturation of the rock overshadows the effect of fluid pressures on resistivity logs, Meissner utilized sonic velocity to locate overpressured regions within the highly resistive shales of the Bakken Formation. Indicated in Figure 15 are the location of Parshall Field and the respective pressure anomaly nearly predicted by Meissner. A map of average water saturation from resistivity measurements of the middle Bakken was created for the Parshall area by Simenson (2010) (Figure 16). The water saturation was determined from the Archie equation:

$$
S_{w}=\left(\frac{a * R w}{R_{t} * \phi^{m}}\right)^{\frac{1}{n}}
$$


Where:

$\mathrm{S}_{\mathrm{w}}=$ water saturation

$\mathrm{Rw}=$ formation water resistivity

$\Phi=$ porosity

$\mathrm{a}=1$ = tortuosity factor

$\mathrm{m}=$ cementation exponent

$\mathrm{n}=1.74=$ saturation exponent

The cementation exponent was calibrated with core data according to Table 2.

It appears that the average saturation for the middle member of the Bakken Formation can be utilized as a predictor for expected cumulative production when comparing Figure 17 to Figure 13. The notion was further reinforced by methods utilized by Bergin and others (2011). In order to plan future development and maximize economic success, the updip eastern limit of the Bakken Formation south of the Parshall Field on the Fort Berthold Indian Reservation was analyzed. Mud gas shows and water saturations obtained from well logs correlated well to oil and water production data. The data were used to identify the transitional zone between commercial and noncommercial production for the eastern edge of the play in McLean and Dunn Counties. Therefore, average water saturations for remaining portions of North Dakota were studied in an attempt to examine the applicability to predicting expected oil production for a wider region of the state.

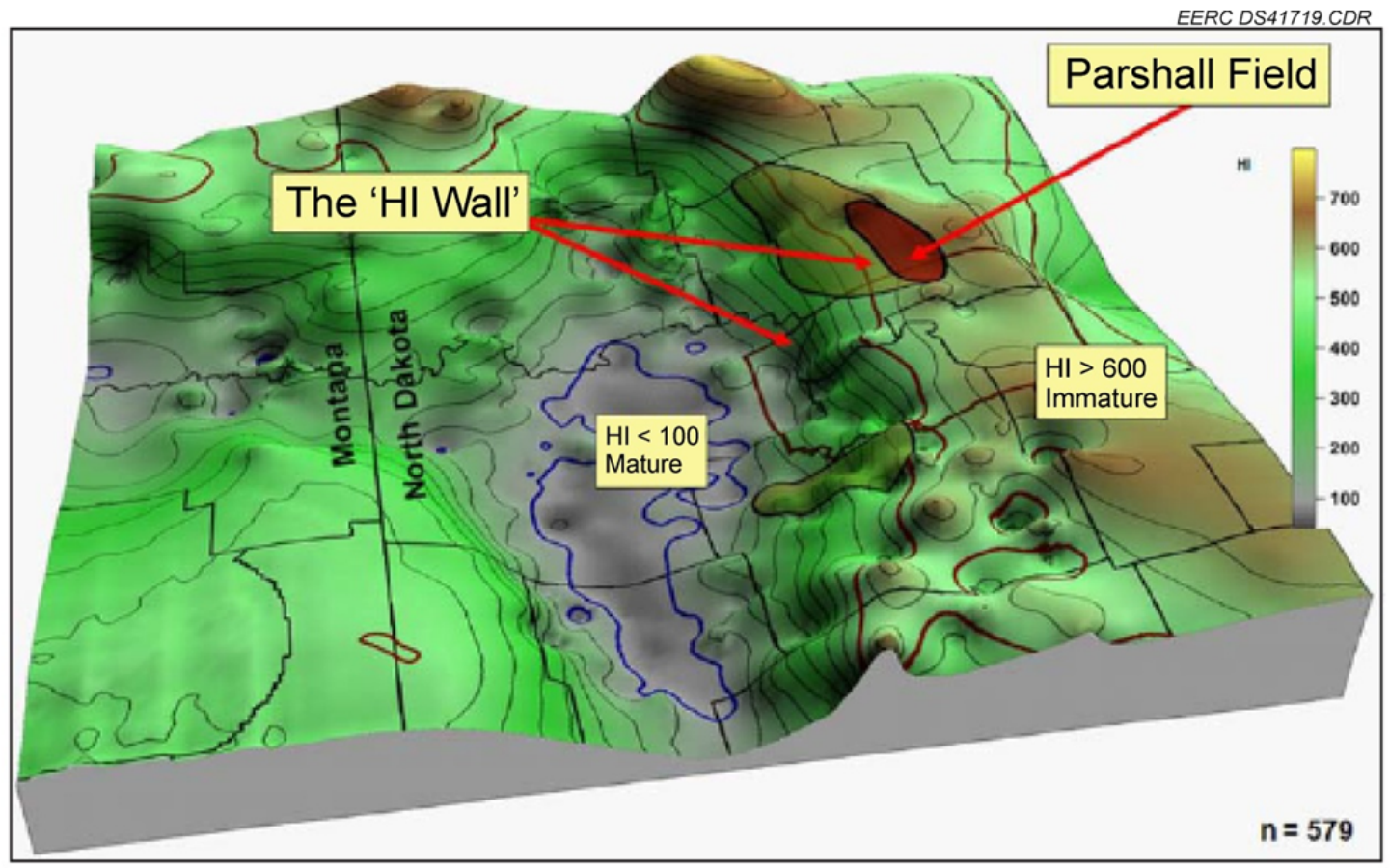

Figure 13. A three-dimensional contour of the hydrogen index wall of the upper Bakken shale and its relation to Sanish and Parshall Fields (Jarvie and others, 2011). 


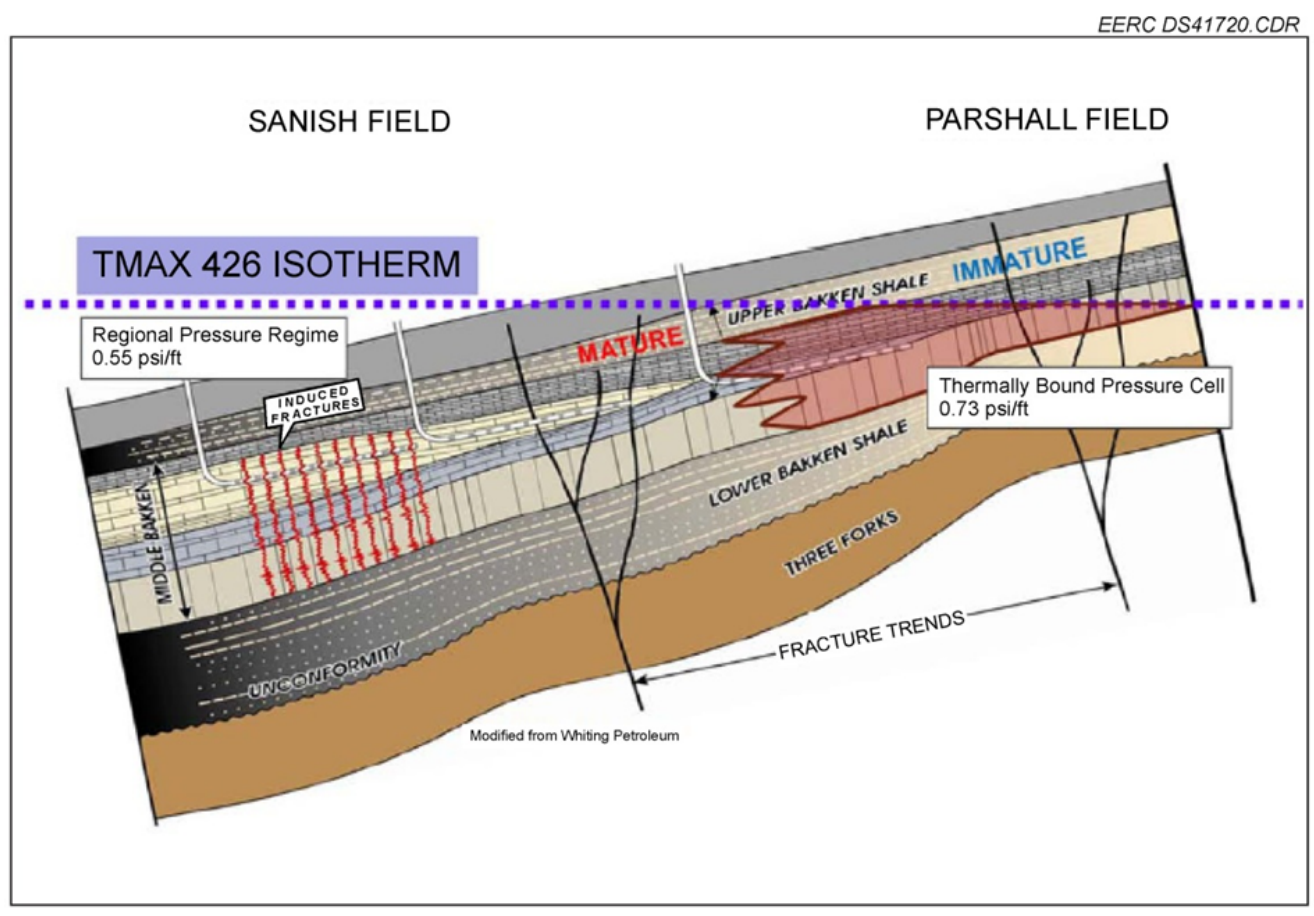

Figure 14. Pressure anomaly of Parshall Field and multitrapping mechanisms (Grau and others, 2011).

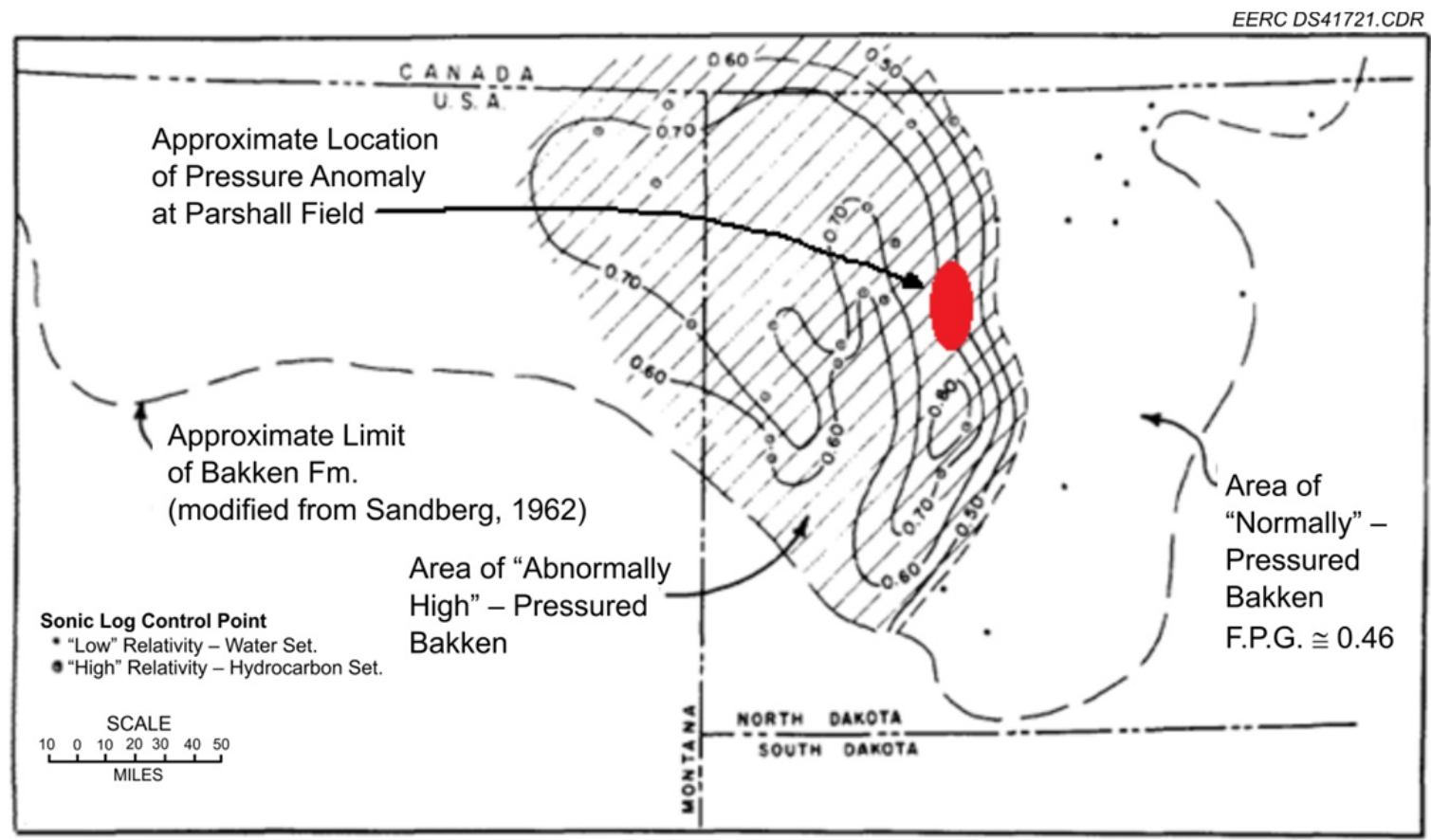

Figure 15. Areal distribution of pore fluid gradients in the Bakken Formation (Meissner, 1984). 
Table 2. Cementation Exponent Utilized

for $S_{w}$ Calculations by Simenson (2010)

\begin{tabular}{lc}
\hline Zone & $\mathrm{m}$ \\
\hline Upper Bakken & 2 \\
L5 & 1.75 \\
L4 & 1.4 \\
L3 & 1.5 \\
L2 & 1.65 \\
L1 & 1.8 \\
\hline
\end{tabular}

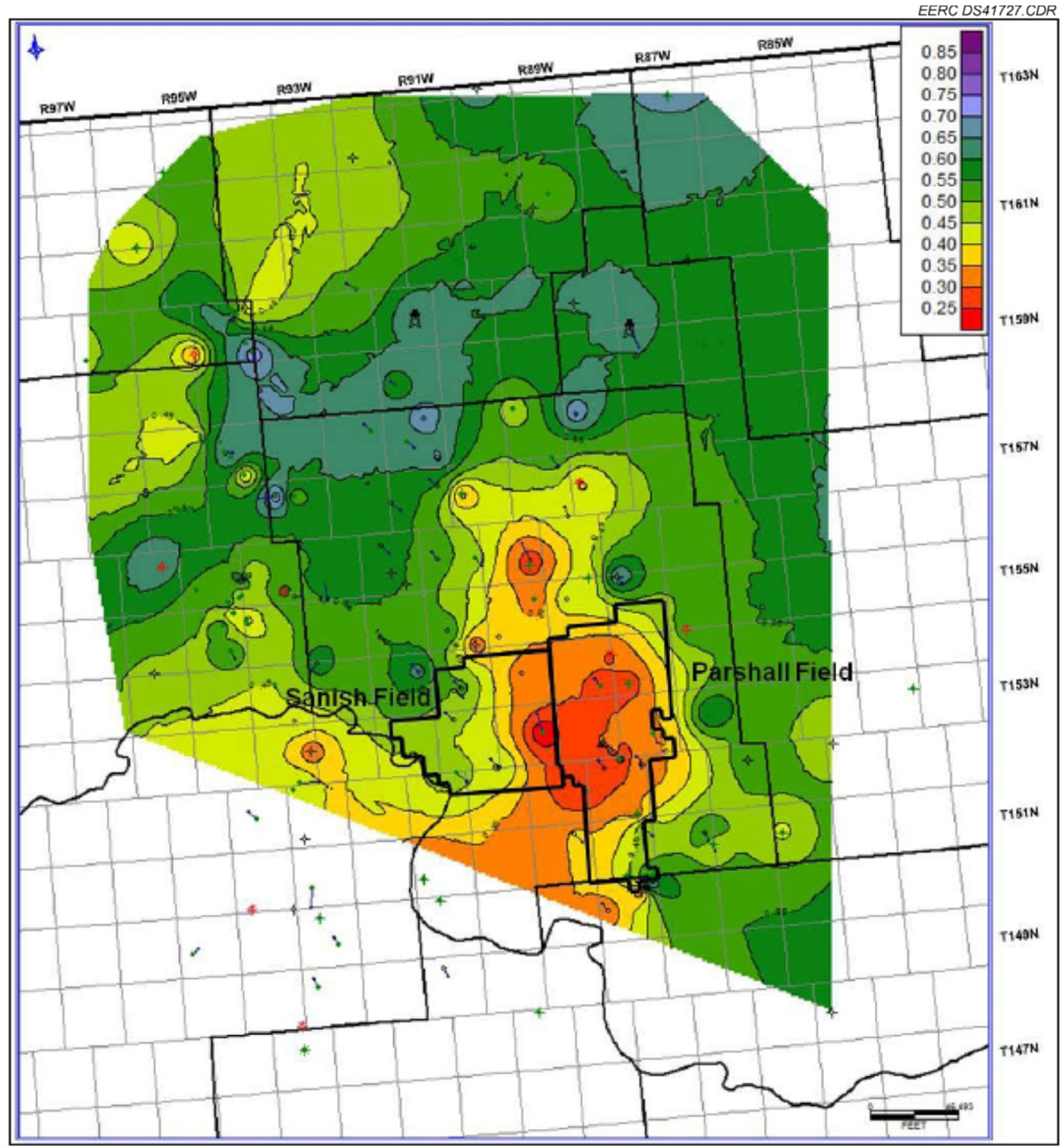

Figure 16. Map of average water saturations from well logs produced by Simenson (2010). 
There are over 2000 wells in North Dakota comprising Bakken Formation oil production history. In relation, publicly available resistivity $\operatorname{logs}$ for calculating formation saturation are limited. Therefore, it was hypothesized that the production water cut may serve as a reasonable covariable for the less frequently available water saturation determination from well logs. A regression analysis was performed to determine the relationship between $S_{w}$ and water cut. The regression analysis confirmed that there was a reasonable correlation between the two properties, and data were further characterized by geostatistical analysis. The following describes and discusses the procedures used to generate a map of $S_{w}$ in the Bakken from a core-calibrated petrophysical analysis.

Water saturation core data were obtained for 50 wells in the middle Bakken interval. As an exercise, the parameters for the Archie equation were iterated to determine average values for formation water resistivity $\left(\mathrm{R}_{\mathrm{w}}\right)$ and cementation factor $(\mathrm{m})$ calibrated to core. The fixed values for tortuosity $(\mathrm{a}=0.63)$ and saturation exponent $(\mathrm{n}=1.74)$ was selected from Crain (2011), assuming majority sandstone, and Simenson (2010), respectively. The statistical results are provided in Table 3 .

Table 3. Archie Variable Statistical Results

\begin{tabular}{lcccc}
\hline & \multicolumn{4}{c}{ Archie Variable Statistics } \\
\hline & $\mathrm{a}$ & $\mathrm{m}$ & $\mathrm{n}$ & $\mathrm{R}_{\mathrm{w}}$ \\
\hline Mean & 0.629 & 1.735 & 1.735 & 0.019 \\
Median & 0.630 & 1.715 & 1.740 & 0.016 \\
Geometric Mean & 0.629 & 1.728 & 1.735 & 0.018 \\
Harmonic Mean & 0.629 & 1.720 & 1.734 & 0.017 \\
Mode & 0.630 & 1.720 & 1.740 & 0.016 \\
\hline
\end{tabular}

Geostatistical methods were used to further develop the maps provided in Figure 17. Because of the high number of sample points, a kriging technique was utilized to populate the data for the production water cut map in Figure 17. Kriging is a linear estimation procedure used to estimate a value at an unsampled location using the value at a neighboring location and the weight assigned to the neighboring value. The resulting estimated value is the weighted average of the neighboring values. The procedure used to populate the formation water saturation map in Figure 17 is known as cokriging. Unlike ordinary kriging, cokriging uses the neighboring values and other related variables to improve the estimated value and reduce the uncertainty. An example of kriging and cokriging is as follows. A kriging procedure can be used to populate permeability data for unsampled areal locations from existing sampled permeability data. A cokriging procedure can be used to do the same, with the addition of using porosity data to improve the results for the estimated unsampled locations. The porosity data would be obtained from the sampled locations, and a regression relationship developed for porosity and permeability. This regression relationship was developed for water cut and water saturation as shown in Figure 18. A linear regression supports the validity of the cokriging technique. 

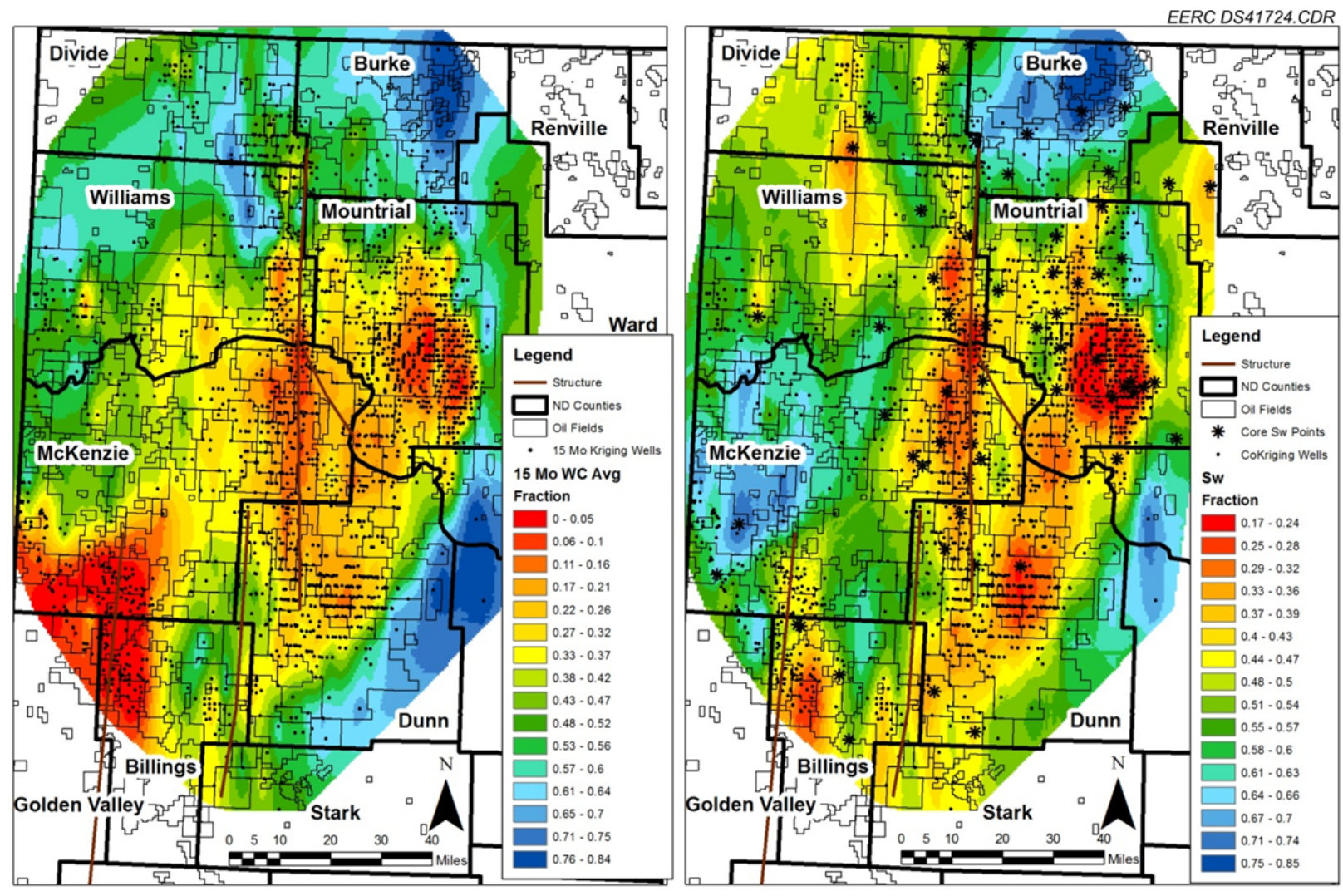

Figure 17. Production water cut (kriging, left) and formation water saturation (cokriging, right).

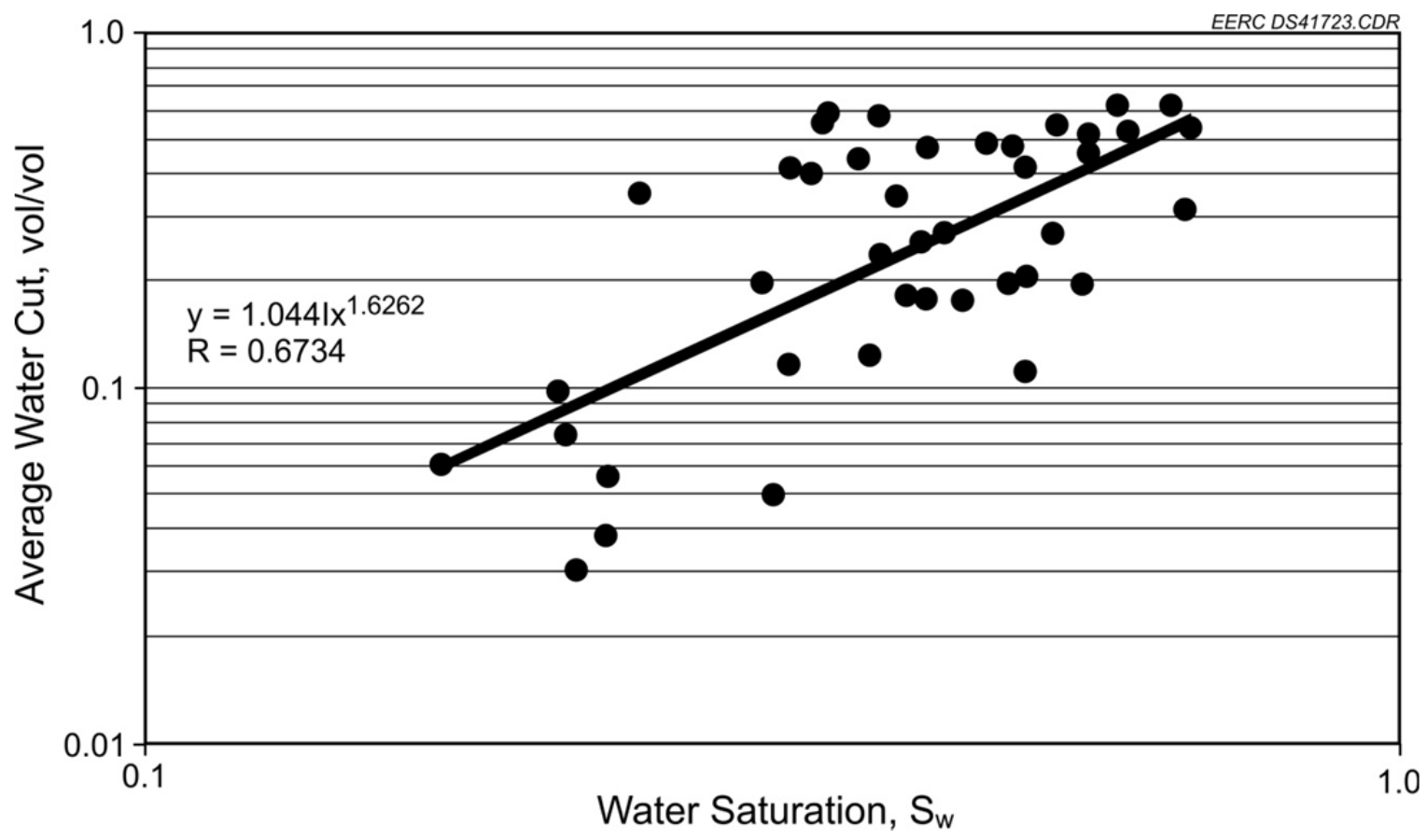

Figure 18. Water-cut and water saturation regression analysis. 


\section{Reservoir Saturation Results and Discussion}

Maps were created to characterize formation saturations in the middle Bakken from oil production data and from calculated water saturations from well logs. The maps provided in Figure 19 illustrate and compare the results. Low water saturation provided in red implies high oil saturation. The formation water saturation map on the right is a result of cokriging the variables of formation water saturation and water cut, of which a greater number of areal data were available for production water cut. Noticeably, the Bakken fairway area of the Billings Nose located at the intersection of McKenzie, Billings, and Golden Valley Counties indicates an area of high oil saturation and coincides with the historic production for this area of the Bakken where some of the early vertical wells (1960s) and first horizontal wells (late 1980s) were drilled. The data from Figure 19 can be further analyzed on a county-by-county basis as provided below:

- The relationships provided for Mountrail County are very consistent, clearly indicating the eastern boundary of the play, the productive zones of the Sanish and Parshall Fields and decreasing oil saturations to the east in proximity of the Nesson anticline.

- The eastern productive boundary of the play also remains consistent in Dunn County. The water-cut production map, taking advantage of kriging analysis, seems to indicate a production trend along the Heart River fault of Dunn County and does not necessarily coincide with the formation saturation trend shown to be in the perpendicular direction.

- Saturation trends are consistent for the eastern portion of McKenzie County; however, data based on water cut production and cokriging predict higher oil saturations for western McKenzie County.

- The trend in Williams County, primarily in the western portion, is the opposite of McKenzie, where kriging of water-cut production data predicts a lower oil saturation. The result should be used with caution however, as very limited sampled data were available for this region.

- The data for Divide County provide a similar trend to Williams. A higher quantity of sampled data is available. Although oil saturation appears low, this portion of the play is experiencing relative success with Three Forks wells.

- Data are consistent for Burke County and provide for limited oil saturations.

- Although data were not completed for Renville County, a small trend of increasing oil saturation is noticeable. Recent activity in Renville County, including a producing Bakken well and leasing, was announced by the NDDMR (Donovan, 2011). This is east of what is generally considered thermally mature Bakken shale; however, both lower and upper shales are present with reasonable organic content. 


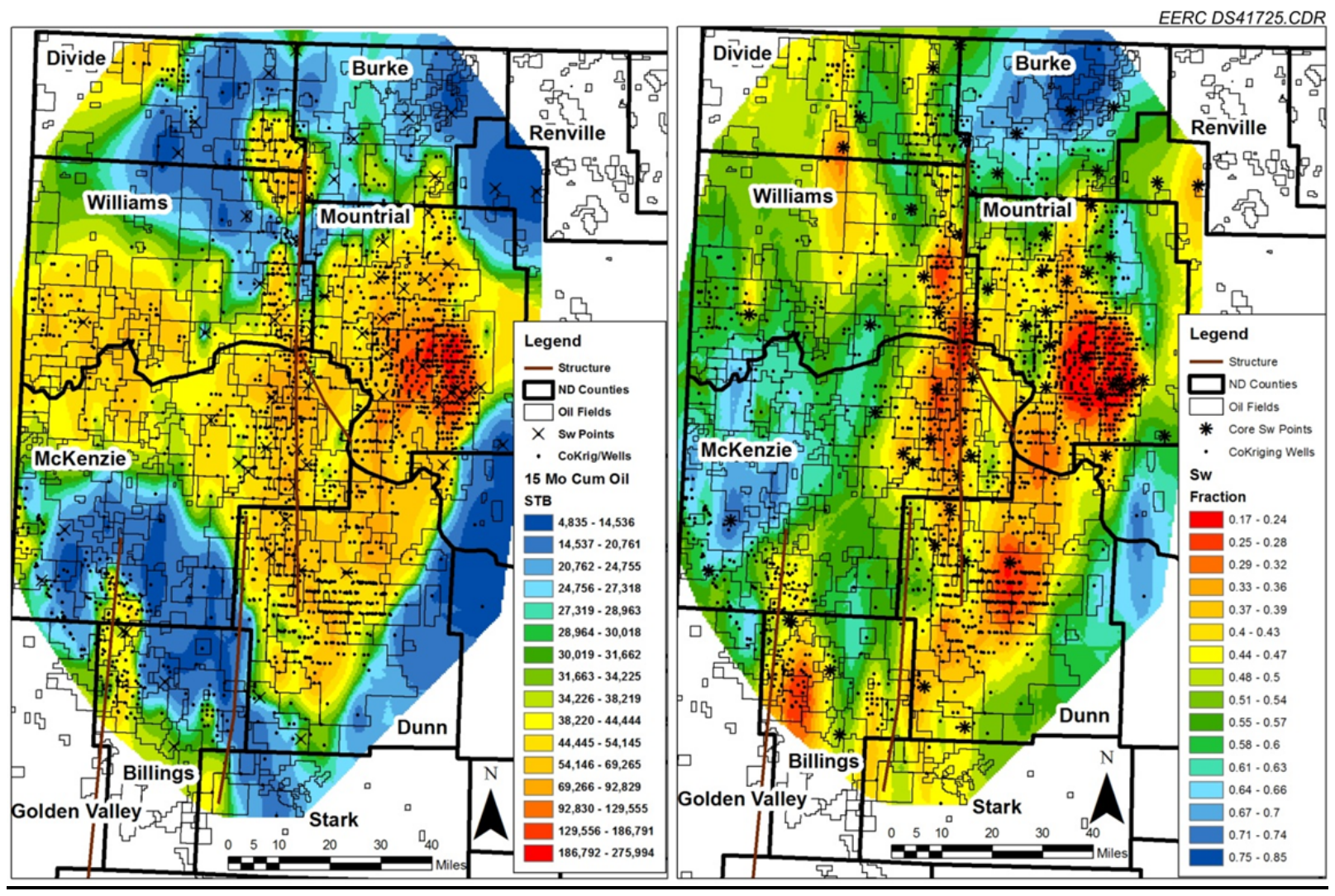

Figure 19. Data for 15 months of cumulative oil production (STB, left) and calculated formation water saturation $(\%$, right $)$.

The objective for collecting data regarding formation saturation was to determine if the method could be a reasonable predictor of cumulative production. A cumulative production map was constructed using similar kriging geostatistical analysis from production data. Cumulative production for 3 and 15 months were reviewed. It was anticipated that a greater number of wells would be available for 3-month data versus a lower number of wells for 15-month data; however, the 15-month data appeared to provide a more accurate production representation. A kriging analysis with the 15-month data was chosen to compare cumulative oil production with formation saturation. As provided in Figure 19, formation saturation does appear to be a relative predictor of cumulative production for the eastern boundary of the Bakken Formation. However, predictive capability may be limited for the western portion of North Dakota in the Billings Nose area and Divide and Williams Counties. The predictive discrepancy in western North Dakota could be due to the following. Data for wells in the Billings Nose area include production from the upper Bakken shale and may not be directly attributable if the production was from the middle member, including a multistage horizontal completion. Production in Williams County is largely attributed to the more aggressive implementation of multistage hydraulic fracturing, which is enabling higher production in areas of lower oil saturation. Figure 20 provides the regression relationship for cumulative production from water saturation. 


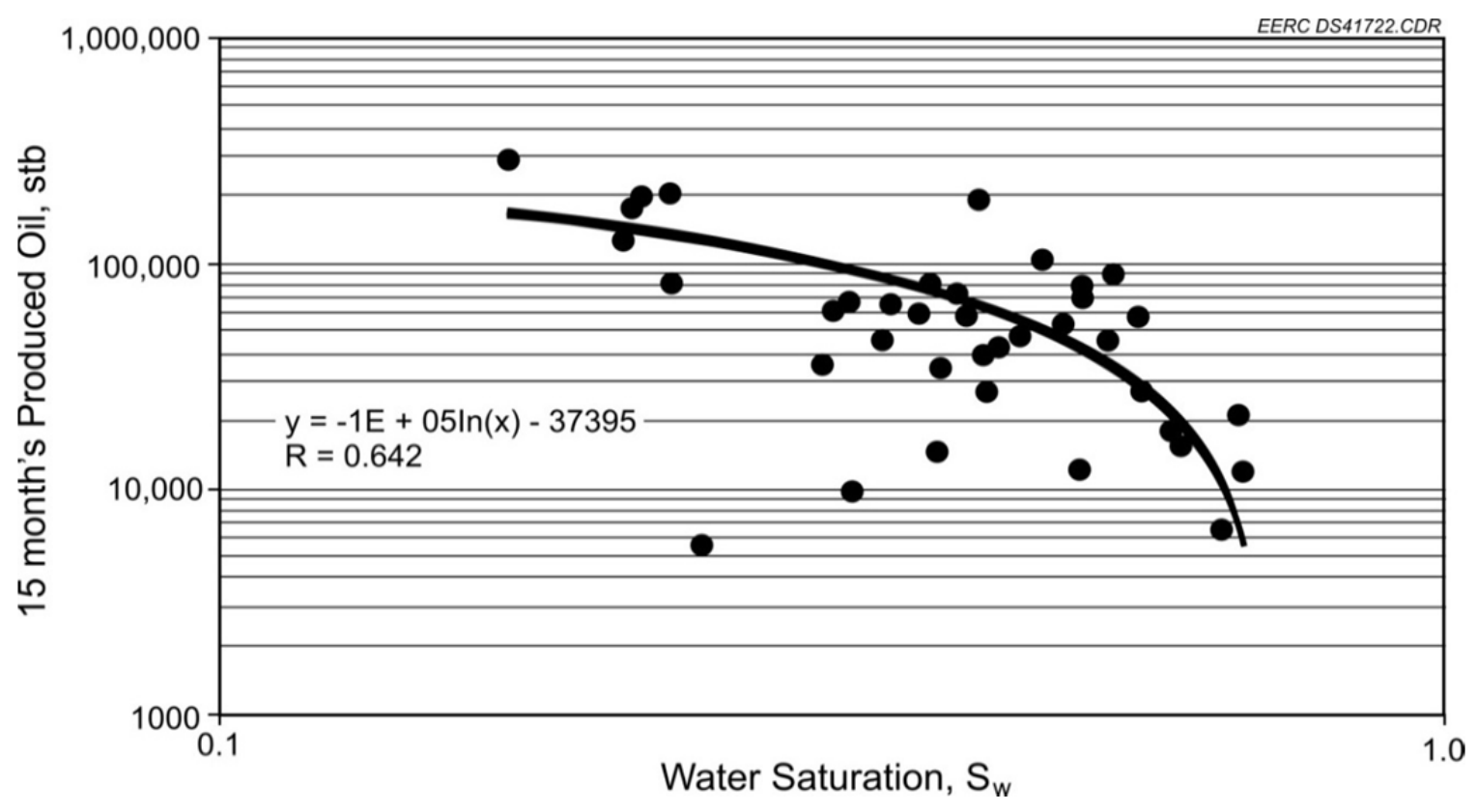

Figure 20. Regression analysis of production versus formation saturation.

\section{Production Analysis of Middle Bakken Lithofacies in Dunn County}

Early well completions in Dunn County included single-stage hydraulic fracture treatments of the horizontal lateral. Variables are limited in these completions, which include vertical height control of the lateral (illustrated in Figure 21), fracture initiation, fracture propagation, and fracture growth. Although well stimulations have been improved with multistage hydraulic fracturing, vertical deviation of the wellbore out of target zones remains a challenge. Current technology, such as rotary steerable drilling combined with measurement while drilling and logging while drilling, can finely control the deviated location of wellbores. However, cost and availability are significant factors in the Bakken play. Therefore, a majority of wells rely on the geosteering experience of mudloggers and directional control using bent sub mud motors as a technique to "stay between the shales" without necessarily paying significant attention to any particular middle Bakken lithofacies. Although some operators do target a lithology trend, the crosscutting of middle Bakken lithofacies in Dunn County provided an opportunity to investigate completions to examine if any particular lithofacies within the middle Bakken provided a production advantage given the $\%$ of the lateral completed within a particular middle Bakken vertical zone.

An analysis of 108 wells located in Dunn County (Figure 22) was completed to examine 6-month cumulative production versus zonal completion in the middle Bakken. The middle Bakken interval was divided equally in depth into "upper," "middle," and "lower" using a model representation of spatial coordinates provided from well files. Additionally, individual Lithofacies 1-5 (L1-L5) were also examined. The lithology from well logs is described in Figure 23. The upper zone of the middle Bakken was defined to include L3, L4, and L5 


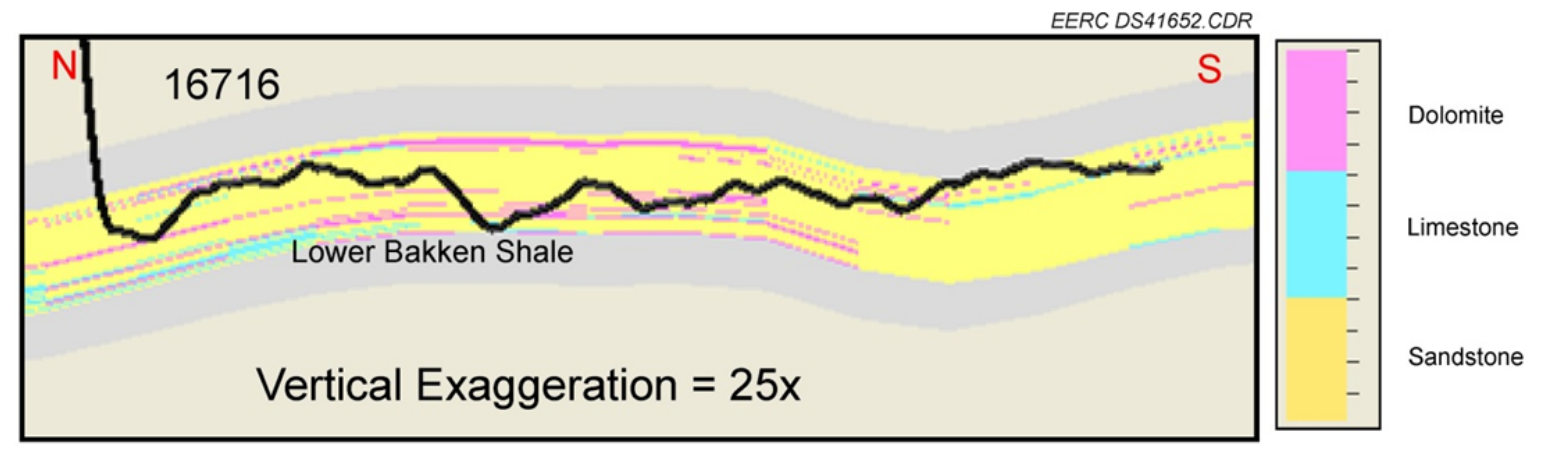

Figure 21. Typical well path in relation to upper and lower Bakken shales for early horizontal completions in Dunn County.

(Figure 24). The middle zone included the porosity streak of L2, or central basin facies (CBF), and the lower zone included the bottom of L2, and all of L1 (Figure 25). The well logs indicate potentially productive zones in L3 and L2. Therefore, wells completed mostly in the upper and middle zones may have higher production. Generally, in other areas of the Bakken, the laminated features such as those shown in L4 are targeted based on a higher degree of natural fracturing and oil saturation. Wells chosen for analysis from these zones (upper, middle, lower) contained greater than $40 \%$ of the lateral wellbore within the zone.

Average well production data were also sorted according to the $\%$ of the lateral completion within a given lithofacies as follows:

- L1 - Total length of horizontal wellbore is greater than $10 \%$.

- L2 - Total length of horizontal wellbore is greater than $70 \%$.

- L3 - Total length of horizontal wellbore is greater than $70 \%$.

- L4 - Total length of horizontal wellbore is greater than $40 \%$.

- L5 - Total length of horizontal wellbore is greater than $10 \%$.

L1 and L5 are very thin and represent the rock layers just below the upper Bakken shale and just above the lower Bakken shale. Few operators target these zones; however, a few wells did have a significant portion of the lateral completed within L1 and L5. The thickness of L1 and L5 is small; therefore, lateral completion of over $10 \%$ within these lithofacies is considered significantly high. L4 was less targeted than L2 and L3; therefore, lateral completion of over $40 \%$ is significant. Notably, a majority of the wells were targeted in L2 and L3. L2 is a large, thick zone with greater porosity, and L3 is a relatively thin zone but noted for good oil show. Wells with greater than $70 \%$ of the lateral completed in L2 and L3 were considered in the analysis in Table 4. 


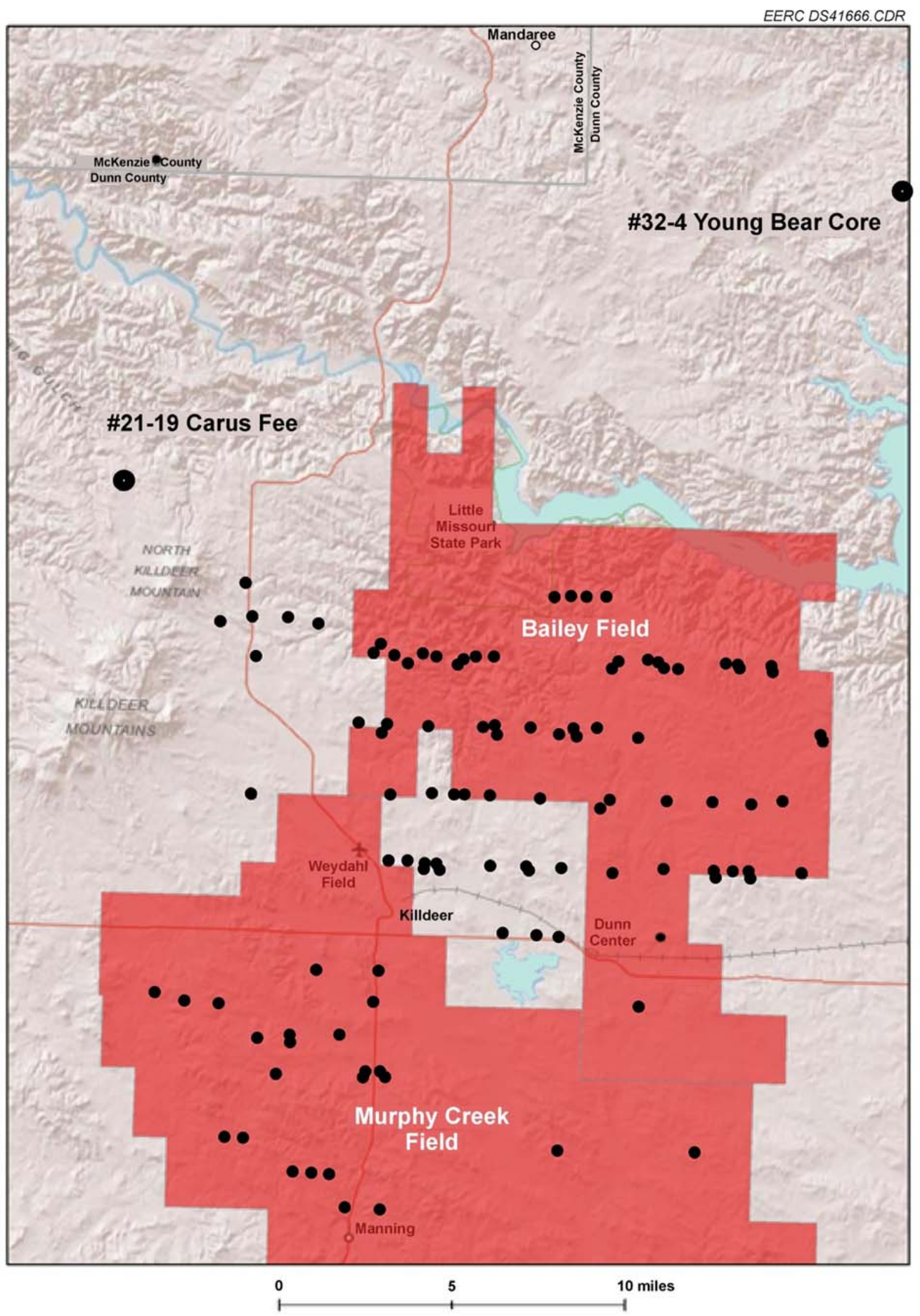

Figure 22. Study area. 
NENW Sec. 19, T.147N., R.96W.

Maxus Exploration Co.
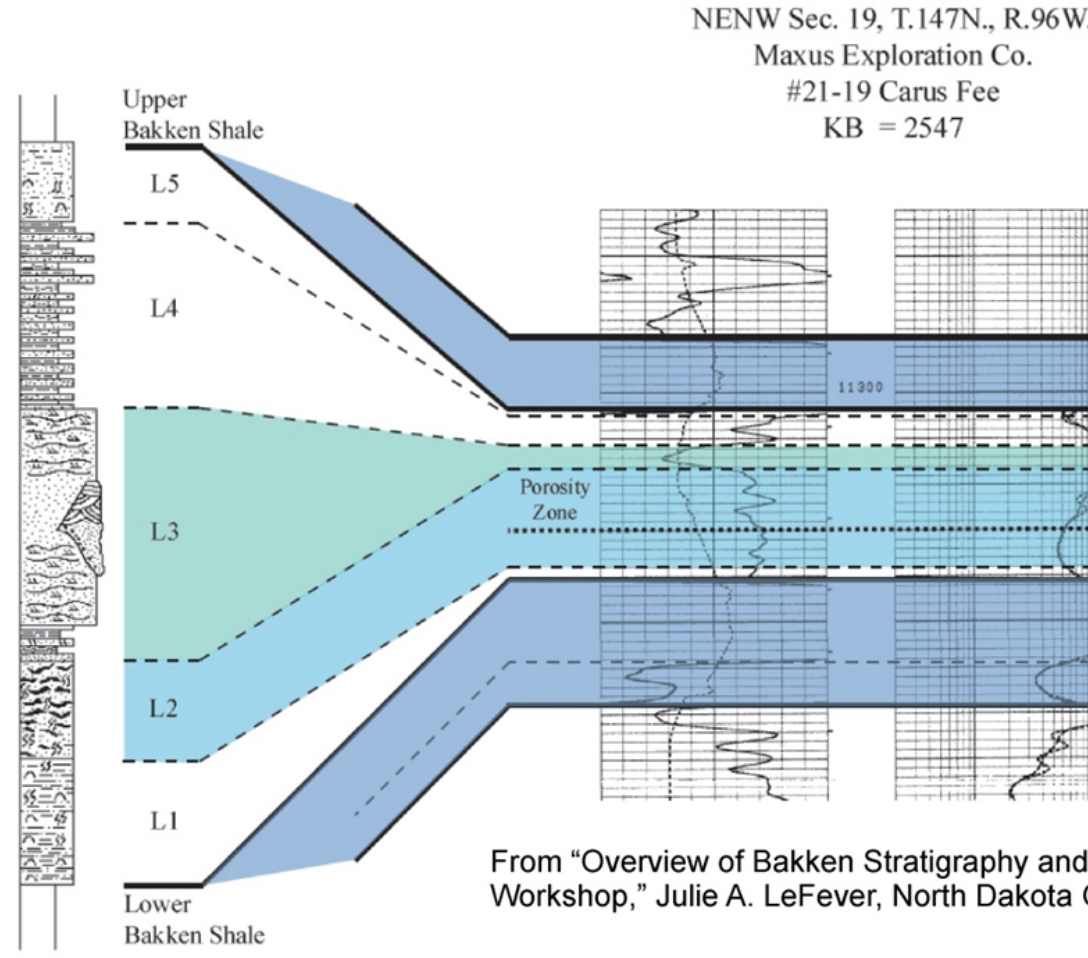

$$
\mathrm{KB}=2547
$$

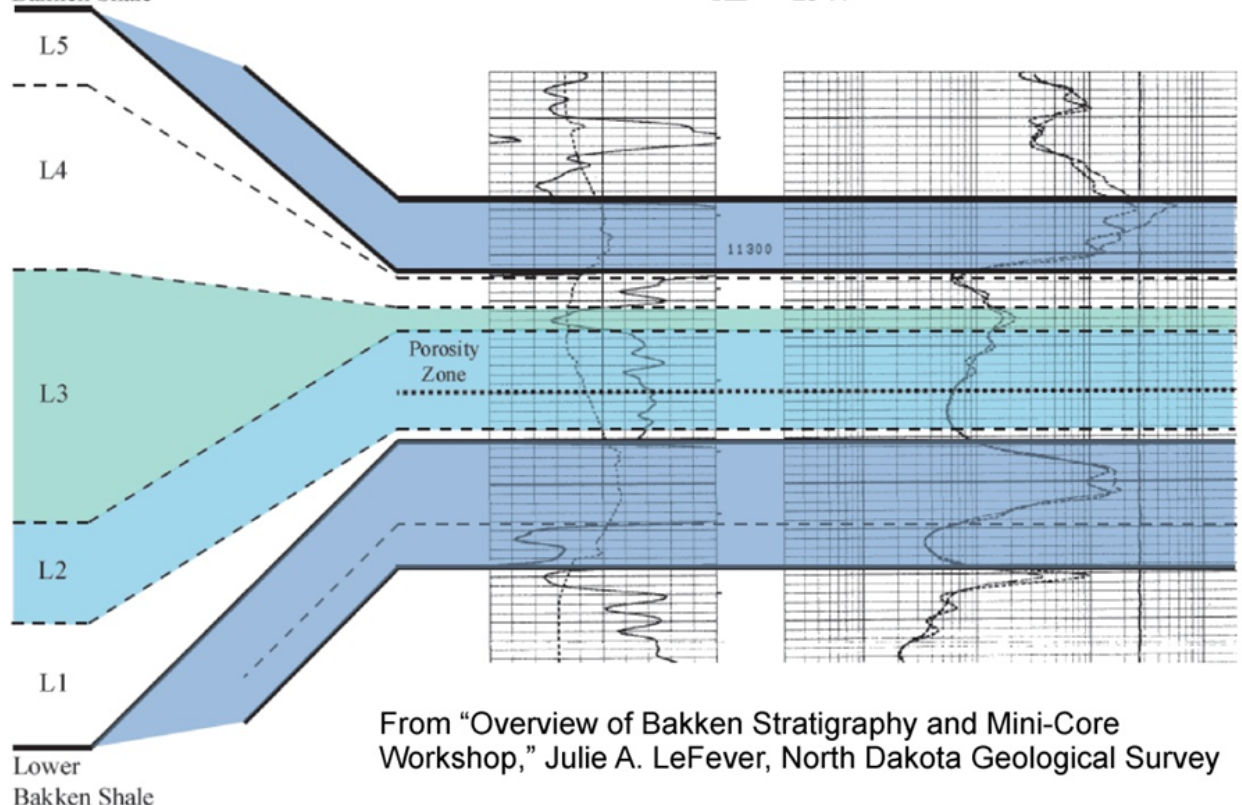

Figure 23. Lithologic description of the Bakken Formation from core showing relation to well $\log$ data.

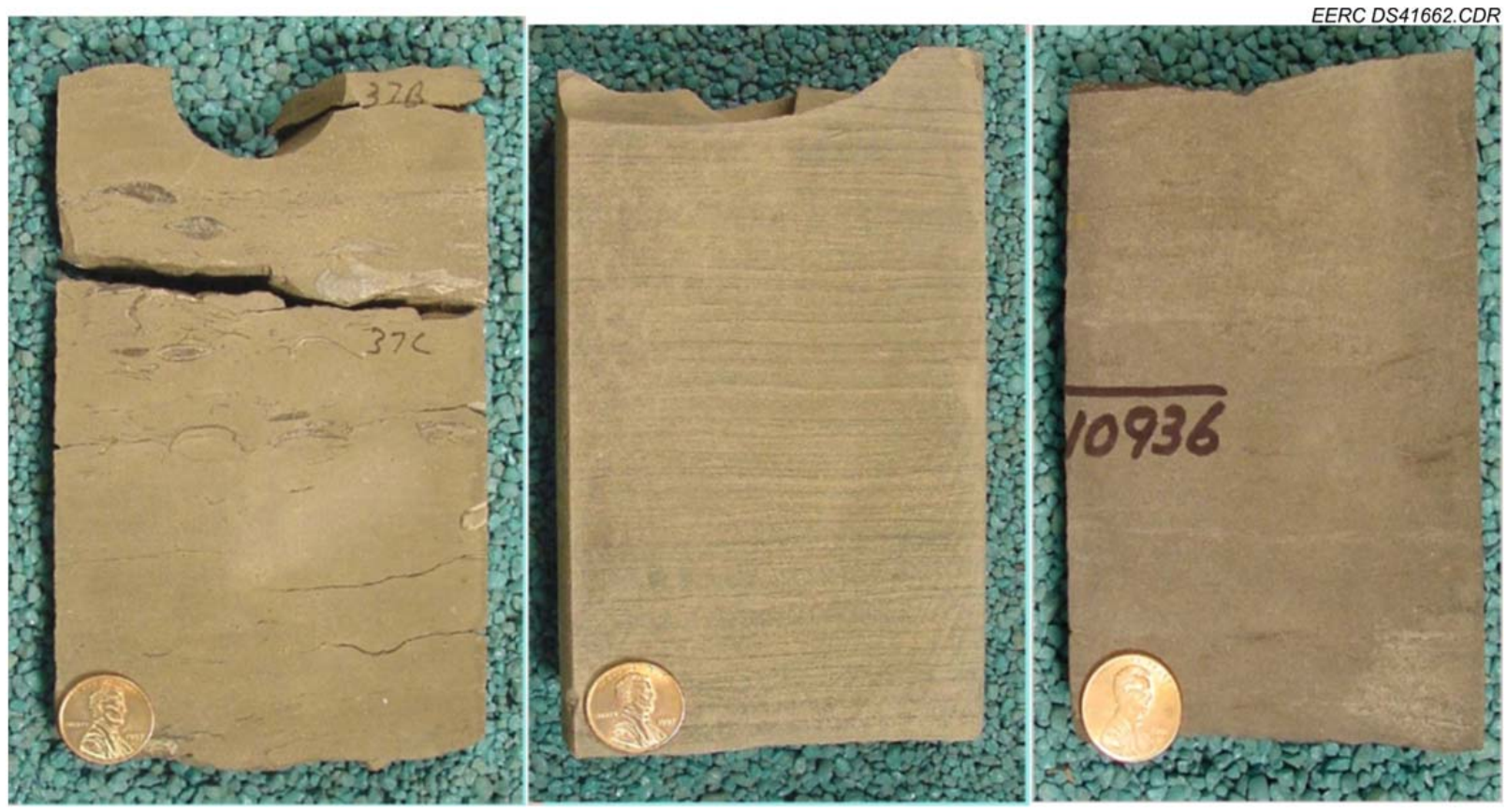

Figure 24. Upper zone L5 left, L4 middle, L3 right (photos from NDDMR). 


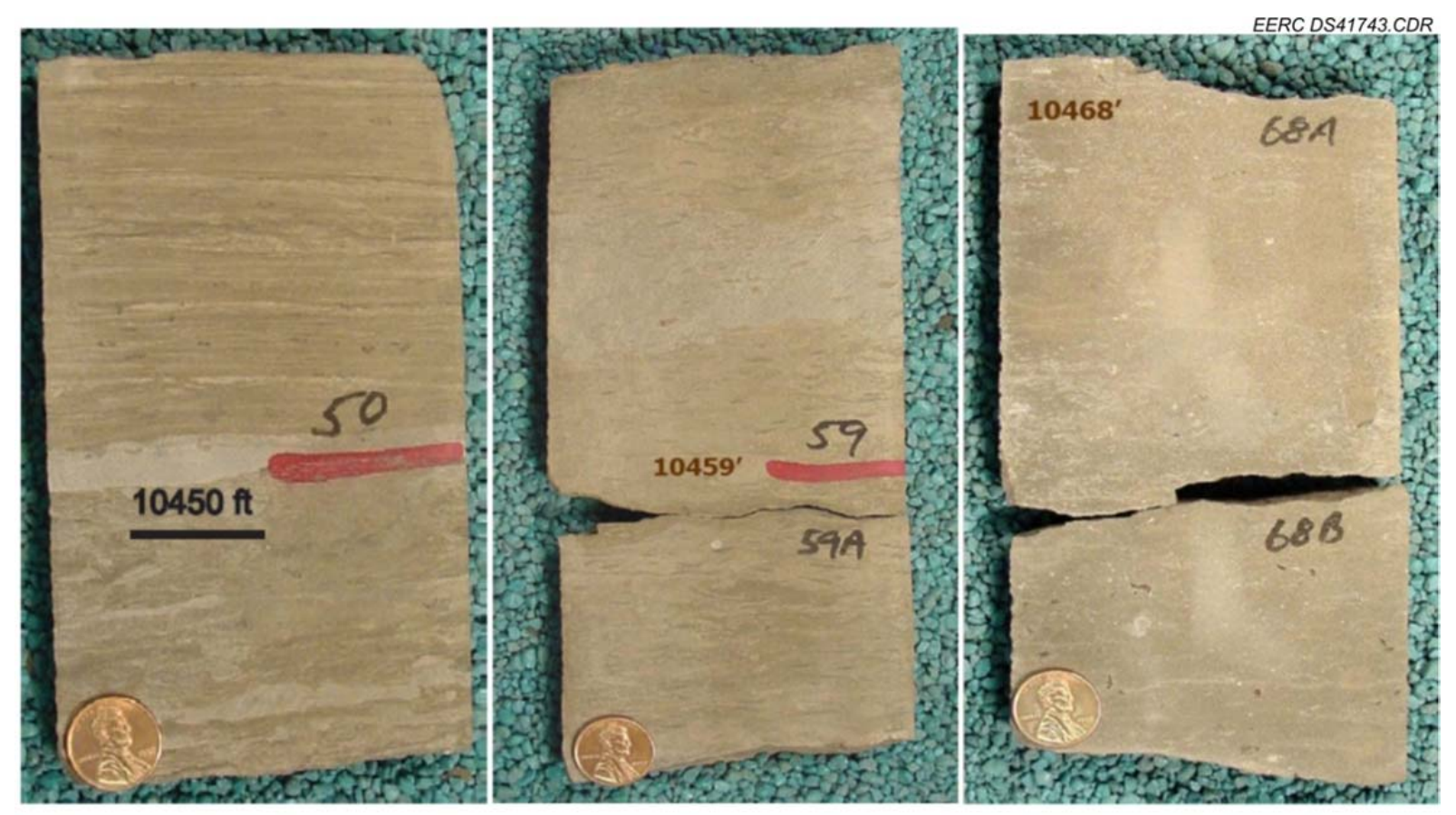

Figure 25. Central basin facies middle zone L2 left and lower zone (bottom of L2) and L1 right. (photos from NDDMR).

Table 4. Average Production (bbl) - Cumulative 6-month and Number of Wells in Data Grouping

\begin{tabular}{ccccccccc}
\hline Upper & Middle & Lower & Upper and Middle & L1 & L2 & L3 & L4 & L5 \\
\hline 27,280 & 28,024 & 25,131 & 25,524 & 25,571 & 23,955 & 27,626 & 22,167 & 32,936 \\
9 & 10 & 19 & 15 & 10 & 11 & 28 & 5 & 2 \\
\hline
\end{tabular}

The first 6-month cumulative production range for the studied wells is 10,000$40,000 \mathrm{bbl}$ with an average of 24,000 bbl. Production data were sorted and averaged. The results are provided in Table 4. Targeting the upper half of the middle Bakken appears to result in better than average production. L2 and L3 or the CBF an equal distance from upper and lower shales appear to out perform other vertical locations for horizontal wellbores in Dunn County that have been hydraulically fractured in a single stage. Analysis of 6-month production data from the 108 wells versus lateral length provided in Figure 26 indicates that longer laterals have generally higher production than shorter laterals. Therefore, the data averaged in Table 4 only included longer laterals of 7000-12,000 ft. The majority of the data includes wells drilled to $9000 \mathrm{ft}$ in horizontal length. The selected wells produced an average of 24,000 bbl within 6 months. Wells appear to perform slightly better than average when completed in the middle zone. This is further corroborated by the production shown for L3, where the lateral wellbore comprises over $70 \%$ within L3. L3 is described as very fine to fine-grained sandstone, massively cross-bedded to thinly laminated, and may have load or channel features, calcite cement, and occasionally pyrite. L3 is potentially not present in all wells analyzed and is likely replaced with the CBF in the Murphy Creek Field. The CBF consists of a highly laminated fine to very fine 


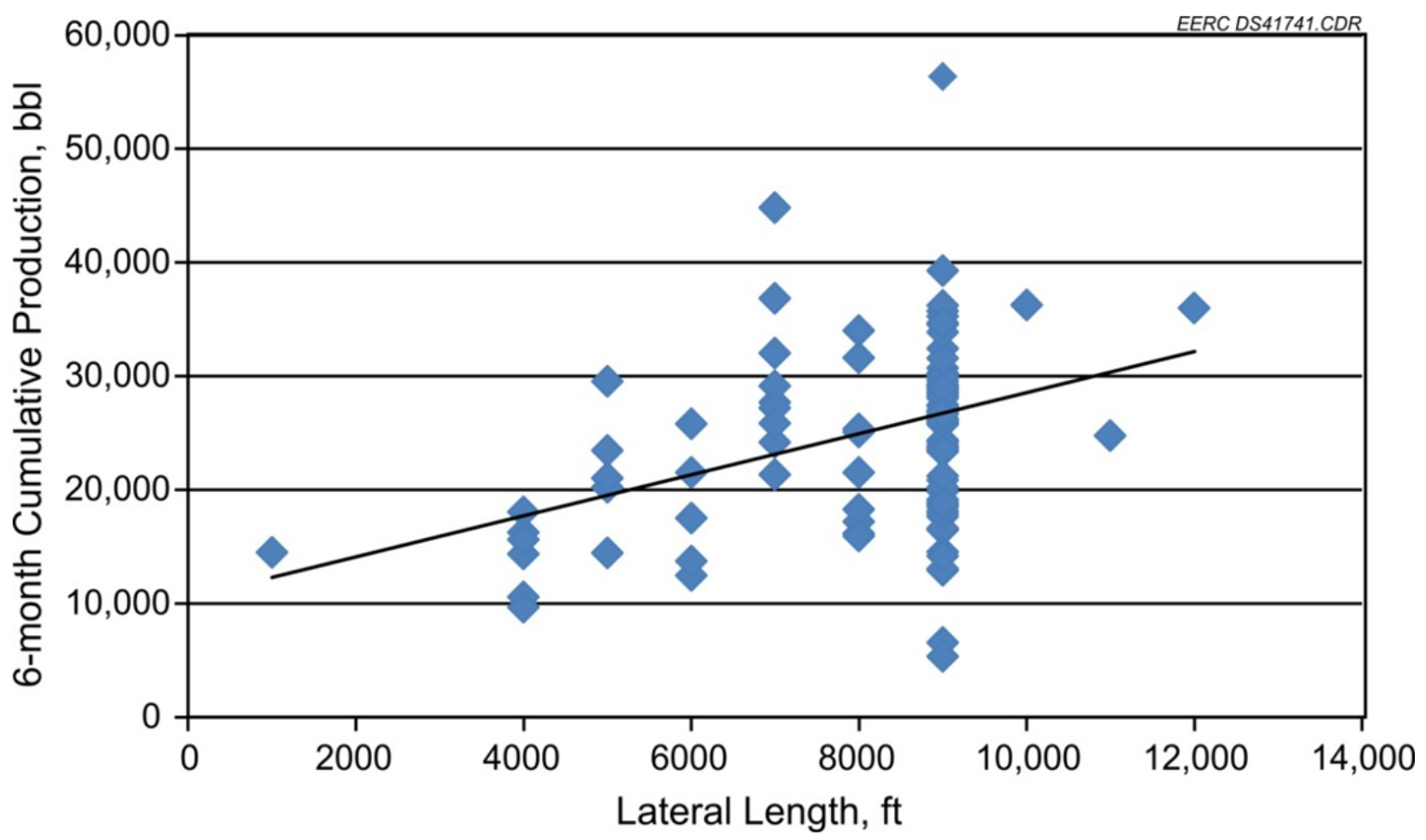

Figure 26. Production versus lateral length.

siltstone. In either case, the depth associated with L3 normally produces a spike in resistivity logs, indicating greater oil saturation. The thick L2 is present throughout Dunn County. The high production in Table 4 for L5 is not statistically significant given data from only two wells. These wells included a lateral completion that crosscuts all lithofacies nearly equally.

One strategy to improve production from single-stage treatments in Dunn County has centered on refracture stimulation treatments. One example is provided in Figure 27, in which the Kulish $24-2 \mathrm{H}$ well was refractured with slickwater on two consecutive occasions. The well is a multilateral completion on a 640 -acre spacing unit. Initial production of over 40,000 bbl was obtained after a single-stage fracture treatment of this well. The initial fracture treatment included 250,000 gallons of crosslink fluid and 500,000 lb of 20/40 sand provided in each lateral wellbore. The first refracture was completed after approximately 15 months of production and included over 500,000 gallons of slickwater pumped into the lateral wellbores simultaneously. The second refracture was also completed after approximately 15 months of production and included 875,000 gallons of slickwater. No proppant was added in the refracture treatments. Production after refracture treatments exceeded 40,000 bbl over 15 months. Refracturing of Bakken wells in Dunn County indicates that additional economic production can be achieved and suggests conductivity of fracture treatments is potentially degrading or that stimulation treatments might be improved. A thorough, although not exhaustive, review of the success of restimulation activity in the Bakken has been provided by Vincent (2011) in which over 100 restimulation treatments are reviewed. Some of the noted conclusions relative to the Bakken include the following: 


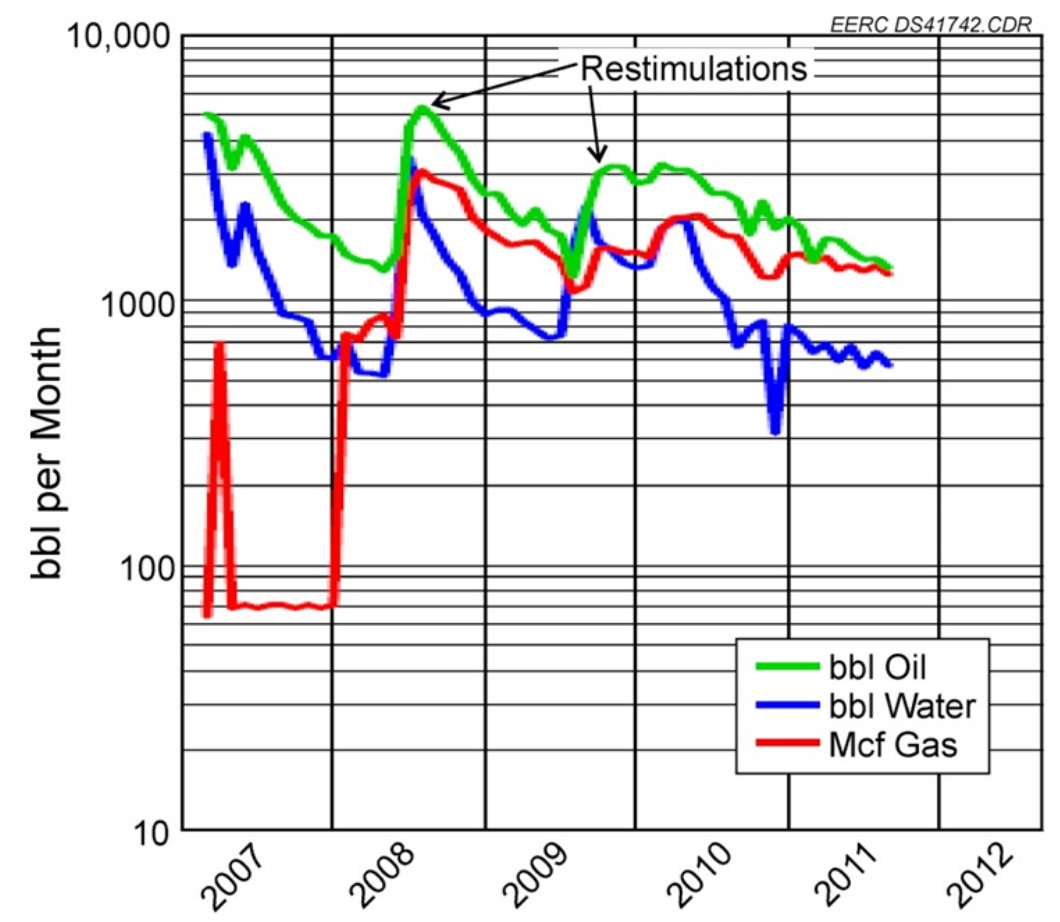

Figure 27. NDIC \# 16412 Kulish 24-2H, results of refracture stimulation.

- Refracturing can clearly add reserves in the Bakken by some diversion or reorientation of fractures that touch new rock and other mechanisms that increase conductivity, either within the fracture or enlarging the connection between the wellbore and the fracture.

- Flowback of sand and resin-coated sand (RCS) is a concern in the Bakken. Wells full of sand are good candidates for cleanout and restimulation. Wells treated with ceramic proppants rarely return ceramic proppant from cleanouts.

- Refracturing of Bakken wells initially stimulated with sand or RCS has resulted in $90 \%$ success rates. Refracturing wells initially completed with ceramic proppants has a lower frequency of success.

\section{Completion and Stimulation Analysis for Wells in the Bakken Formation}

\section{Database Description}

A database of well completion and stimulation information was assembled for the purpose of investigating the various completion and stimulation factors that are contributing to improved production in the Bakken Formation. The database includes 815 wells from nine counties and 54 different operators. Specifically excluded from the collection are wells in the Parshall and Sanish Fields. Generally, production from wells in Parshall and Sanish are largely influenced by high oil saturation and anomalous high formation pressure and have little variation in stimulation technique, which provides difficulty in determining how changes in completion methods influence production. The range of well parameters collected is listed below. The data can be characterized by a number of well characteristics, including various completion and stimulation parameters. These general well features are listed below and statistically highlighted in Table 5: 
Table 5. Characterization of Completion and Stimulation Database

\begin{tabular}{ll}
\hline $\begin{array}{l}\text { No. of } \\
\text { Wells }\end{array}$ & Feature \\
\hline 404 & Short lateral $<5000^{\prime}$ on 640 -acre spacing unit \\
378 & Long lateral $>5000^{\prime}-10,000^{\prime}$ on 1280 -acre spacing unit \\
121 & Spud date $1987-2002$ \\
139 & Spud date $2004-2007$ \\
555 & Spud date $2008-2010$ \\
37 & Single-stage (bullheaded) fracture treatments \\
406 & Multistage fracture treatments \\
6 & Diesel gel fracture treatments \\
65 & Gelled water fracture treatments \\
34 & Slickwater fracture treatments \\
63 & Freshwater fracture treatments \\
20 & Crosslink gel fracture treatments \\
131 & Wells treated with ceramic proppant \\
5 & Wells treated with RCS \\
345 & Wells treated with sand proppant \\
78 & Wells stimulated using plug and perforate \\
107 & Wells stimulated using sliding sleeves \\
33 & Wells stimulated using a combination of sliding sleeves and plug and perforate \\
\hline
\end{tabular}

- Spud date

- 6-month production

- Lateral length

- County

- Operator

- Fluid volumes and type

- Proppant volumes, type, and size

- Completion type (openhole, liner, cemented, swell pack liner)

- Stimulation type (bullhead, sliding sleeve, plug and perforate, or a combination)

- Flow test data (choke size, pressure)

- Stimulation data (injection rate, treating pressure)

Wells included in the database represent a diversity of location, operators, completion methods, stimulation choices, and time periods. Data were collected by operator and analyzed during collection to determine if various technology progressions were implemented. Approaches from different operators varied, including the following:

- Switching from diesel-based fracturing to water-based

- Increasing sand concentrations over time

- Increasing fracture stages over time

- Switching between sliding sleeve and plug and perf stimulations

- Switching from sand to ceramic proppant 
- Moving from single-stage fracture treatments to multistage

- Changing from $40 / 70$ sand to $20 / 40$ sand

- Switching between water fracturing and gelled fracturing

- Mixing sand and ceramic proppant

- Combining sliding sleeve stimulation with plug and perf

\section{Multistage Hydraulic Fracturing}

Multistage hydraulic fracturing continues to evolve in the Bakken and Three Forks Formations in North Dakota. Some of the first evolutions are described by Miller and Paneitz (2008), in whose work the first swellable packer liner systems combined with multistage ballactuated fracture sleeve systems are discussed. The technique, first implemented in more productive areas of the Bakken and normally completed in ten stages, has increased to over 40 stages, proving to unlock greater volumes of hydrocarbons in relatively less productive areas. The success of increased multistage completions has been demonstrated by Rankin and others (2010) providing a greater return on investment for increasing the number of stages. The investment in total well cost has essentially doubled over single-stage completions; however, the finding and development cost (F\&D) has decreased from nearly $\$ 40 /$ barrel of oil equivalent (BOE) to approximately $\$ 15 / \mathrm{BOE}$. The data analysis conducted for this project from 815 Bakken Formation wells supports the earlier publications.

Data were first analyzed to determine the relative trend over time. Figure 28 provides the data for production and the number of hydraulic fracture stages given spud dates (the day the drill bit enters the surface) from 2004 to 2010. The data provide an increasing trend in production and number of stages, with a spread indicating that some operators are also continuing to implement single-stage hydraulic fracture treatments. By plotting fracture stages and production, a positive linear trend can be established between the data sets with some scatter. Further analysis revealed that the scatter in the data could be attributed to production from short laterals $(<5000 \mathrm{ft})$ on 640 -acre spacings. Therefore, data limited to four operators known for implementing an increasing number of fracture stages over time were analyzed. The data include 37 wells with long multistage laterals completed in Williams, Divide, Dunn, and McKenzie Counties. The data in Figure 29 provide a relationship between production and increasing the number of fracture stages. The linear nature of the relationship implies that a productive limit for the maximum number of fracture stages implemented in a given well has not yet been reached. Operators are beginning to push completions to over 40 stages with "repeater sleeve" technology; however, the majority of recent activity reports for the Bakken Formation include wells completed using $20-40$ staged fracture treatments for each well.

\section{Diesel Gel and Water-Based Gel Hydraulic Fracture Fluids}

Diesel- and water-based hydraulic fracturing fluids have been used in the Bakken Formation to stimulate oil production. The Bakken Formation contains clay-rich organic shales in the Upper and Lower Members and smaller clay concentrations within the middle Bakken member. Clay content in producing rock formations may warrant the use of fluids that are sensitive to formation damage caused by clay mineralogy. Freshwater is known to cause the 

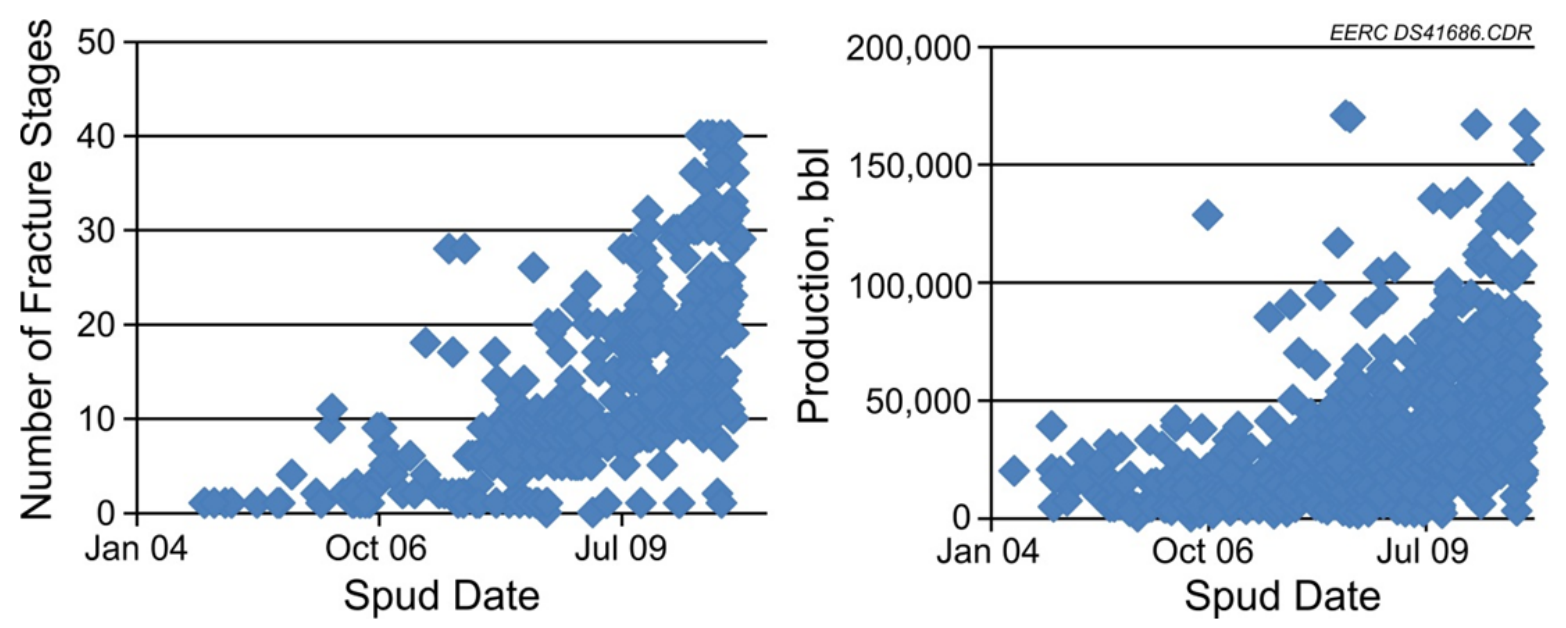

Figure 28. Number of hydraulic fracture stages for each well and 6-month cumulative production over time in the Bakken Formation.

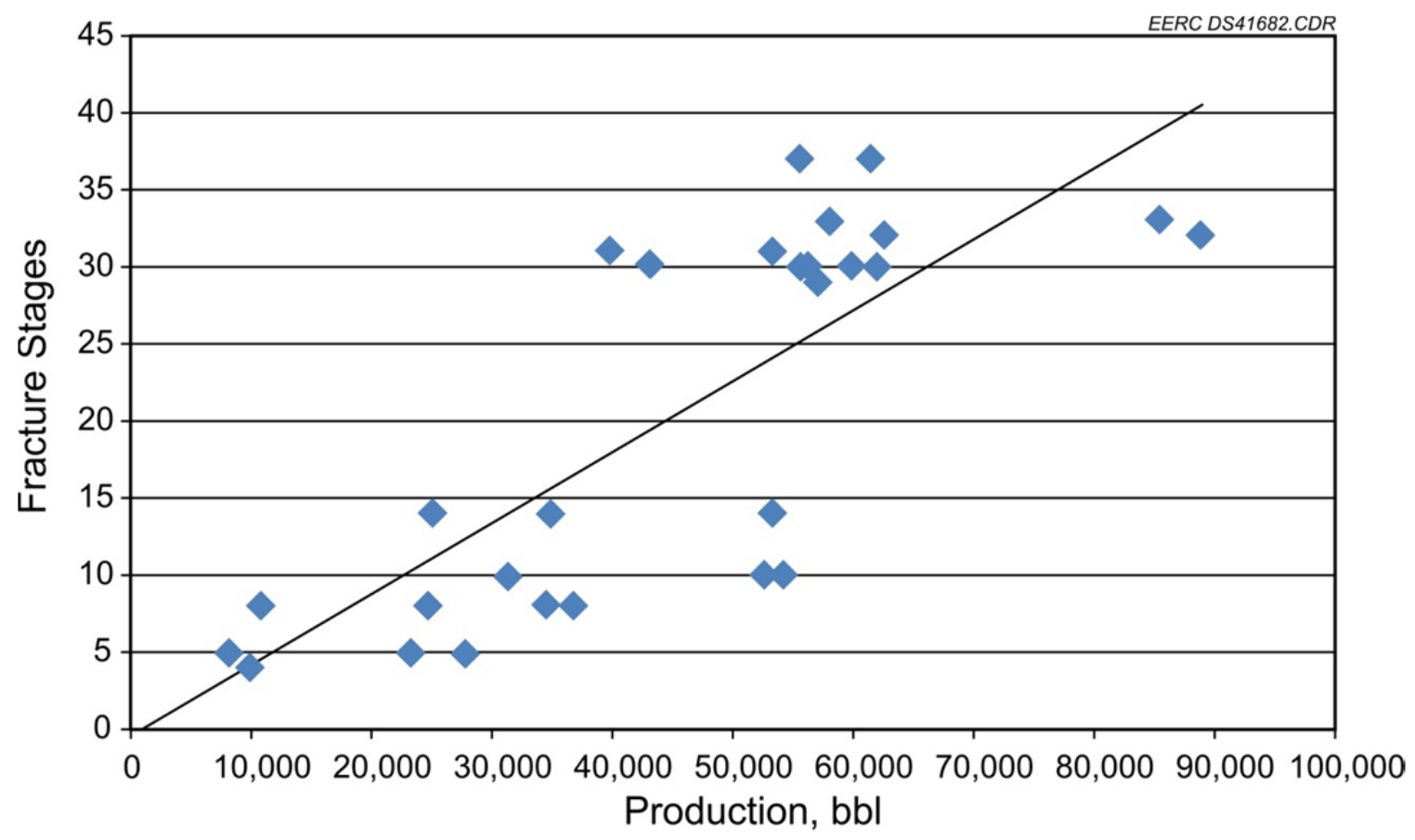

Figure 29. Number of stages hydraulically fractured in a well versus 6-month cumulative production.

swelling of clays and the precipitation of minerals that can contribute to formation damage by blocking effective porosity, which limits the ability to flow hydrocarbons to the wellbore. Dieselbased fluids or water-based fluids treated with clay inhibitors are commonly used to prevent clay-related formation damage. Wells located in Divide and Burke Counties were identified from three different operators. The wells were stimulated with an average quantity of approximately 250,000 gallons of fluid, and 550,000 lb of proppant (sand) at a relatively high proppant loading 
of nearly $2 \mathrm{lb} /$ gallon. The data set includes 12 wells, five treated with gelled water and seven treated with gelled diesel. Wells included both single-stage and multistage treatments as shown in Figure 30. Various completion parameters were examined. No relationship was established based on fluid type when comparing diesel to water. The only correlation that appeared consistent was the production relationship to multistage stimulation. Wells that included four to eight stage completions appeared to have higher production. It appears that the costs of diesel gel stimulation treatments have not been justifiable relative to water-based treatments, in this limited analysis of these less prolific producing areas.

Other hydraulic fracturing fluids used in the Bakken Formation include slickwater, linear gel, and crosslinked gels. Slickwater is defined here as a freshwater with added friction reducers and no gel. The term slickwater is often used interchangeably to refer to both gelled and nongelled fluids. Slickwater/freshwater is absent of densifying agents that increase the ability of the fluid to carry proppant. Slickwater treatments allow greater settling of proppant by gravity in the hydraulic fracture. A linear gel includes the addition of guar to thicken the fluid. Fracturing fluids are gelled to prevent proppant settling and carry proppant more effectively into hydraulic fractures. Breakers are used to lower the viscosity of the gel after exposure to formation fluids and allow efficient flow back of the fracturing fluids. A crosslinked gel includes the addition of borate to enable greater gel concentration for the purpose of achieving higher proppant carrying capacity.

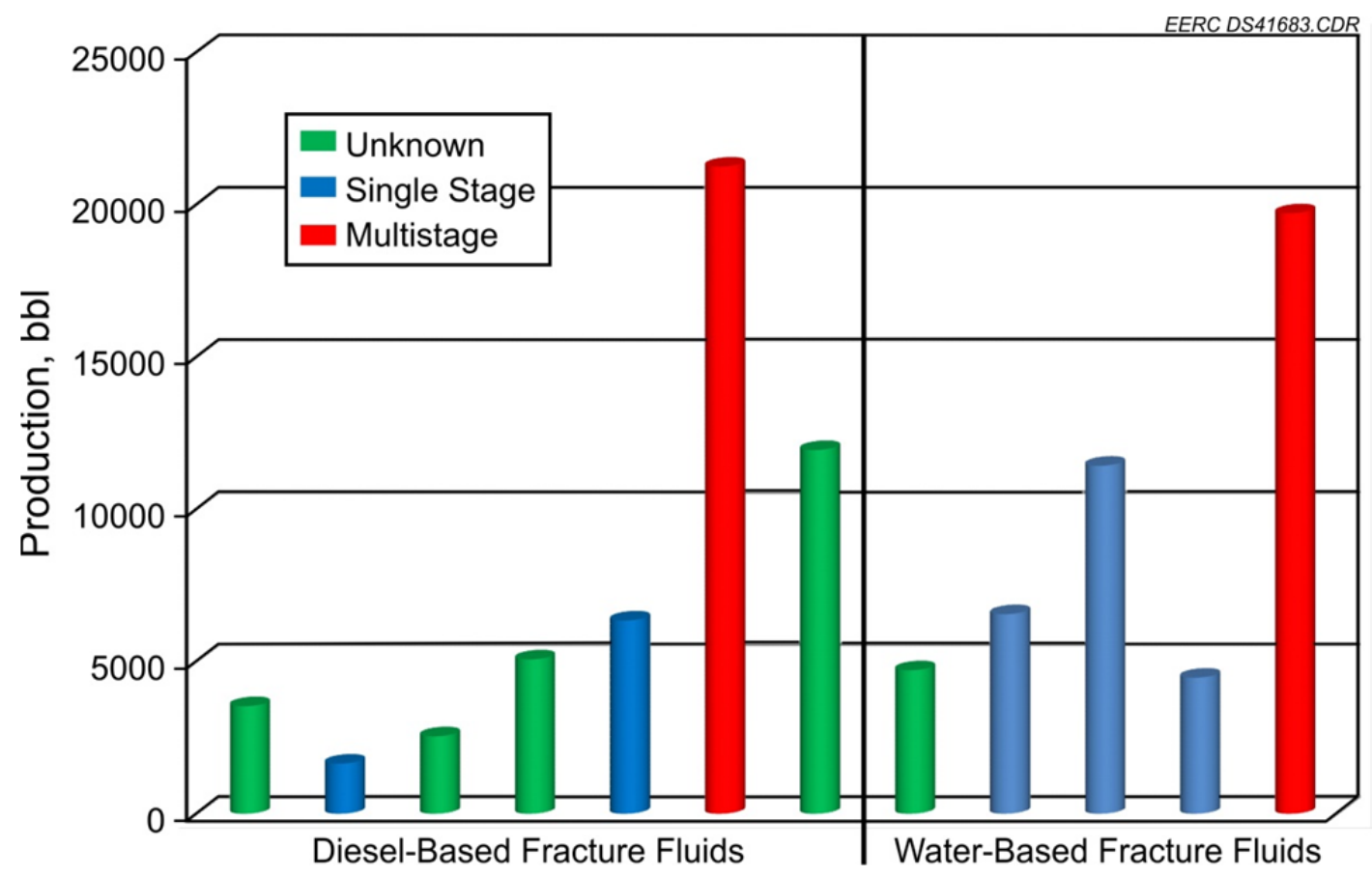

Figure 30. Cumulative (6-month) production comparison of wells stimulated with gelled diesel and gelled water. 
Data were sorted according to slickwater, gelled, and crosslinked treatments. Results indicated that fluid choice was relative to the operator, and few operators changed fluid selection over time. A significant data set was not available to compare production for gelled versus nongelled completions.

\section{Well Completions and Stimulations}

Multistage well completions in North Dakota utilize various stimulation techniques. The completion in a horizontal wellbore is defined by materials used to construct the mechanical components within the lateral. The various completion options can include the following:

- Openhole - The horizontal lateral is drilled to 6 inches in diameter and left open.

- Swellable packer liner - The openhole may be filled with a $4 \frac{1}{2} 2$-inch-internal-diameter uncemented liner that includes individual swell packers to provide zonal isolation.

- Sliding sleeve liner - The openhole may also be completed with a "sleeved" liner similar to the "swell pack" liner; however, including sliding sleeve mechanisms built into the liner in which the zonal isolation is provided by hydraulically activated packers.

- Cemented or uncemented liners - Liners that do not include packers can be cemented in place or left uncemented. Liners may also be preperforated.

The stimulation of the well refers to the techniques used to create hydraulic fractures and pump fluids and proppant into the fracture. Multistage stimulation techniques include the following:

- Sliding sleeve - Sliding sleeves are mechanical devices installed in the wellbore that provide diversion to isolated zones along the lateral portion of the well. Sliding sleeves may be installed inside of the openhole or inside of a lined hole. Sliding sleeves are activated sequentially from the toe of the well to the heel by dropping balls of increasing diameter. Sliding sleeves have become popular because of the reduced time required to stimulate the individual fracture stages.

- Plug and perforate - This method of well stimulation includes perforating the liner and selectively pumping the hydraulic fracture treatment. Stages are sequentially stimulated from the toe to the heel of the well. A plug is set after each treatment to isolate the completed stages from the next job. The plugs are collectively drilled out after all stages are complete.

- Combination - Many wells include more stages than some sliding sleeve systems can accommodate. Although recent systems have increased the number of stages possible in a single-sleeve system, combination of sliding sleeves and plug and perforate have been utilized in the Bakken Formation. Normally, the plug and perforate is completed near the heel of the well, to reduce time required for tripping. 
Completions and stimulation practices can affect production results from wells from a number of aspects such as the initiation of fractures from the horizontal wellbore. It is believed that small horizontal stress anisotropy within the middle Bakken is likely to result in a higher number of transverse fractures created from the wellbore, although both longitudinal and transverse fractures appear to be generated in the near wellbore (Olsen and others, 2009). Longitudinal rupture of the wellbore is believed to be likely in openhole completions because of the nature of the applied hydraulic pressure, whereas cemented liners that are perforated can create initiation points that allow direct growth of transverse fractures immediately from the wellbore. Regarding wells completed perpendicular to maximum horizontal stress, initially created longitudinal fractures are expected to reorient and propagate in the direction of maximum stress (Gidley and others, 1989). This possible reorientation in openhole completions can create more complex fracturing near the wellbore. The nature of fractures created from the horizontal wellbore (longitudinal or transverse) can greatly affect the placement of proppant and nearwellbore conductivity (Besler and others, 2007).

Production from wells completed with greater than 15 fracture stages are compared in Figure 31. Wells were selected over a wide range of areas and included 42 plug and perf, 26 sliding sleeve, and 24 combination stimulations. Plug and perf methods, which have the potential to provide for better fracture initiation, did not appear to have any distinct advantage over sliding sleeve systems or the combination of the two.

A few operators have elected to utilize relatively high numbers of fracture stages in "short" horizontal wells. These wells are completed on 640-acre spacings and include lateral lengths of

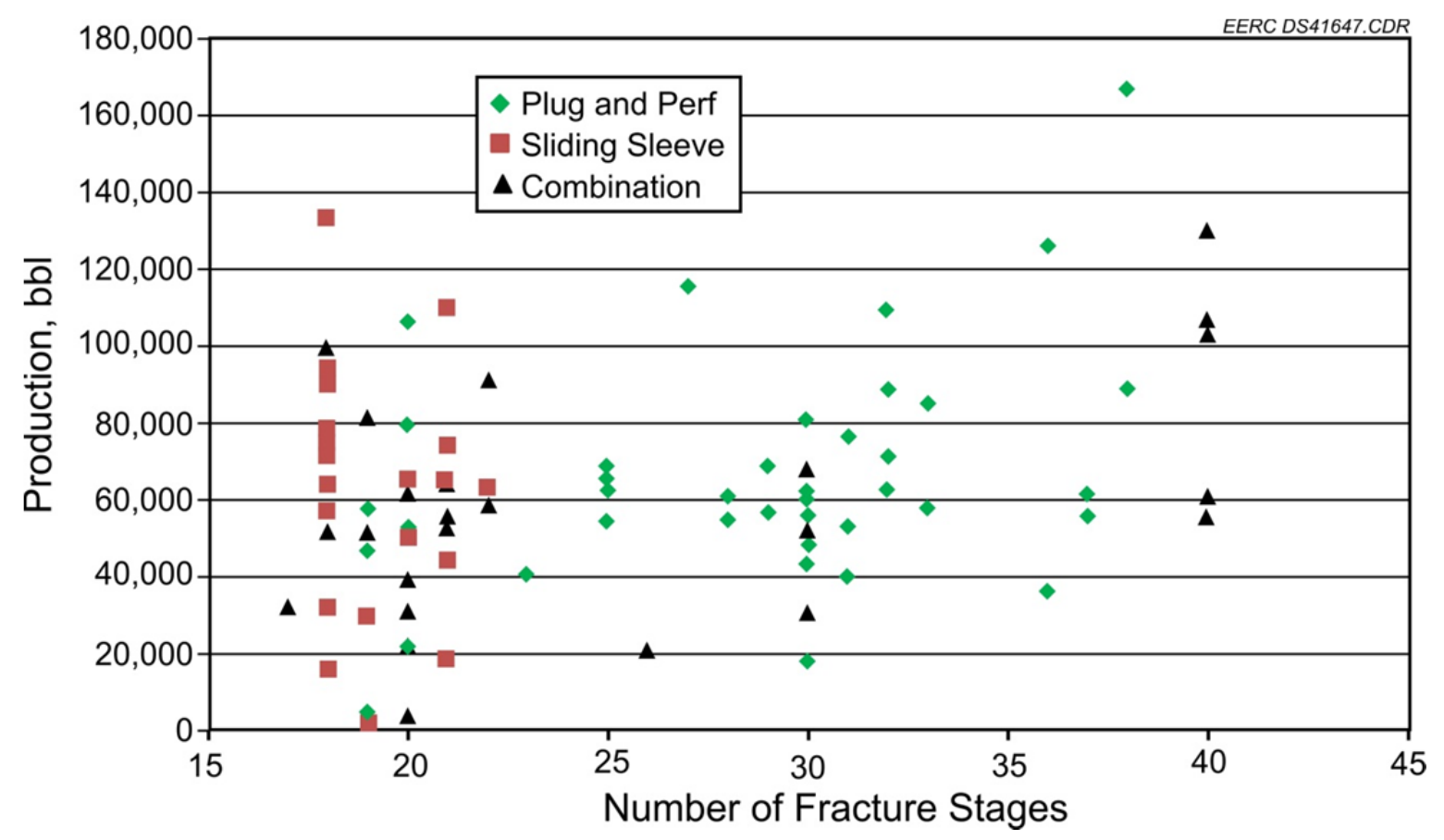

Figure 31. Comparison of production from wells using sliding sleeves, plug and perf, and combination stimulation methods. 
less than $5000 \mathrm{ft}$. Operators have stimulated over 20 stages in these short lateral wells. Performance in terms of production per linear foot was examined for short (22 wells) and long (14 wells) lateral completions in Mountrail County (Figure 32). Short lateral completions fractured at nearly the same spacing as long lateral completions appear to have better production efficiency.

Further investigation considered 674 North Dakota Bakken wells in Figure 33 to examine the result of reducing fracture spacing in horizontal wells. Early long lateral completions in the Bakken included 10,000-ft lateral wells fractured in ten stages providing a spacing of $1000 \mathrm{ft}$ between treatments. As additional staging in wells began to show productivity gains and technology improved, fracture spacing decreased with the objective of producing greater conductivity and connection of the wellbore to the formation.

\section{Proppants}

Proppant selection and application are significant well completion variables for Bakken development in North Dakota. Proppants, or propping agents, are pumped during hydraulic fracturing treatments to maintain fluid conductivity of the fractures induced in the Bakken Formation. Three basic types of proppant are ceramic (sintered bauxite, alumina, kaolin), sand (sorted silica sand), and resin-coated ceramics or sand. Ceramic proppants comprise three groups: lightweight, intermediate density, and high density. The performance of ceramic proppants varies greatly both by composition and manufacturer; however, numerous ceramic

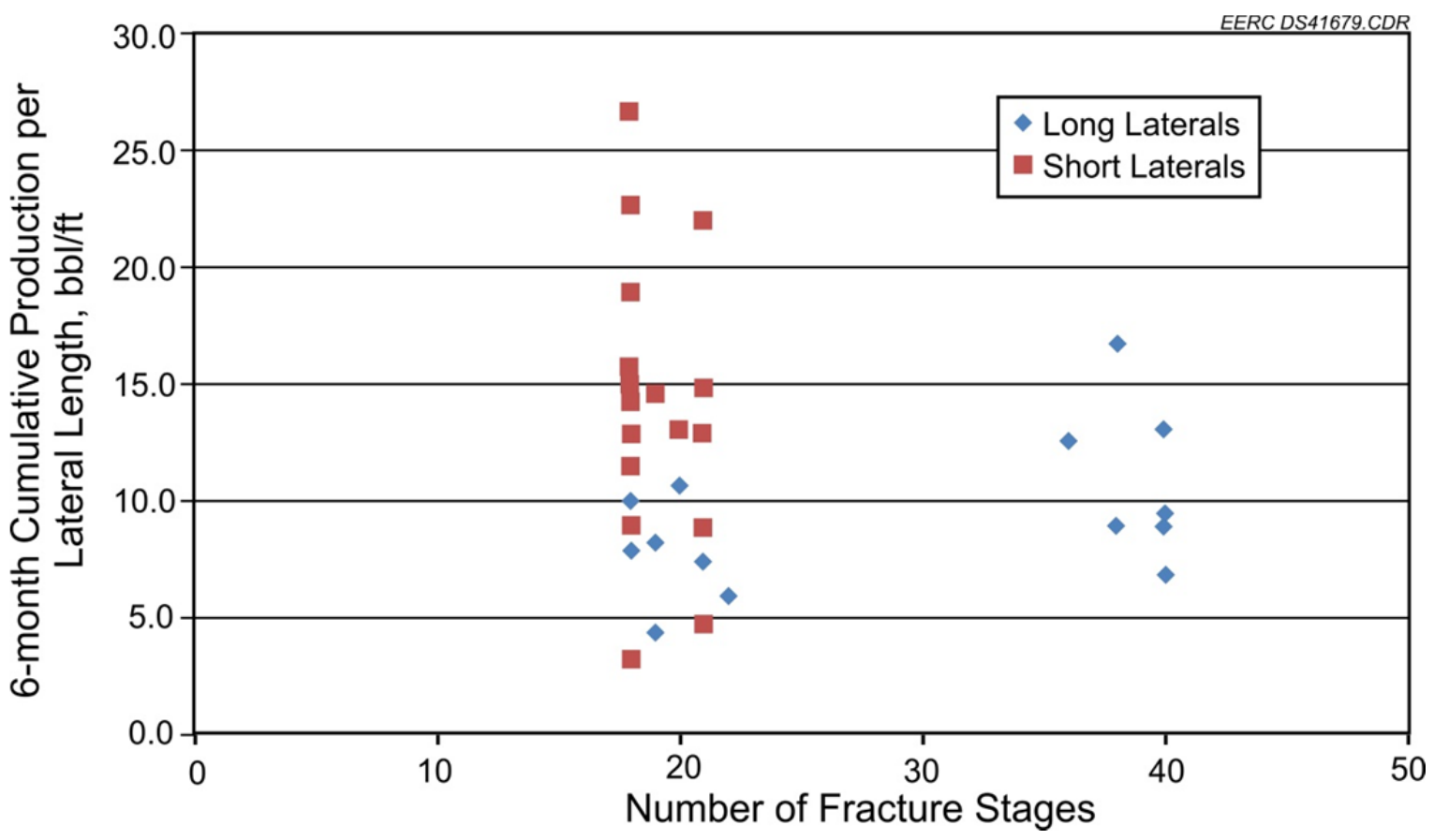

Figure 32. Production per linear foot for short and long laterals in Mountrail County. 


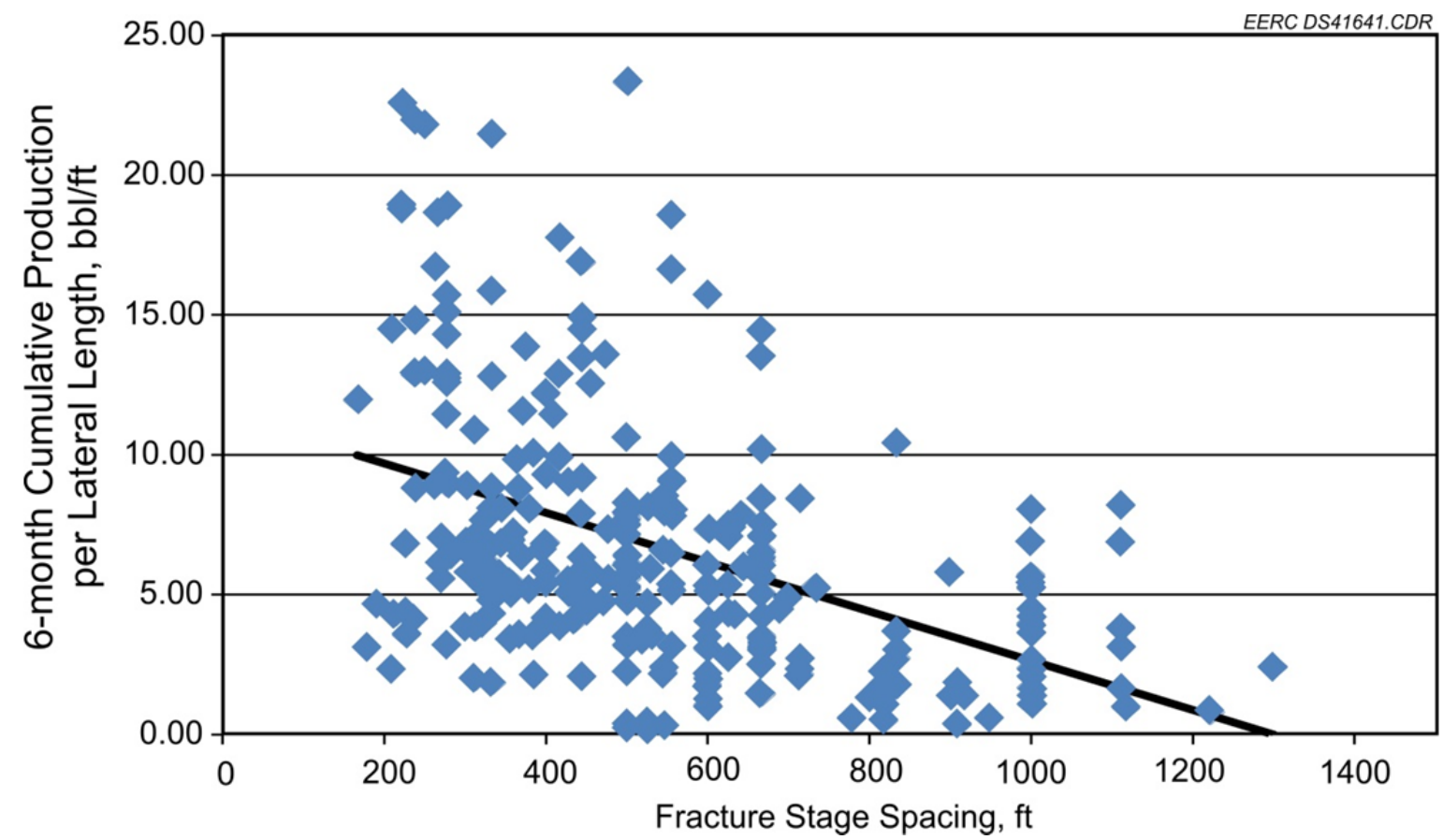

Figure 33. Production per linear foot relative to the spacing of isolated hydraulical fracture zones in lateral wellbores.

proppants used in the Bakken are advertised to withstand closure stresses of 6000 to 14,000 psi. Relative closure stresses of the Bakken Formation in North Dakota cover the performance range of ceramic proppants. Fracturing sand is typically divided into two types: white sand and brown sand. White sand, the stronger of the two, is sourced from formations such as St. Peter's sandstone in Ottawa, Illinois, while an example of brown sand is the Hickory sandstone near Brady, Texas. Fracture sand is typically used in environments below 6000 psi (Halliburton, 2005). Resin coating of sand does not increase the strength of individual grains; however, RCS is a popular proppant choice because of better consolidation that reduces flow back and provides for better stress distribution across the proppant pack. Resin-coating ceramic proppant provides similar performance enhancements. All of the above are being used in Bakken completions.

The data regarding well performance using various proppants included a significant number of wells using both ceramic and sand proppants in Mountrail, Williams, and Dunn Counties. Operators within the study group exclusively used ceramic or sand as their primary proppant. Data suggest few operators are switching proppant types, although the use of 20/40 ceramic combined with 40/70 sand is a popular choice. Few data were available for wells treated with RCS. Generally, ceramics appear to provide better production results relative to sand, although this does not hold true in all cases. Greater production is shown using ceramic proppants in Figures 34 and 35 for Dunn and Williams Counties, respectively; however, performance relative to sand and ceramics is indiscernible in Figure 36 for Mountrail County. The performance of wells stimulated with sand in Mountrail County was further investigated. Treatments of five operators (Figure 37) included gel-based fluids, similar proppant loadings, 


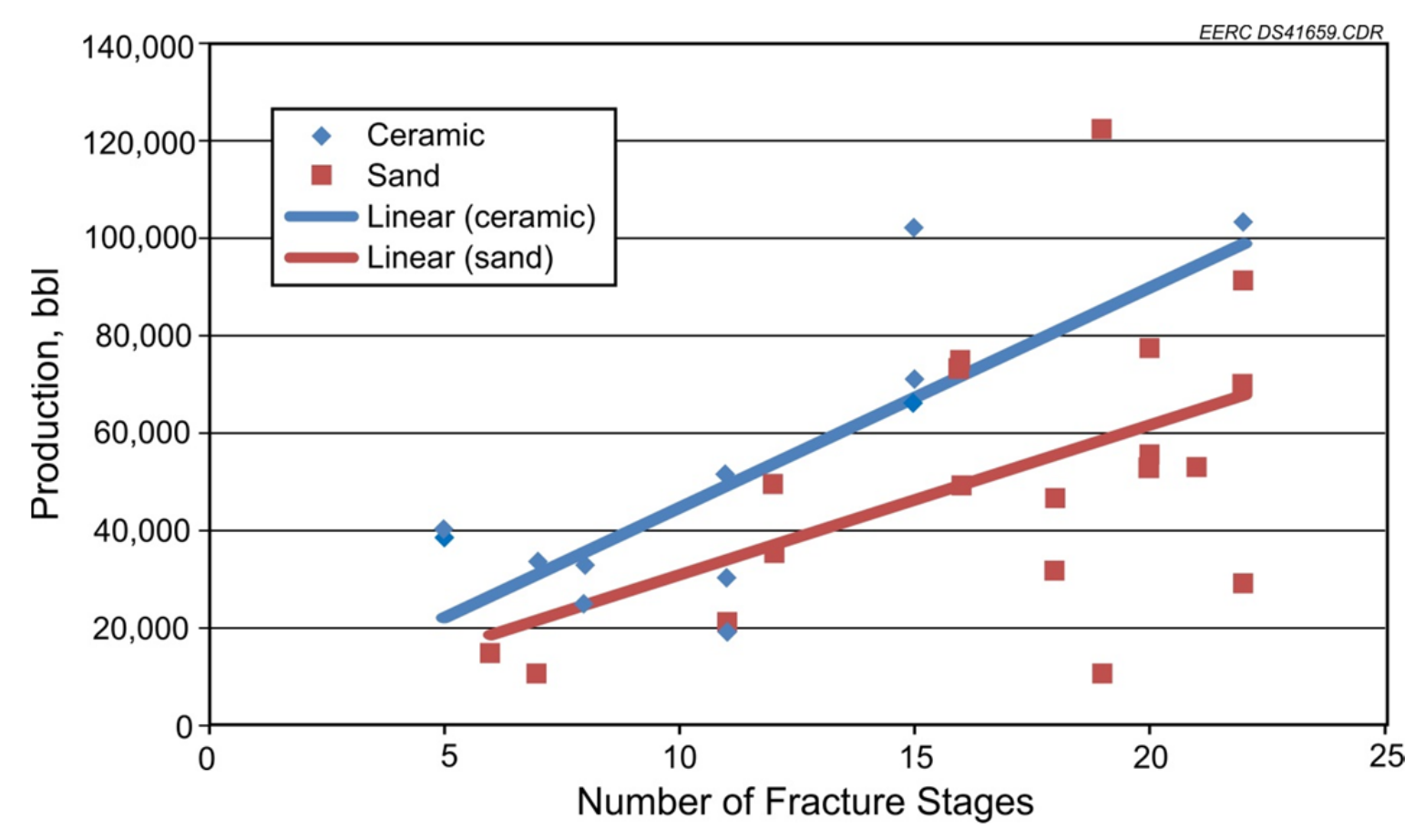

Figure 34. Performance of ceramic and sand proppants in Dunn County, 6-month cumulative production (ceramic 12 wells, sand 18 wells).

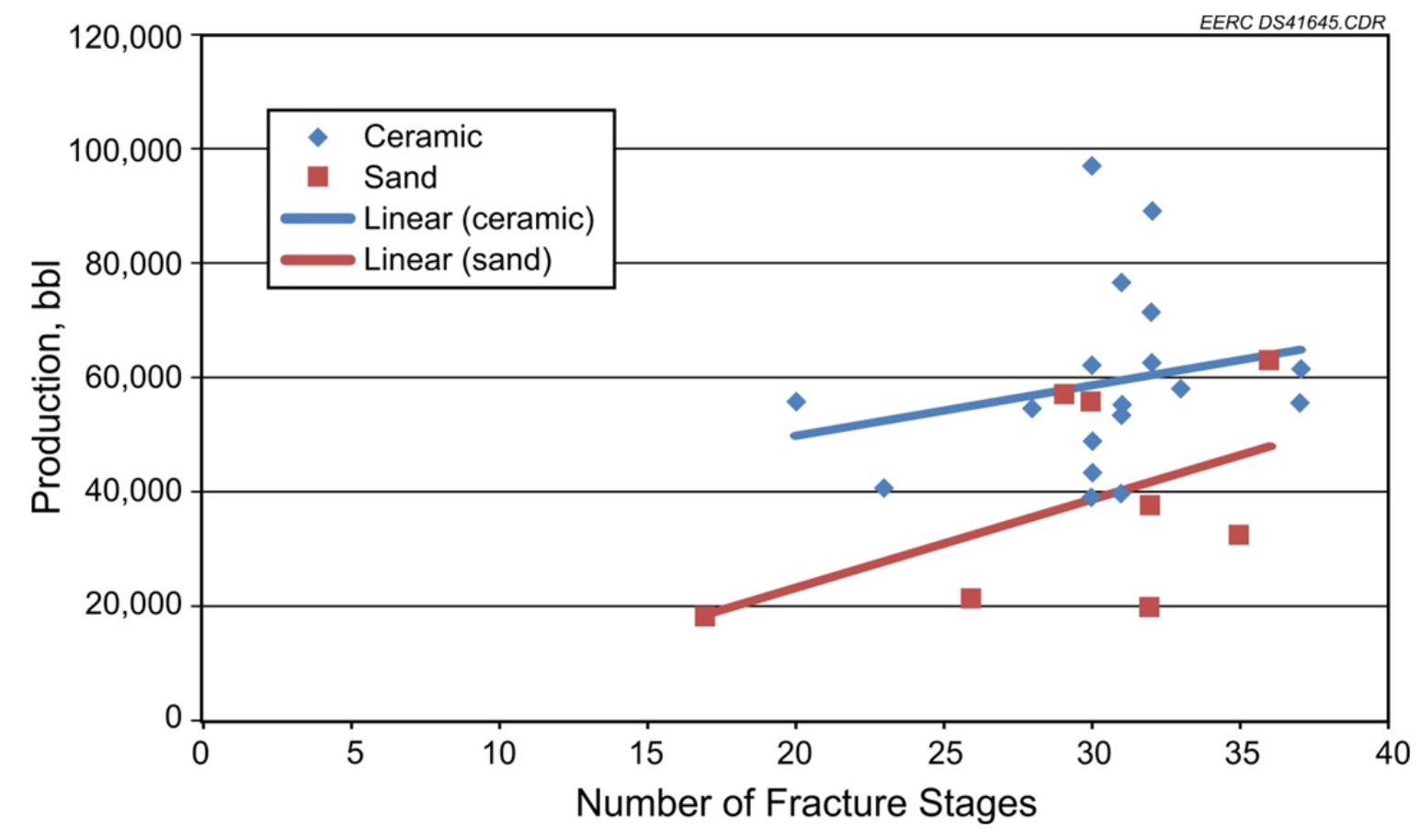

Figure 35. Performance of ceramic and sand proppants in Williams County, 6-month cumulative production (ceramic 18 wells, sand 8 wells). 


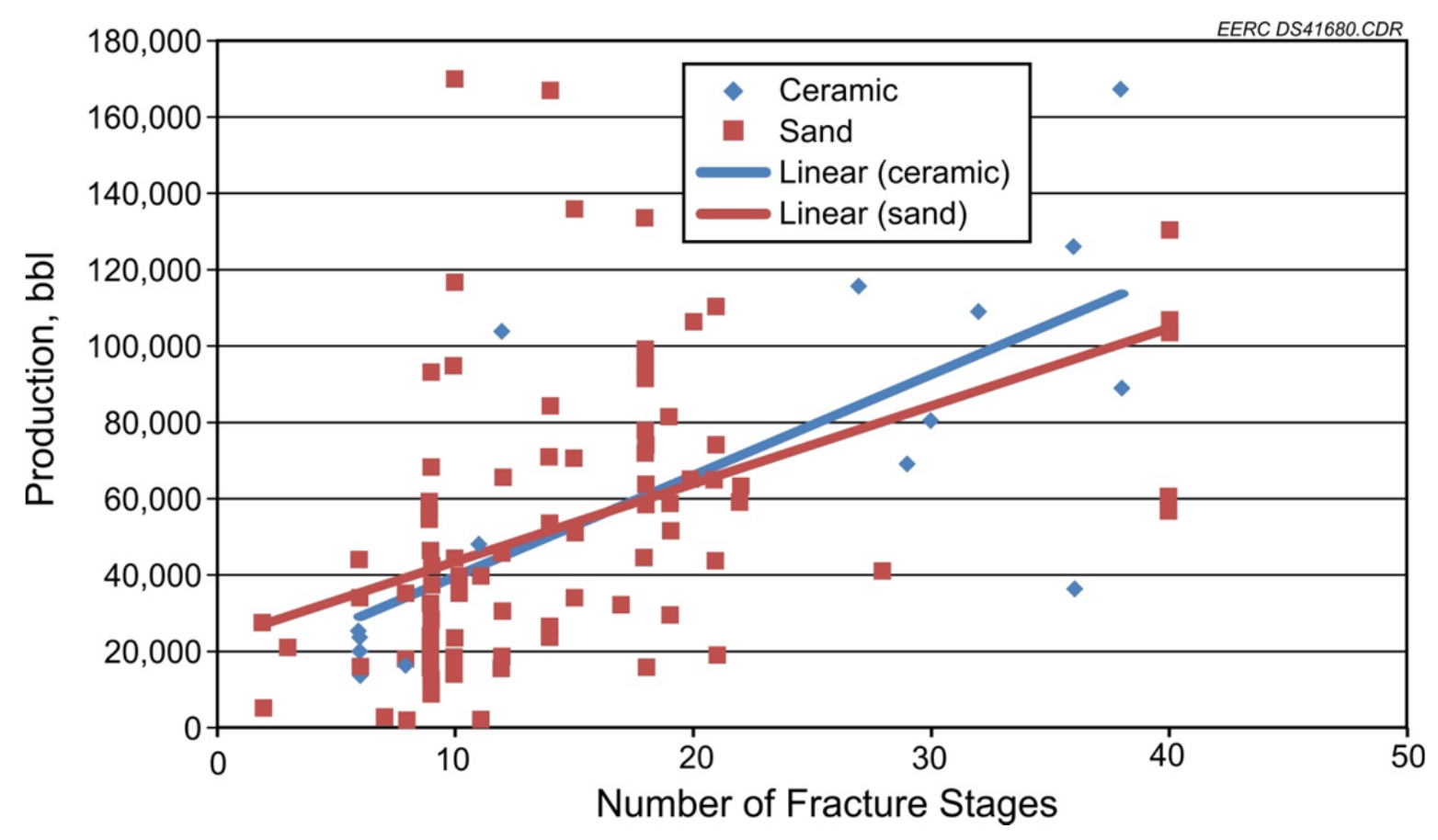

Figure 36. Performance of ceramic and sand proppants in Mountrail County, 6-month cumulative production (ceramic 19 wells, sand 111 wells).

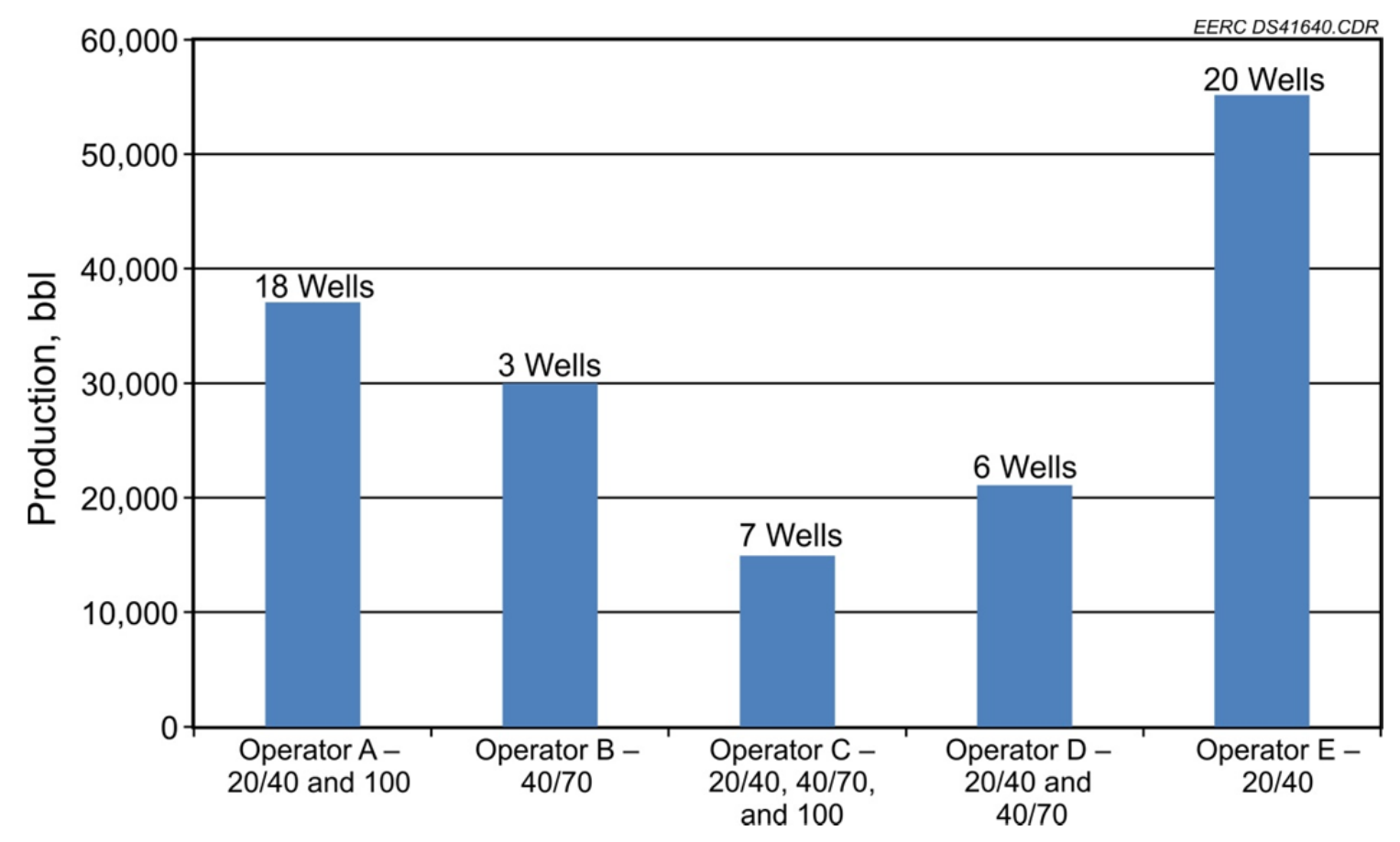

Figure 37. Cumulative 6-month production of wells stimulated with various sizes of sand in Mountrail County. 
and a similar number of fracture stages. Operator E, using a single 20/40 grain specification, appeared to have better production than operators who mixed sizes or used smaller 40/70 proppant. Given the potential implication that mixing of proppant sizes may influence production, operators using ceramic and sand combinations were investigated (Figure 38). Operators using a mix of 20/40 ceramic and 40/70 in wells fractured with over 30 stages appear to be making good wells and are notably equivalent to Operator E using 20/40 sand. Operators B and $\mathrm{C}$ in Figure 38 were compared using a single-size ceramic versus mixing of ceramic and sand in wells stimulated with $<$ ten stages. Operator $\mathrm{C}$ using a mix of proppant appeared to produce better wells.

\section{Proppant Concentrations}

Proppant concentrations used in Bakken completions did not appear to have a significant influence on well production. Data were examined in short and long laterals including singlestage and multistage treatments. Additionally data were examined delineating ceramic and sand proppants. Figure 39 provides data plotted for proppant concentrations from multistage completions for short and long laterals. Although excluded, the relationship is similar for singlestage treatments. The data provide evidence that concentrations of 1 and $2 \mathrm{lb} / \mathrm{gal}$ are popular choices. The plot to the right in Figure 39 provides data for a single operator in which various concentrations of proppant were attempted over 3 years, increasing from $1 \mathrm{lb} / \mathrm{gal}$ to $2 \mathrm{lb} /$ gal. Wells were stimulated in multiple stages ( $>$ ten) with mostly 40/70 sand. Again, no particular relationship simply based on proppant concentration was evident. Theoretically, higher

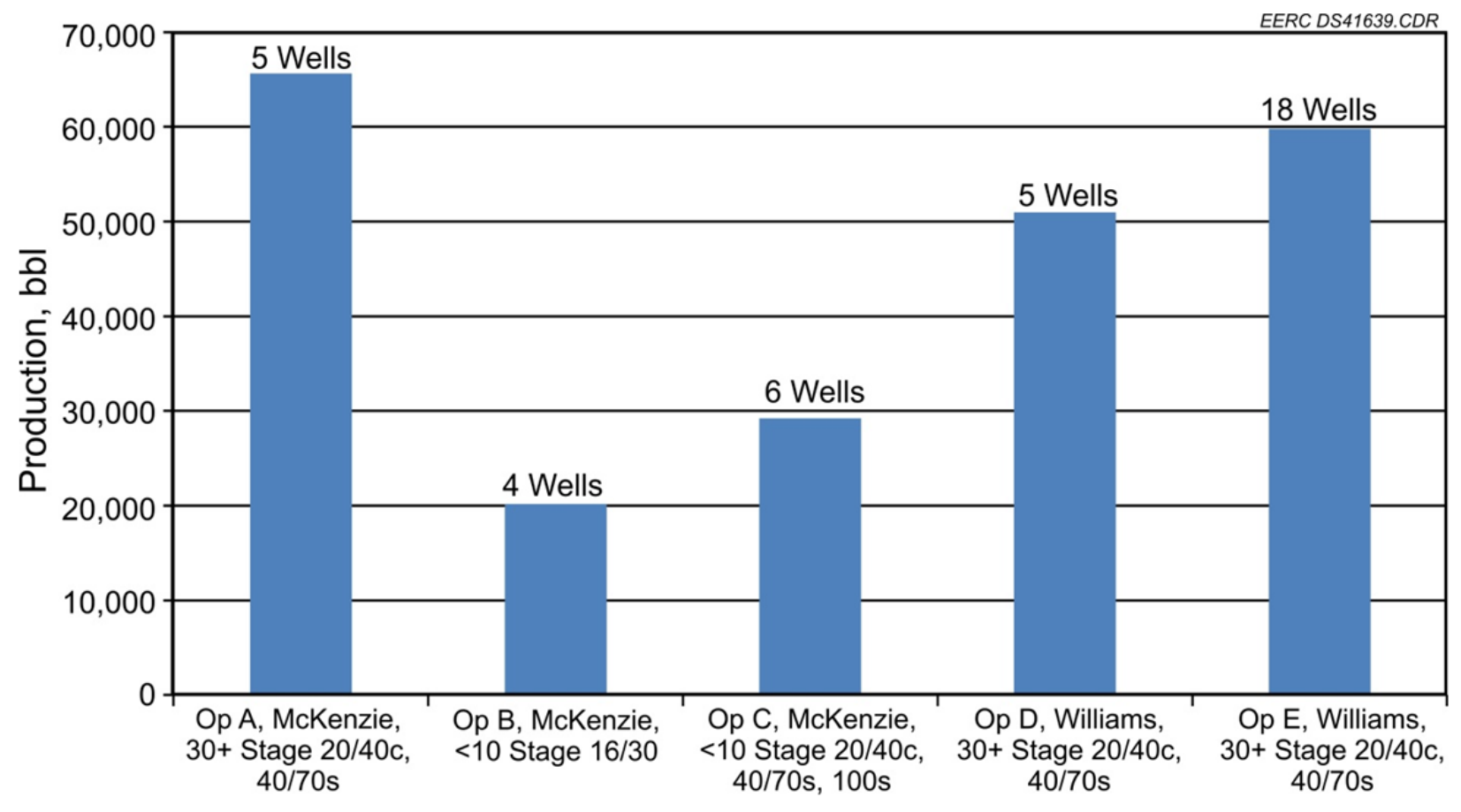

Figure 38. Cumulative 6-month production for wells stimulated with various sizes of ceramics and sand in McKenzie and Williams Counties. 

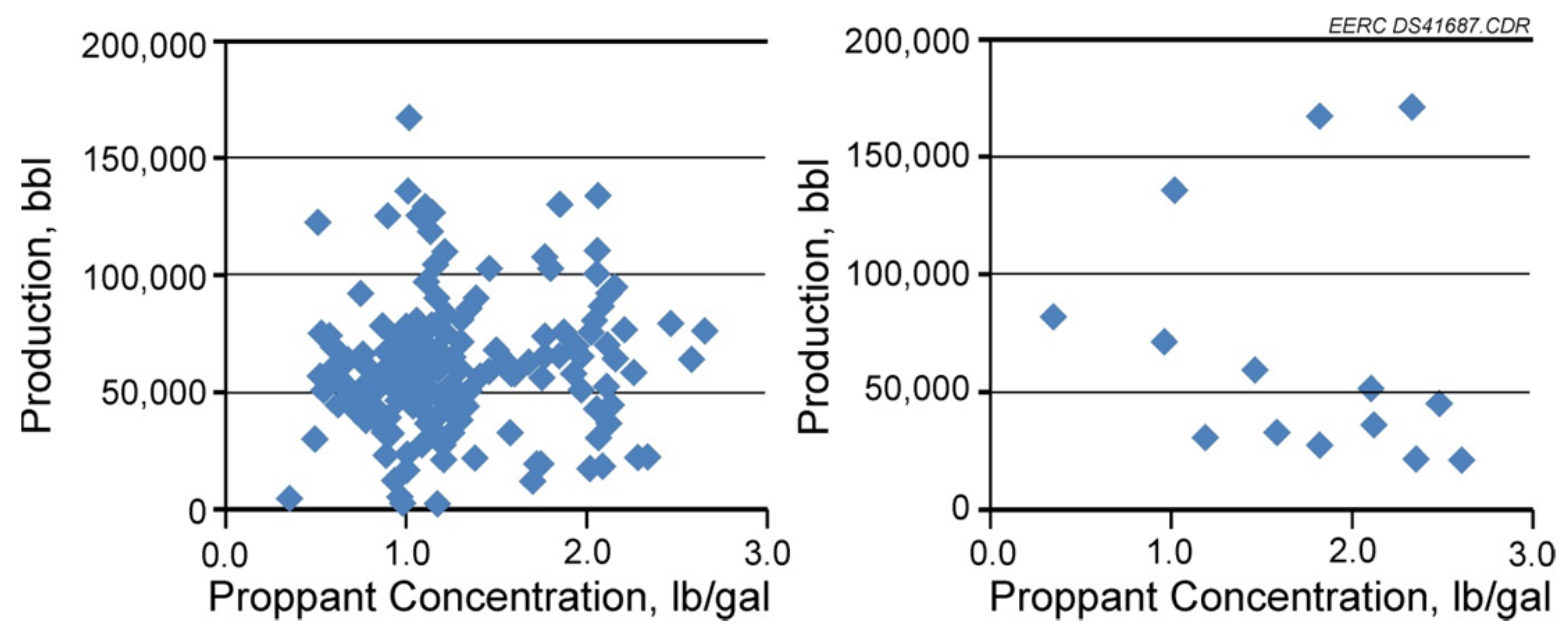

Figure 39. Proppant concentration and 6-month cumulative oil production.

proppant concentrations are expected to yield greater conductivity in the formation, assuming adequate proppant placement and proppant durability. Overly high concentrations are avoided to prevent screening out in the fracture where proppant can backfill into the wellbore requiring costly clean out.

\section{Summary of Analysis of Completion and Stimulation Database}

- Data indicate higher productivity from wells with a higher number of fracture stages.

- A limited history of wells stimulated with diesel-based fracturing fluids did not appear to have any significant advantage over water-based fracturing fluids.

- The choice of other fluids, such as slickwater, linear gel, and crosslinked gels, appears to be indicative of the well operator.

- Plug and perforate, sliding sleeve, and combinations of the two completion methods do not appear to have any distinct production-related advantages over each other.

- Highly fractured short laterals in Mountrail County appear to be providing greater production than long laterals with similar concentration of fractures (not including Parshall Field).

- On average, ceramic proppants appear to be providing increased production relative to sand proppants, but not in all areas of the Bakken play.

- Mixing of 20/40 ceramic with 40/70 sand does not appear to have any detrimental influence on production; however, mixing of various sand sizes may result in decreased performance.

- Operators are using proppants at concentrations of 1 and $2 \mathrm{lb} /$ gallon. Analysis of data in this study could not discern a production advantage relative to proppant concentration. 
Higher production is being realized across the Bakken play in North Dakota from increased staging of hydraulic fracturing. The most massive jobs include 40-stage hydraulic fracture treatments using 2 million gallons of fluid and nearly 4 million $\mathrm{lb}$ of proppant. Early wells in Dunn County were fractured in a single-stage treatments. Single-stage production strategies include refracturing the wells over 15-month periods in which original initial production is nearly achieved, producing good economic return. The average single-stage completion in Dunn County is approximately 25,000 bbl over 6 months. Production relative to multistage completions in Dunn County is provided in Figure 40. Figure 40 indicates that a significant percentage of wells using multistage completions achieve greater than 50,000 bbl over 6 months, with some multistage treatments achieving over 100,000 bbl and some marginal production. Given the advent of new technologies, operators are increasing the number of stages hydraulically fractured in a given well. The data from this study suggest that the spacing of treatments can be decreased and that a productive limit relative to number of stages has not yet been identified.

\section{Relationship Between Rock Fabric and Geomechanical Properties}

Because proper application of fracture stimulation is a key to sustained production from a Bakken or Three Forks well and geomechanical data are essential for designing effective hydraulic fracturing schemes, it is necessary to understand the geomechanical properties of the formation. Because the Bakken and Three Forks Formations comprise multiple lithofacies, each of which in turn has its own heterogeneities with respect to mineralogy and rock fabric, it is also

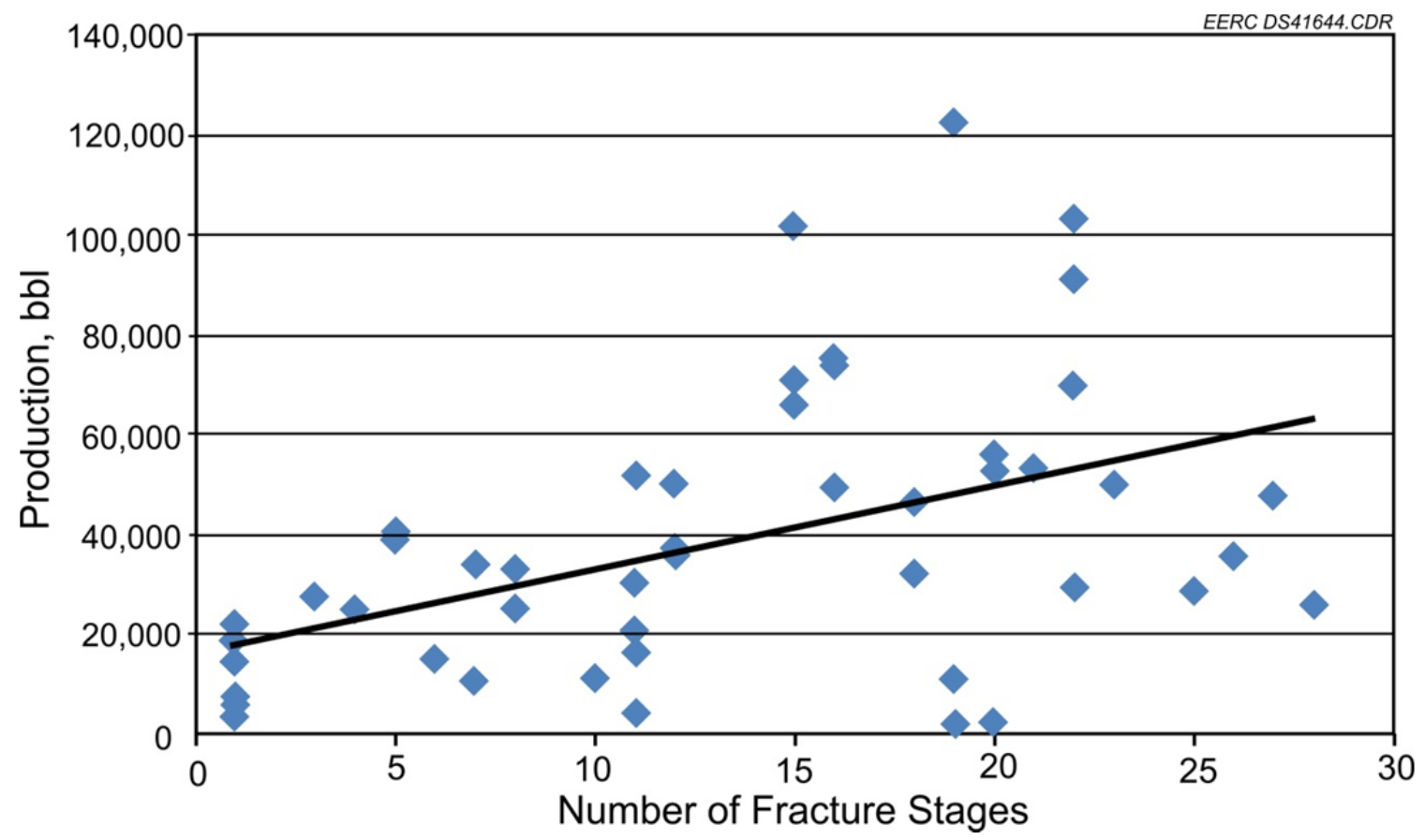

Figure 40. Multistage completions and 6-month cumulative production for Dunn County wells. 
important to understand the relationships that may exist between mineralogy, the fabric of rock, and geomechanical properties. As part of the Bakken research program, the EERC conducted a suite of analytical activities on samples representing a variety of lithofacies to evaluate potential relationships between petrographic properties and geomechanical properties.

This assessment focuses on petrophysical classification and description of the middle Bakken and Three Forks Formations and geomechanical testing on corresponding samples. When evaluated together, mechanical and petrophysical characterization provides an increased understanding of the complex relationships between mineralogy; rock fabric structure at the macro-, meso-, and microscales; existing fracture networks; and the location of residual hydrocarbons with respect to their potential effects on rock mechanical strength and, inevitably, oil production.

\section{Petrographic Studies}

EERC petrographic studies were focused on the creation and analysis of thin sections from samples of the middle Bakken and upper Three Forks Formations. These data are generally used to improve the basic understanding of rock properties contributing to the ultimate productivity of the reservoir. The Bakken Formation is typically composed of three members: the upper shale, middle, and lower shale. Lithologically, the upper and lower members of the Bakken are dominated by shales rich in organic carbon that act as the source rock for oil reservoirs in the middle Bakken. The lithology of the middle Bakken varies widely from clastics (including shales, silts, and sandstones) to carbonates (primarily dolomites), with five distinct lithofacies identified in the North Dakota portion of the Williston Basin (LeFever, 2007). The Bakken overlies the Three Forks Formation, a mixture of siltstone, shale, and dolomite that is also highly productive. Figure 41 shows examples of core samples from the upper Bakken shale, the middle Bakken, and the Three Forks Formation. In general, all of these rocks are characterized by low porosity and permeability (Pittman and others, 2001).

This study details the results of petrographic analysis performed on samples of rock taken from cores that are housed at the NDGS Core Library in Grand Forks, North Dakota. The samples were selected and collected in 2011 by EERC personnel and subsequently delivered to the EERC for analysis. Thirty-one samples were selected from 22 wells (Figure 42) for thinsection analysis representing a variety of rock fabrics, ranging from carbonate mudstone and shale to fine-sand/ooid mixtures. Table 6 presents a summary of the thin-section analyses with respect to depositional environment and estimated porosity.

As part of the petrographic evaluation, a series of descriptive analyses were conducted on each thin-section sample. Thin sections were created according to EERC standard operating procedures for the creation of thin sections. The analysis of thin sections was accomplished according to the following procedures:

- Photographs of core condition and context at the NDGS core library, plug samples in asreceived condition, and photomicrographs at $40 \times$ and $100 \times$ magnifications. 

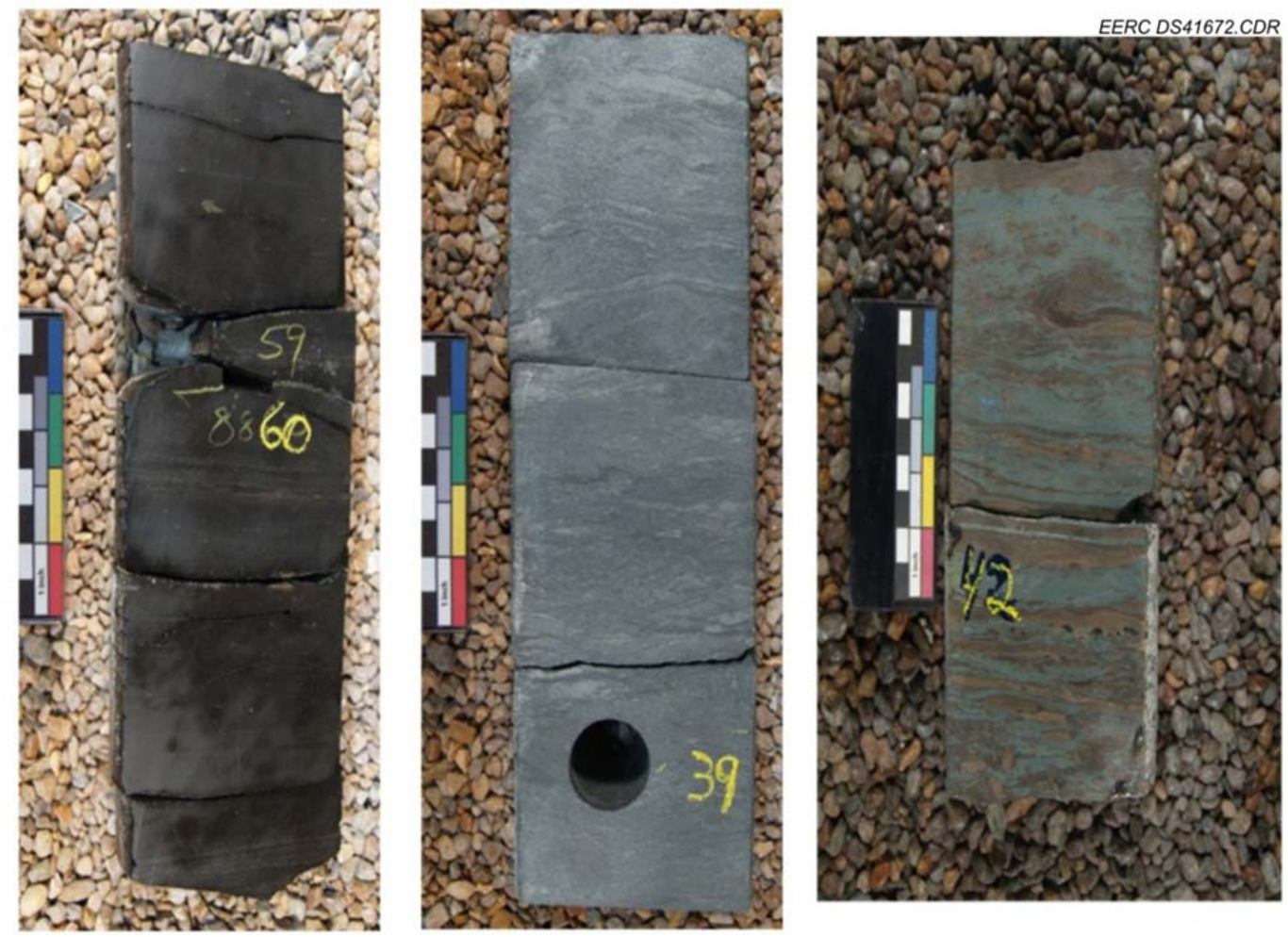

Figure 41. Photographs of slabbed core samples representing the upper Bakken shale (left), middle Bakken (middle), and Three Forks Formations (right).

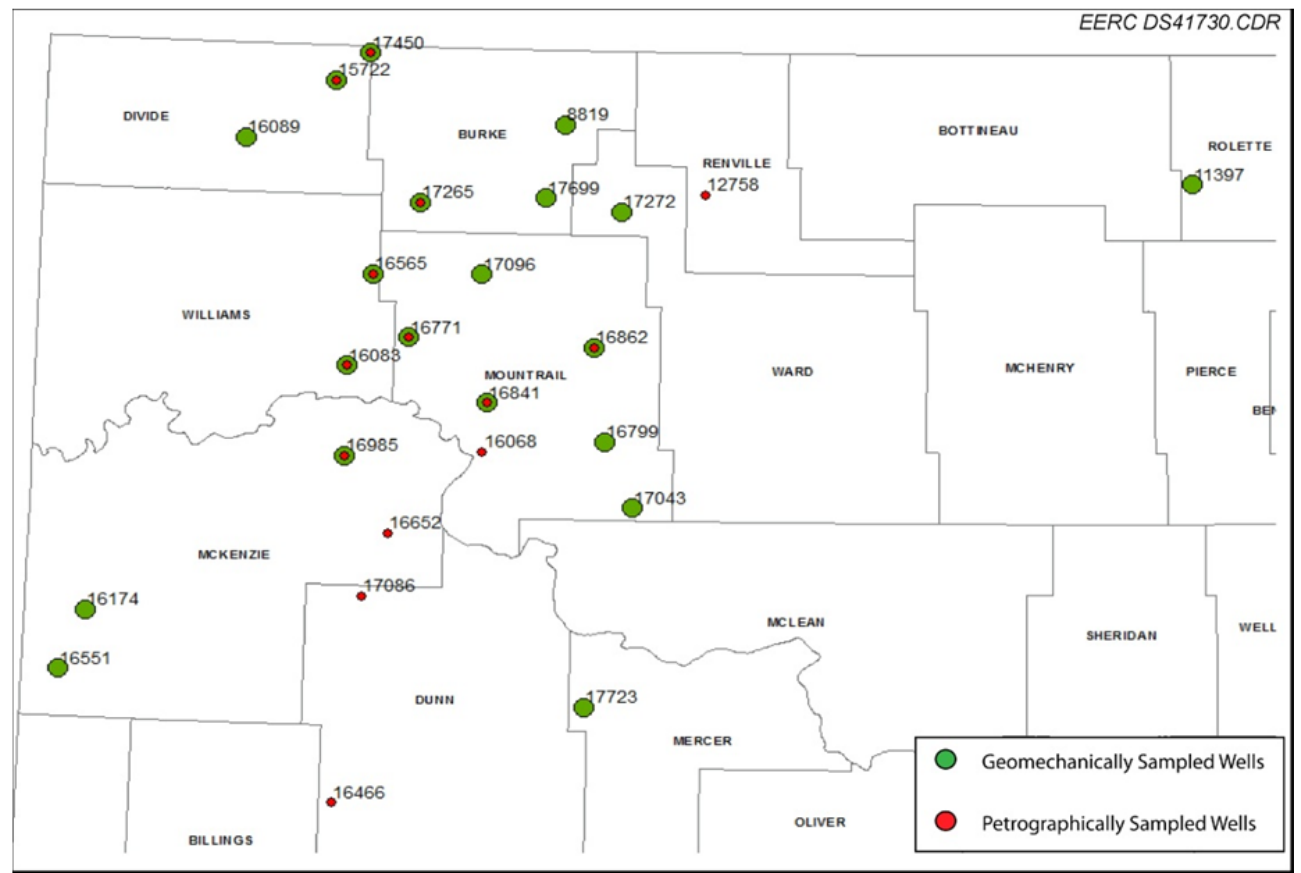

Figure 42. Location of wells from which thin sections were analyzed. 
Table 6. Results of Petrographic Analysis for Bakken Thin-Section Samples

\begin{tabular}{|c|c|c|c|c|c|c|}
\hline $\begin{array}{l}\text { Slide } \\
\text { No. }\end{array}$ & Well & Depth, ft & Porosity, $\%$ & Class $^{1}$ & Depositional Environment & Formation \\
\hline 1 & 17450 & 7448.0 & 3.68 & 2 & Lower shoreface & Three Forks \\
\hline 2 & 16083 & 9823.0 & 3.35 & 3 & Offshore & Three Forks \\
\hline 3 & 16771 & $10,357.9$ & 1.31 & 3 & Offshore & Middle Bakken \\
\hline 4 & 16771 & $10,298.2$ & 3.46 & $2 / 3$ & Lower shoreface & Middle Bakken \\
\hline 5 & 16771 & $10,452.9$ & 2.30 & $2 / 3$ & Lower shoreface & Three Forks \\
\hline 6 & 16771 & $10,429.1$ & 1.91 & 3 & Offshore & Three Forks \\
\hline 7 & 15722 & 7641.0 & 3.12 & $1 / 2$ & Middle shoreface & Middle Bakken \\
\hline 8 & 17086 & $10,983.8$ & 0.40 & 2 & Lower shoreface & Middle Bakken \\
\hline 9 & 17265 & 9390.0 & 0.64 & 3 & Offshore & Three Forks \\
\hline 10 & 16083 & 9725.1 & 3.26 & 3 & Offshore & Middle Bakken \\
\hline 11 & 16083 & 9740.8 & 6.27 & 2 & Lower shoreface & Middle Bakken \\
\hline 12 & 16068 & $10,226.0$ & 0.67 & 3 & Offshore & Middle Bakken \\
\hline 13 & 16083 & 9754.4 & 0.89 & 2 & Lower shoreface & Middle Bakken \\
\hline 14 & 16862 & 8850.7 & 1.48 & 3 & Offshore & Middle Bakken \\
\hline 15 & 17450 & 7354.0 & 2.02 & 2 & Lower shoreface & Middle Bakken \\
\hline 16 & 16862 & 8826.4 & 0.24 & 3 & Offshore & Middle Bakken \\
\hline 17 & 16862 & 8838.8 & 3.01 & 2 & Lower shoreface & Middle Bakken \\
\hline 18 & 16862 & 8876.5 & 6.04 & 3 & Offshore & Three Forks \\
\hline 19 & 12785 & $11,321.7$ & 0.35 & 2 & Lower shoreface & Middle Bakken \\
\hline 20 & 16841 & $10,091.0$ & 3.93 & 1 & Upper shoreface & Middle Bakken \\
\hline 21 & 16985 & $10,496.1$ & 1.48 & 1 & Upper shoreface & Middle Bakken \\
\hline 22 & 16652 & $10,726.0$ & 0.38 & $2 / 3$ & Lower shoreface & Three Forks \\
\hline 23 & 17086 & $11,058.3$ & 5.25 & 3 & Offshore & Three Forks \\
\hline 24 & 16841 & $10,203.0$ & 3.20 & 3 & Offshore & Three Forks \\
\hline 25 & 15722 & 7730.0 & 3.10 & $2 / 3$ & Lower shoreface & Three Forks \\
\hline 26 & 17265 & 9270.8 & 2.99 & 2 & Lower shoreface & Middle Bakken \\
\hline 27 & 16652 & $10,660.0$ & 3.94 & 2 & Lower shoreface & Middle Bakken \\
\hline 28 & 16466 & $10,651.0$ & 2.88 & 3 & Offshore & Middle Bakken \\
\hline 29 & 16565 & 9645.0 & 1.10 & 1 & Upper shoreface & Middle Bakken \\
\hline 30 & 16565 & 9736.0 & 3.45 & 2 & Lower shoreface & Three Forks \\
\hline 31 & 16466 & $10,677.2$ & 3.84 & 3 & Offshore & Three Forks \\
\hline
\end{tabular}

${ }^{1}$ The depositional model by which class is assigned is presented in Figure 43.

- Description of meso- and/or macroscale depositional bedding structures (or lack thereof) was assigned according to the classification scheme presented in Figure 40.

- Porosity, mineralogical assemblages (including mineral cement identification), and their prevalence were determined and estimated through the use of standard optical techniques utilizing a combination of plane-polarized, cross-polarized, and reflected light. 
- Classification was determined by analyzing grain size and microstructure and assigned a petrographic class thought to represent depositional energy as well as depth in the shallow clastic shelf system.

- Depositional environment was estimated by analyzing rock fabric, fossils (if present), and microstructure and defined according to descriptions presented in "Facies Models 4" (James and Dalrymple, 2010; (Figure 43).

- Photomicrographs were produced at $40 \times$ and $100 \times$ magnification with plane- and crosspolarized light.

The intervals examined from the Bakken and Three Forks Formations are interpreted to represent a clastic shelf environment that is thought to have fluctuated between near-shore beach level and a deeper anoxic shelf, with some samples appearing to have experienced sedimentary reworking. Despite the rare occurrence of fossil evidence, organic content in samples is high, suggesting a biologically rich, warm-water environment. A majority of the analyzed sections contained a high concentration of fine-grained microsparitic dolomite, thought to be originally deposited as carbonate mud that later recrystalized under hypersaline conditions.

All intervals were observed to be extremely tight, with the only observable porosity found in partially healed microfractures. Hydrocarbon accumulations and organic content appear to preserve porosity in many occasions. These structures are largely cut off from a porous network but nonetheless are extremely important as being indicative of a potential oil-producing zone. A summary of key observations from the petrograhic studies is as follows:

- The rocks of the middle Bakken Formation were biologically rich when deposited, based on organic content of the samples; however, fossil assemblages were rare and only preserved in deep, low-energy lithologies (Figure 44). Fossils were not observed in the Three Forks Formation, although organic content was commonly preserved (Figure 45).

- The analyzed intervals had no occurrences of "classic" reservoir rock with clean intragranular porosity. The majority of displayed porosity was in partially healed microfractures (Figure 46) or in residual hydrocarbon-filled accumulations (Figure 47). Primary and secondary dolomite cement growth has significantly reduced porosity diagenetically (Figure 48).

- Pore structures are highly disconnected, and intragranular permeability is highly compact and cemented. This analysis supports the observation that the productivity of the Bakken and Three Forks Formations has historically been attributed to natural and/or induced fractures (Sorensen and others, 2010). 


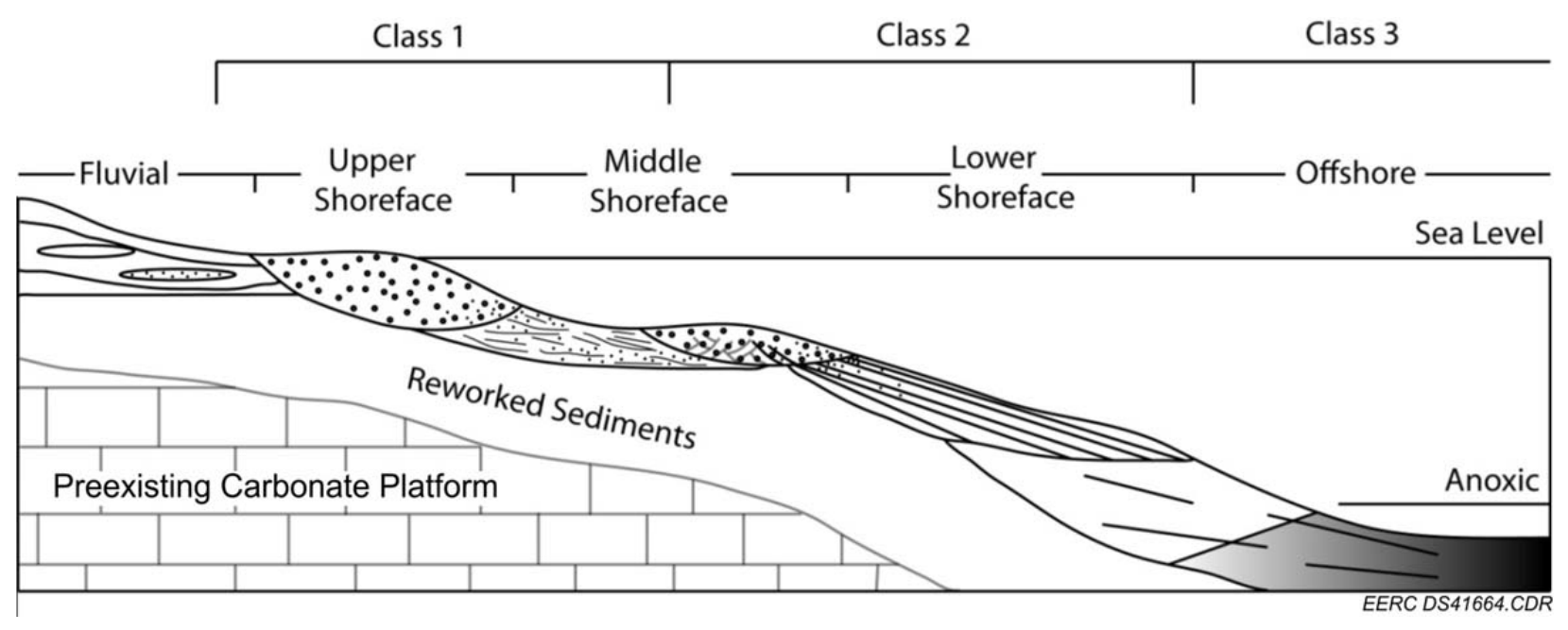

Figure 43. Generalized depositional model for the Bakken system (modified from James and Dalrymple, 2010).

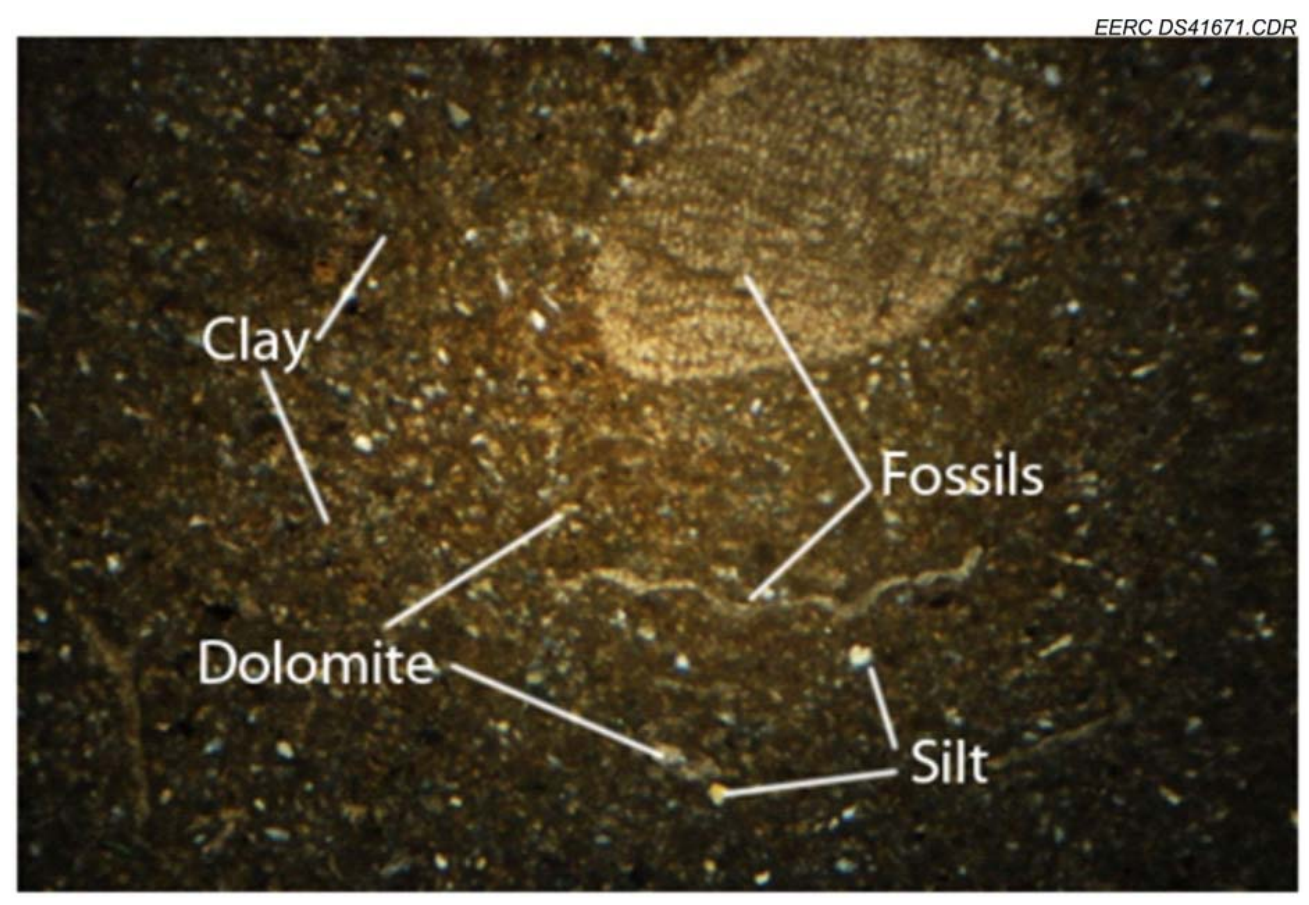

Figure 44. Photomicrograph of the middle Bakken (NDIC Well 16862, 8850.7', 40× XP) showing tight, argillaceous, fine-grained dolomite with floating silt grains. Fossil fragments have been preserved, which were found in a limited number of samples. 


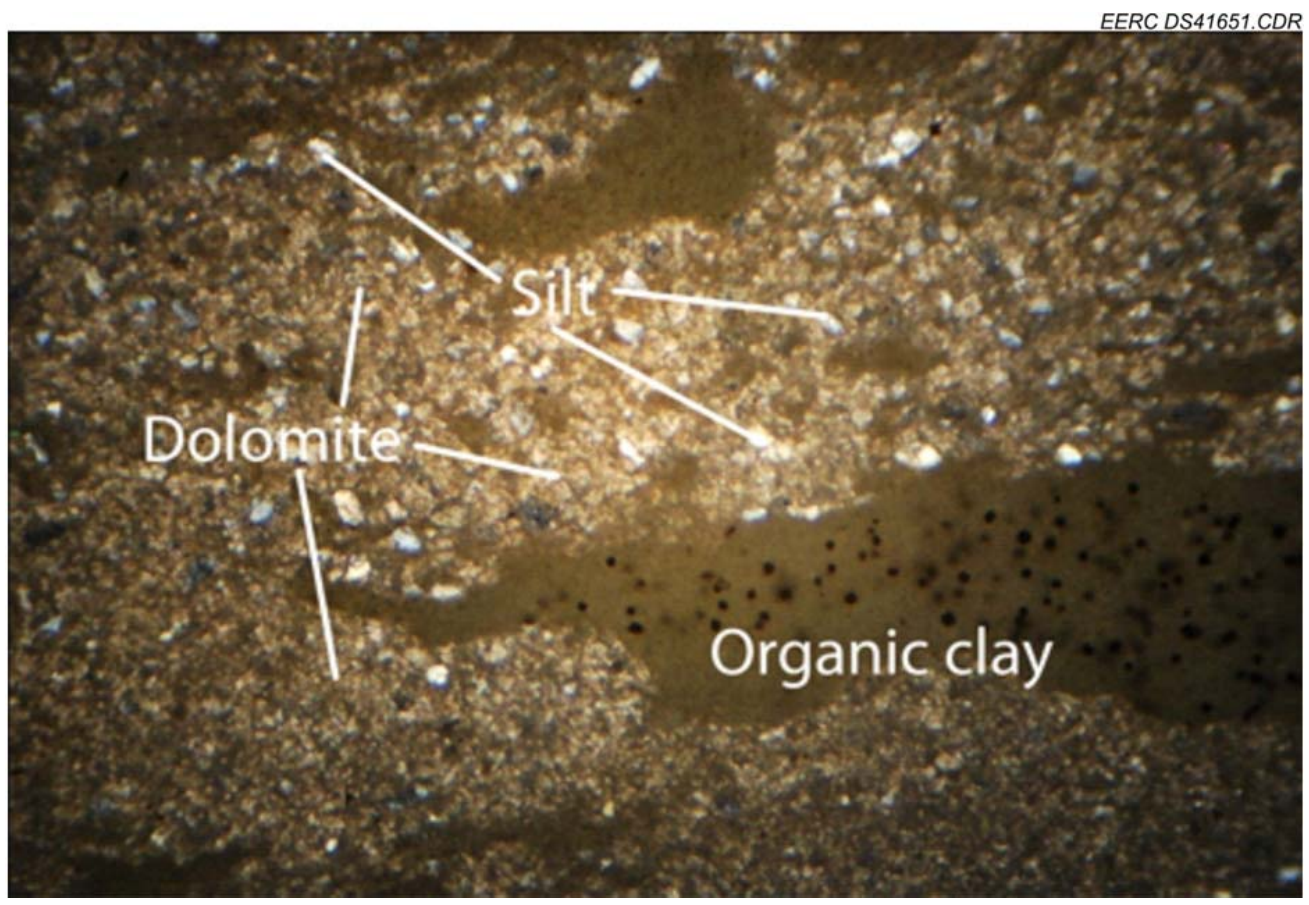

Figure 45. Thin-section photomicrograph of the Three Forks Formation (NDIC Well 15722, 7730.0 ', 40× XP) showing chaotically bedded organic clays, microsparitic dolomite, and floating silt grains.

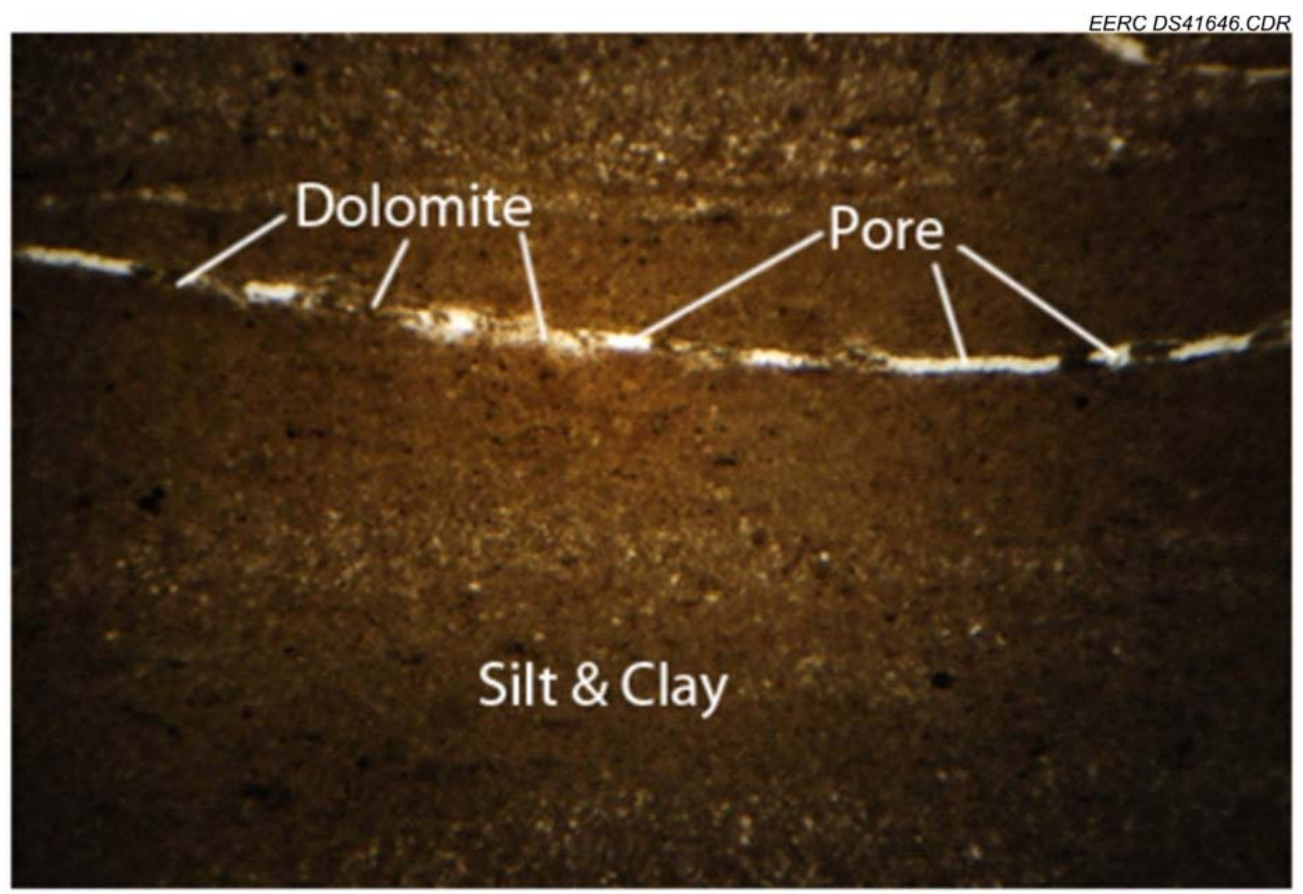

Figure 46. Thin-section photomicrograph of Sample 00531 (NDIC Well 16466, 10677.2', 40× PP) showing a partially healed microfracture. This type of porosity was the most common open porosity observed in this study. 


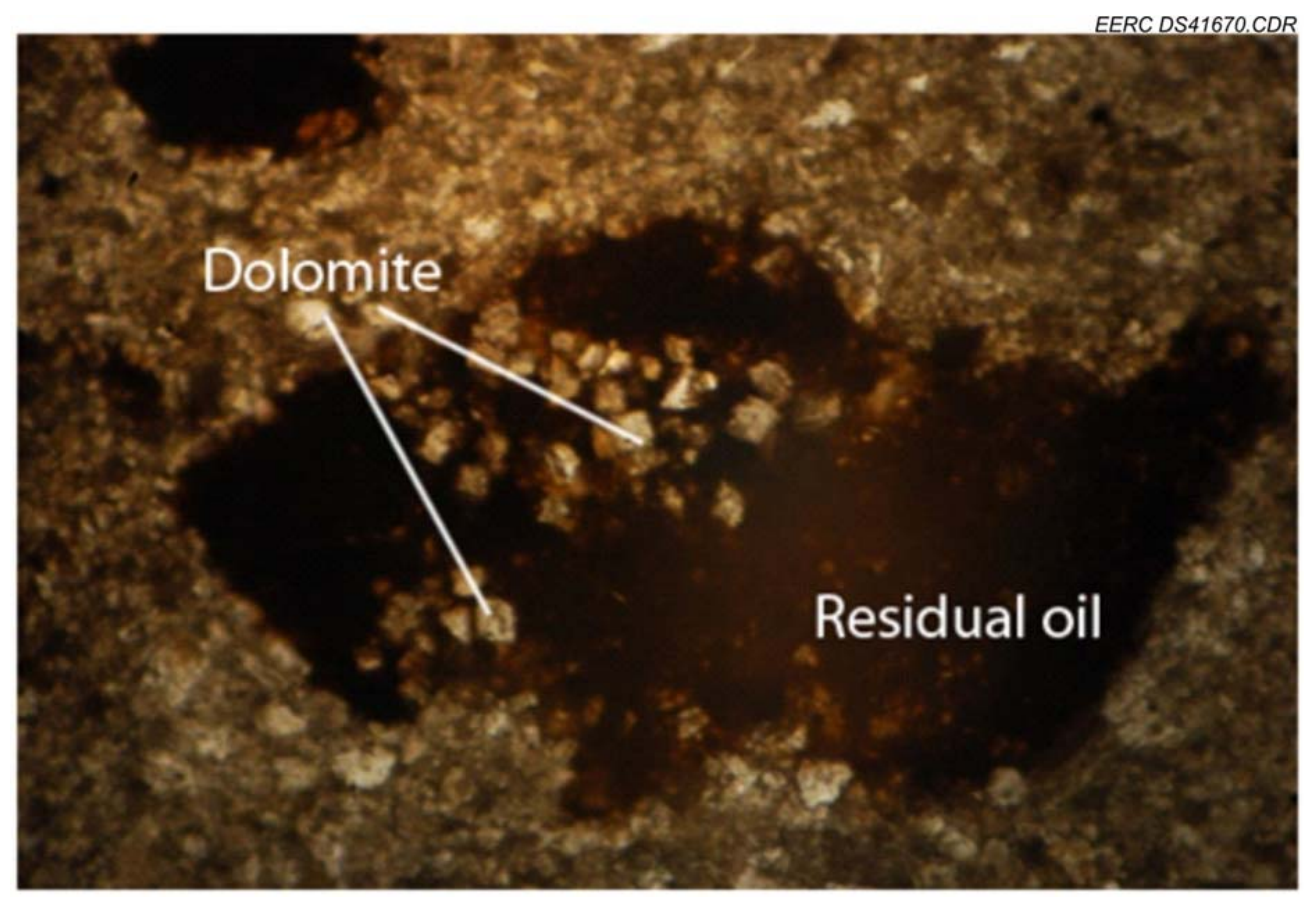

Figure 47. Thin-section photomicrograph of Sample 00638 (NDIC Well 16771, 10429.1', 100× PP) showing a hydrocarbon-filled, partially cement-filled pore. Hydrocarbon accumulations appeared to preserve porosity in this method in nearly every sample.

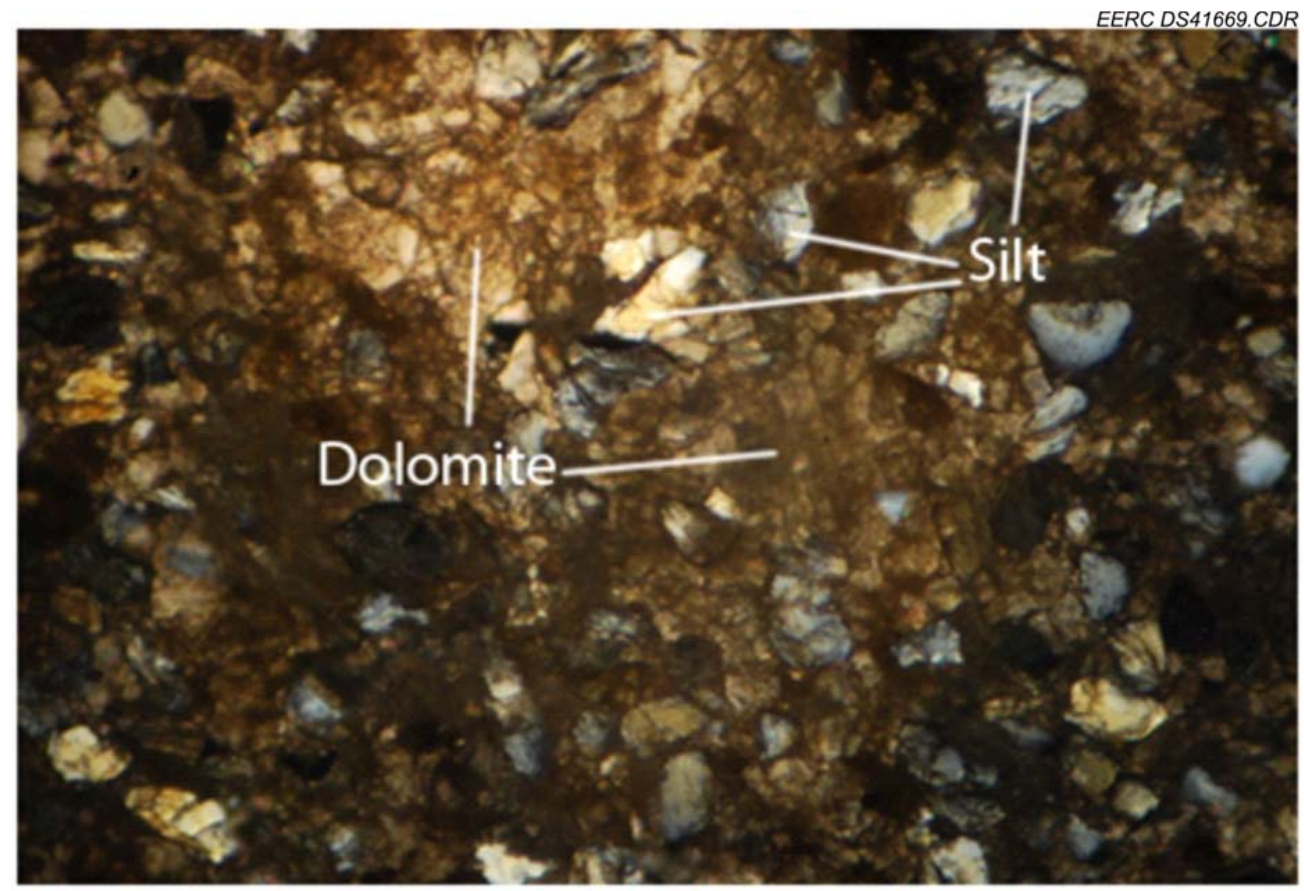

Figure 48. Thin-section photomicrograph of Sample 00625 (NDIC Well 16895, 10496.1', 100× XP) showing heavy dolomite cement growth through a very fine sand/siltstone matrix. This sample was likely deposited as a porous material that was later filled diagenetically. 
- Lithologically, the Bakken and Three Forks Formations are composed of very poor quality reservoir rock; however, residual oil is common in nearly every analyzed sample.

- Samples representing the upper shoreface were rare compared to the more common lower shoreface/slope and offshore environments.

- Hydrocarbon accumulations are responsible for preserving porosity; however, they are isolated from the larger porous network.

- Observed facies and fossil assemblages as well as microstructures are consistent with a shallow warm-water clastic shelf environment. Thin and chaotic bedding suggest large environmental fluctuations, and some samples appear to contain brecciated or reworked sedimentary material.

\section{Classification of Samples for Geomechanical Testing}

While lithofacies characterization is important to the understanding of depositional environments and stratigraphic relationships and their correlation to production, this study aimed to understand the role that depositional bedding structures might play in the geomechanical strength of reservoir rock. Because a single lithofacies may feature rocks with different bedding structures, the "traditional" classification of samples according to established lithofacies (e.g., LeFever, etc.) was set aside. A total of 48 samples of the Bakken-Three Forks system (28 from the middle Bakken and 20 from the Three Forks) from 20 different wells in North Dakota were analyzed by the EERC and classified according to notable bedding structure characteristics. The following are the rock fabric characteristics by which samples were classified:

- Structureless

- Weakly laminated

- Strongly laminated

- Chaotic

- Shale

Figure 49 illustrates the manner by which the samples were classified and presents example images of core illustrating the different types of bedding structure, plugs as sampled, and thin-section micrographs with an assigned classification number. 


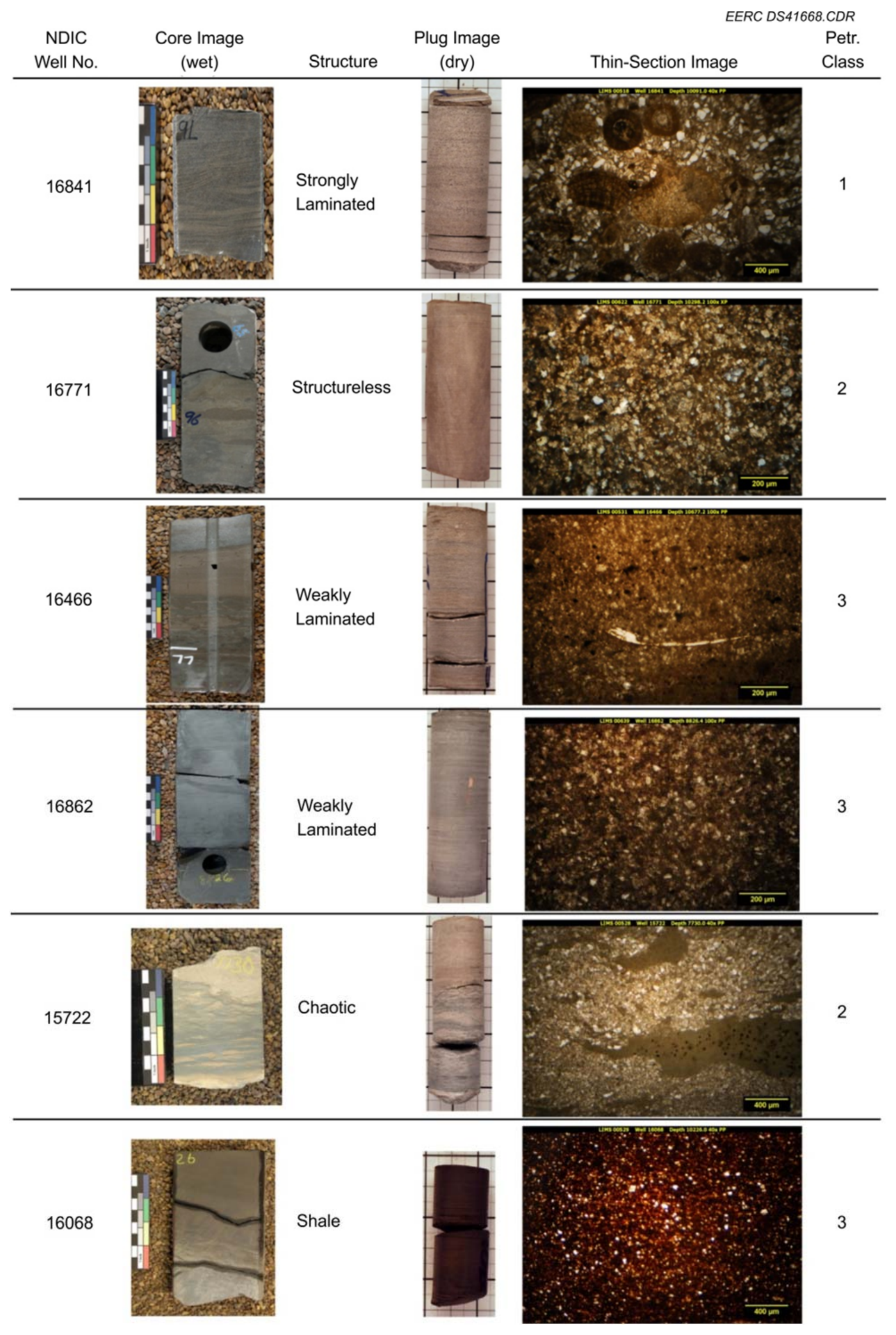

Figure 49. Examples of the scheme for classification of thin-section samples. 


\section{Rock Mechanics Studies}

Rock mechanics refers to the study of rock deformation and fracture. Standard laboratory tests are used to describe properties such as Young's modulus, peak strength, and Poisson's ratio. Briefly, these properties provide the following insight regarding the geomechanical strength of a rock:

- Young's modulus, also called the elastic or tensile modulus, quantifies the degree of stiffness of a solid material. Stiffness is the resistance to deformation a material exhibits when under load.

- Poisson's ratio describes how the dimension perpendicular to the applied force is distorted by relating strain in this direction to strains parallel to the applied force. Poisson's ratio together with Young' modulus describe the volumetric behavior of a sample under load.

- Peak strength is a measure of the pressure, in psi, at which a rock sample under confining load will fail. Peak strength is found using data from triaxial testing and, in this case, using the ISRM Type 2 standard method.

\section{Geomechanical Results}

Table 7 shows a summary of key results obtained through the mechanical testing of Bakken and Three Forks Formation samples. This table includes the maximum confining load applied and associated elastic parameters and peak strength values observed in the destructive tests. The peak strength occurs at the point where the sample fails and loading on the rock is relieved. The values obtained by the testing range from 18,000 to over 97,000 psi across both formations. While this is a broad range, only a small number of samples tested are at these fringe points, with the average peak strength for the sample set at approximately 45,000 psi. Figure 50 shows the distribution of all samples tested and illustrates the clustered data trending at the 45,000 psi range.

These data may suggest that strength measurements derived in this study are independent of depth. However, rock fabric and, hence, depth may and likely does play a role in mechanical strength because of changes in grain-to-grain relationships and associated porosity within each sample. It appears that the data set has a distinct trend based on the rock fabric classification observed in this work. Specifically, structureless or weakly laminated samples exhibit generally higher strength measurements as compared to the strongly laminated and chaotically bedded classes (Figure 51). Figure 52 highlights the more "regular" grouping of the Young's modulus vs. peak strength values for the middle Bakken as compared to the Three Forks Formation. This is likely a function of sample heterogeneity, with the Three Forks having a much higher fraction of clay interbedding with silt particles. Significant differences in sample bulk density and Poisson's ratio were not observed across the range of the sample set. 
Table 7. Data Derived from Mechanical Testing of the Middle Bakken and Three Forks Formations

\begin{tabular}{|c|c|c|c|c|c|c|c|c|c|}
\hline $\begin{array}{l}\text { AGL }^{1} \\
\text { Sample }\end{array}$ & $\begin{array}{l}\text { NDDMR } \\
\text { Well No. }\end{array}$ & Depth, $\mathrm{ft}$ & $\mathrm{Fm}^{2}$ & $\begin{array}{c}\text { Bulk } \\
\text { Density, } \\
\mathrm{g} / \mathrm{cm}^{3}\end{array}$ & $\begin{array}{c}\text { Porosity, } \\
\%\end{array}$ & $\begin{array}{c}\text { Max. Conf. } \\
\text { Pressure, } \\
\text { psi }\end{array}$ & $\begin{array}{c}\text { Young's } \\
\text { Modulus, } \\
10^{6} \text { psi }\end{array}$ & $\begin{array}{c}\text { Poisson's } \\
\text { Ratio }\end{array}$ & $\begin{array}{c}\text { Peak } \\
\text { Strength, } \\
\text { psi }\end{array}$ \\
\hline S-00523 & 8819 & 7180.0 & M. B. ${ }^{3}$ & 2.6 & 3.9 & 4041 & 3.15 & 0.19 & 39,425 \\
\hline S-00687 & 11397 & 3331.9 & M. B. & 2.4 & 6.3 & 1873 & 2.19 & 0.17 & 18,117 \\
\hline S-00527 & 15722 & 7641.0 & M. B. & 2.6 & 3.1 & 4295 & 3.43 & 0.17 & 45,749 \\
\hline S-00614 & 16083 & 9725.1 & M. B. & 2.6 & 3.3 & 5425 & 3.37 & No data & 58,148 \\
\hline S-00611 & 16083 & 9729.1 & M. B. & 2.6 & 2.5 & 5475 & 3.80 & 0.23 & 46,784 \\
\hline S-00615 & 16083 & 9740.8 & M. B. & 2.5 & 6.3 & 5415 & 2.91 & 0.35 & 43,198 \\
\hline S-00616 & 16083 & 9754.4 & M. B. & 2.6 & 0.9 & 5477 & 3.59 & 0.39 & 44,232 \\
\hline S-00617 & 16083 & 9770.2 & M. B. & 2.7 & 0.4 & 5435 & 3.74 & No data & 46,148 \\
\hline S-00690 & 16089 & 8661.8 & M. B. & 2.6 & 3.0 & 4830 & 3.21 & 0.26 & 43,000 \\
\hline S-00530 & 16174 & $10,690.7$ & M. B. & 2.6 & 5.5 & 6008 & 4.13 & 0.24 & 56,546 \\
\hline S-00622 & 16771 & $10,298.2$ & M. B. & 2.6 & 3.5 & 5791 & 3.77 & 0.24 & 48,962 \\
\hline S-00624 & 16771 & $10,306.9$ & M. B. & 2.6 & 2.0 & 5742 & 3.31 & No data & 48,591 \\
\hline S-00623 & 16771 & $10,320.0$ & M. B. & 2.6 & 1.6 & 5753 & 3.22 & No data & 45,298 \\
\hline S-00632 & 16771 & $10,343.0$ & M. B. & 2.5 & 3.7 & 5808 & 2.68 & No data & 36,735 \\
\hline S-00633 & 16771 & $10,357.9$ & M. B. & 2.6 & 1.3 & 5827 & 3.62 & 0.26 & 47,629 \\
\hline S-00518 & 16841 & $10,091.0$ & M. B. & 2.6 & 3.9 & 5673 & 4.02 & 0.28 & 44,527 \\
\hline S-00639 & 16862 & 8826.4 & M. B. & 2.7 & 0.2 & 4915 & 3.84 & No data & 48,884 \\
\hline S-00641 & 16862 & 8836.5 & M. B. & 2.6 & 2.6 & 4922 & 3.02 & No data & 44,158 \\
\hline S-00642 & 16862 & 8838.8 & M. B. & 2.5 & 3.0 & 4974 & 3.19 & 0.27 & 39,296 \\
\hline S-00643 & 16862 & 8844.6 & M. B. & 2.6 & 1.4 & 4973 & 3.13 & 0.24 & 41,803 \\
\hline S-00644 & 16862 & 8850.7 & M. B. & 2.6 & 1.5 & 4929 & 3.32 & No data & 44,130 \\
\hline S-00625 & 16985 & $10,496.1$ & M. B. & 2.7 & 1.5 & 5869 & 4.01 & 0.29 & 43,770 \\
\hline S-00516 & 17043 & 9089.7 & M. B. & 2.6 & 2.8 & 5108 & 3.16 & No data & 42,797 \\
\hline S-00685 & 17069 & 9653.9 & M. B. & 2.6 & 0.6 & 5409 & 3.91 & 0.27 & 45,332 \\
\hline S-00627 & 17265 & 9270.8 & M. B. & 2.6 & 3.0 & 5150 & 2.96 & No data & 37,661 \\
\hline S-00539 & 17272 & 7576.0 & M. B. & 2.6 & 2.8 & 4254 & 3.14 & 0.27 & 36,865 \\
\hline S-00521 & 17450 & 7354.0 & M. B. & 2.6 & 2.0 & 4138 & 3.55 & 0.22 & 46,280 \\
\hline S-00613 & 17699 & 8343.5 & M. B. & 2.6 & 3.0 & 4694 & 3.10 & 0.23 & 42,331 \\
\hline S-00701 & 16799 & $10,040.6$ & T. F. ${ }^{4}$ & 2.7 & 1.9 & 5639 & 5.06 & 0.31 & 97,580 \\
\hline S-00688 & 11397 & 3341.0 & T. F. & 2.5 & 7.9 & 1882 & 2.23 & 0.26 & 18,990 \\
\hline S-00693 & 16083 & 9815.0 & T. F. & 2.7 & 3.1 & 5447 & 4.46 & No data & 48,389 \\
\hline S-00619 & 16083 & 9823.0 & T. F. & 2.7 & 3.3 & 4370 & 3.94 & No data & 25,899 \\
\hline S-00620 & 16083 & 9829.1 & T. F. & 2.6 & 4.1 & 5520 & 3.14 & 0.26 & 38,868 \\
\hline S-00542 & 16174 & $10,721.0$ & T. F. & 2.6 & 2.3 & 5976 & 3.05 & No data & 37,521 \\
\hline S-00692 & 16551 & $10,643.0$ & T. F. & 2.7 & 0.8 & 5932 & 4.11 & No data & 36,463 \\
\hline S-00540 & 16565 & 9736.0 & T. F. & 2.7 & 3.4 & 5471 & 5.26 & No data & 76,450 \\
\hline S-00638 & 16771 & $10,429.1$ & T. F. & 2.7 & 1.9 & 5797 & 3.82 & No data & 55,092 \\
\hline S-00634 & 16771 & $10,444.3$ & T. F. & 2.7 & 2.0 & 5867 & 4.28 & 0.28 & 89,076 \\
\hline S-00635 & 16771 & $10,452.9$ & T. F. & 2.6 & 2.3 & 5887 & 2.98 & No data & 40,360 \\
\hline S-00648 & 16862 & 8872.6 & T. F. & 2.6 & 4.9 & 4979 & 3.87 & 0.24 & 41,409 \\
\hline S-00646 & 16862 & 8875.6 & T. F. & 2.7 & 1.6 & 0 & 4.33 & No data & 0 \\
\hline S-00647 & 16862 & 8876.5 & T. F. & 2.6 & 6.0 & 4931 & 3.42 & No data & 42,502 \\
\hline S-00520 & 17043 & 9132.7 & T. F. & 2.6 & 4.8 & 5473 & 2.81 & 0.26 & 38,535 \\
\hline S-00686 & 17069 & 9723.0 & T. F. & 2.6 & 4.0 & 5461 & 3.08 & 0.14 & 43,735 \\
\hline S-00628 & 17265 & 9390.0 & T. F. & 2.7 & 0.6 & 5268 & 2.89 & 0.26 & 39,236 \\
\hline S-00517 & 17450 & 7448.0 & T. F. & 2.7 & 3.7 & 4151 & 4.69 & No data & 72,252 \\
\hline S-00694 & 17699 & 8408.8 & T. F. & 2.7 & 3.3 & 4730 & 5.48 & 0.33 & 34,090 \\
\hline S-00519 & 17723 & 9524.5 & T. F. & 2.6 & 2.7 & 4232 & 3.70 & No data & 19,783 \\
\hline
\end{tabular}




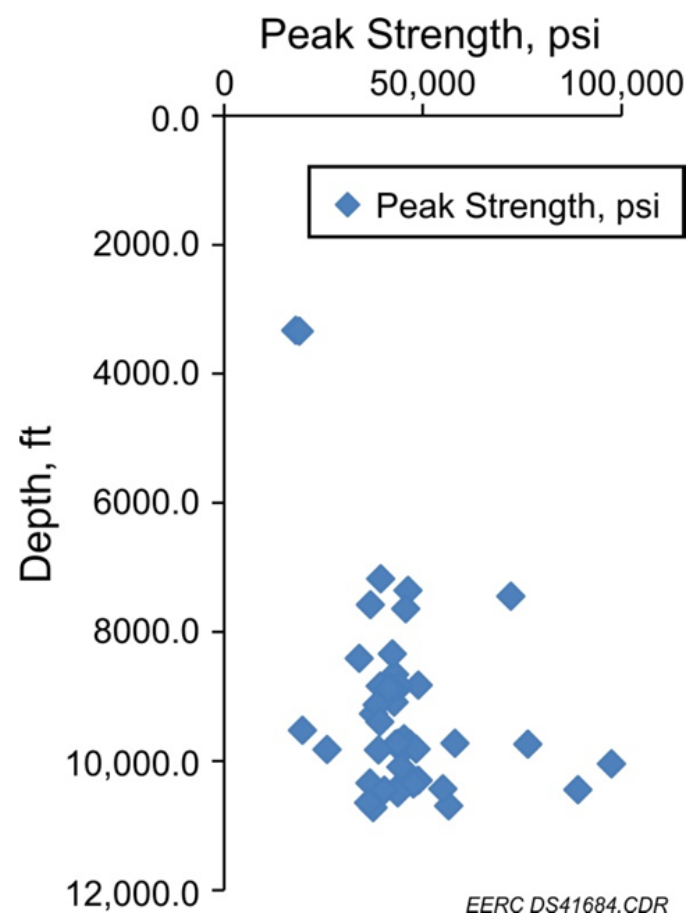

Figure 50. Chart showing the relationship between depth and measured peak strength for all samples in the study area.

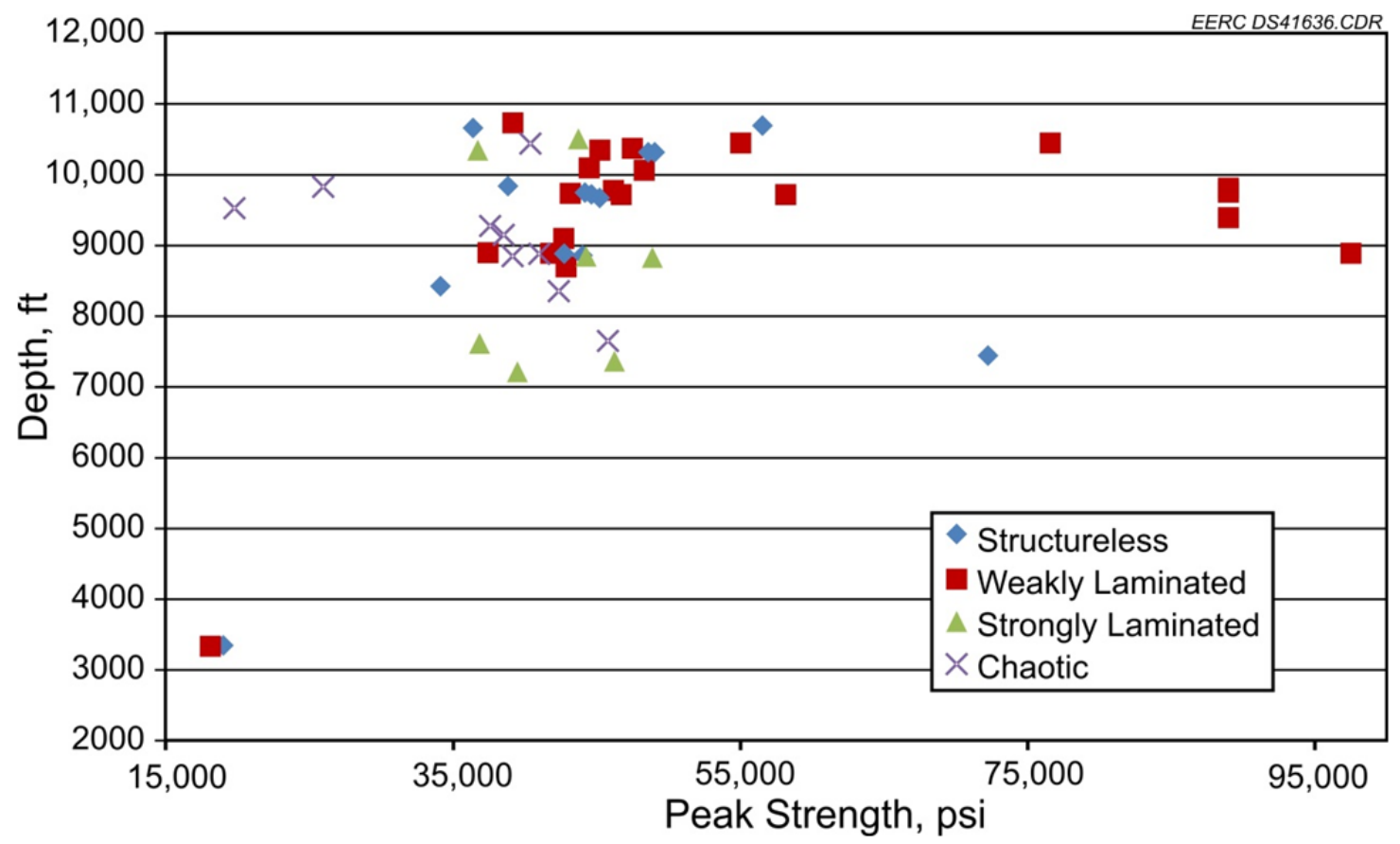

Figure 51. Chart showing the relationship between depth and measured peak strength for all samples tested. 


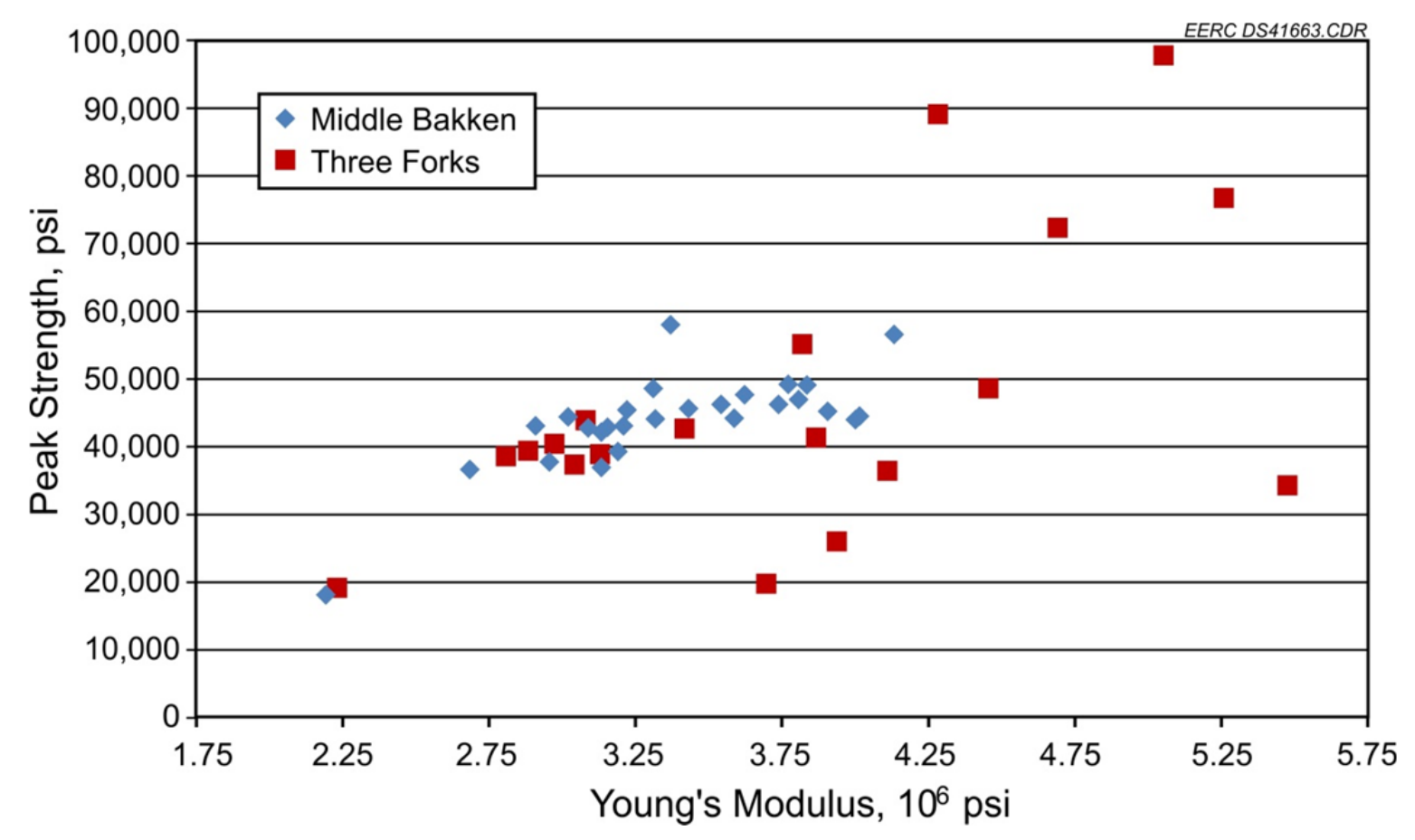

Figure 52. Chart showing the relationship of peak strength and Young's modulus for the middle Bakken and Three Forks Formations.

Three wells within the study area were sampled vertically to determine the strength profile for the lithofacies represented across each productive interval of the middle Bakken and Three Forks Formations. Table 8 shows the results of analyses performed on each sample and highlights the Young's modulus, Poisson's ratio, peak strength, and rock fabric classification assigned to the sample. Figure 53 shows the Young's modulus results graphically when compared with sample depth and further illustrates that depth seems to be contributing little to the overall stiffness of these rocks. Finally, Figure 54 shows the same data set, plotting depth against peak strength. Similarly, sample data for the Bakken are very consistent, falling in the 50,000-psi range; however, minor fluctuations are present within the Three Forks Formation, which are likely tied to bedding structure and facies heterogeneity. In general, structureless and weakly laminated samples resulted in higher peak strength, whereas strongly laminated or chaotically bedded samples were weaker.

Figures 55 and 56 are charts illustrating the results of derived properties for the middle Bakken, including Young's modulus (Figure 53) and peak strength (Figure 54) plotted against sample depth. It may be worth noting that a well in Rollette County (NDIC 11397), which is in the extreme northeastern part of the study area and over 100 miles from the next nearest sampling point, is found to have significantly lower Young's modulus and peak strength values when compared to the other samples. Likewise, a well in McKenzie County (NDIC 16083) located in the extreme southwestern portion of the study area displays the highest values. 
Table 8. Display of Sample and Mechanical Data for the Three Wells from Which Samples from Multiple Vertical Zones Were Tested for Mechanical Properties

\begin{tabular}{|c|c|c|c|c|c|c|c|c|c|}
\hline $\begin{array}{l}\text { AGL } \\
\text { Sample }\end{array}$ & $\begin{array}{l}\text { NDDMR } \\
\text { Well No. }\end{array}$ & $\begin{array}{c}\text { Depth, } \\
\mathrm{ft}\end{array}$ & Fm. & $\begin{array}{c}\text { Porosity, } \\
\%\end{array}$ & $\begin{array}{l}\text { Max. Conf. } \\
\text { Pressure, psi }\end{array}$ & $\begin{array}{c}\text { Young's } \\
\text { Modulus, } \\
10^{6} \mathrm{psi} \\
\end{array}$ & $\begin{array}{c}\text { Poisson's } \\
\text { Ratio } \\
\end{array}$ & $\begin{array}{c}\text { Peak Strength, } \\
\text { psi }\end{array}$ & Facies \\
\hline S-00614 & 16083 & 9725.1 & M. B. & 3.3 & 5425 & 3.37 & & 58,148 & 1 \\
\hline S-00611 & 16083 & 9729.1 & M. B. & 2.5 & 5475 & 3.80 & 0.23 & 46,784 & 1 \\
\hline S-00615 & 16083 & 9740.8 & M. B. & 6.3 & 5415 & 2.91 & 0.35 & 43,198 & 1 \\
\hline S-00617 & 16083 & 9770.2 & M. B. & 0.4 & 5435 & 3.74 & & 46,148 & 1 \\
\hline S-00693 & 16083 & 9815.0 & T. F. & 3.1 & 5447 & 4.46 & & 48,389 & 1 \\
\hline S-00619 & 16083 & 9823.0 & T. F. & 3.3 & 4370 & 3.94 & & 25,899 & 3 \\
\hline S-00620 & 16083 & 9829.1 & T. F. & 4.1 & 5520 & 3.14 & 0.26 & 38,868 & 0 \\
\hline S-00622 & 16771 & $10,298.2$ & M. B. & 3.5 & 5791 & 3.77 & 0.24 & 48,962 & 0 \\
\hline S-00624 & 16771 & $10,306.9$ & M. B. & 2.0 & 5742 & 3.31 & & 48,591 & 0 \\
\hline S-00623 & 16771 & $10,320.0$ & M. B. & 1.6 & 5753 & 3.22 & & 45,298 & 1 \\
\hline S-00632 & 16771 & $10,343.0$ & M. B. & 3.7 & 5808 & 2.68 & & 36,735 & 2 \\
\hline S-00633 & 16771 & $10,357.9$ & M. B. & 1.3 & 5827 & 3.62 & 0.26 & 47,629 & 1 \\
\hline S-00638 & 16771 & $10,429.1$ & T. F. & 1.9 & 5797 & 3.82 & & 55,092 & 1 \\
\hline S-00634 & 16771 & $10,444.3$ & T. F. & 2.0 & 5867 & 4.28 & 0.28 & 89,076 & 1 \\
\hline S-00635 & 16771 & $10,452.9$ & T. F. & 2.3 & 5887 & 2.98 & & 40,360 & 4 \\
\hline S-00639 & 16862 & 8826.4 & M. B. & 0.2 & 4915 & 3.84 & & 48,884 & 2 \\
\hline S-00641 & 16862 & 8836.5 & M. B. & 2.6 & 4922 & 3.02 & & 44,158 & 2 \\
\hline S-00642 & 16862 & 8838.8 & M. B. & 3.0 & 4974 & 3.19 & 0.27 & 39,296 & 3 \\
\hline S-00643 & 16862 & 8844.6 & M. B. & 1.4 & 4973 & 3.13 & 0.24 & 41,803 & 1 \\
\hline S-00644 & 16862 & 8850.7 & M. B. & 1.5 & 4929 & 3.32 & & 44,130 & 0 \\
\hline S-00648 & 16862 & 8872.6 & T. F. & 4.9 & 4979 & 3.87 & 0.24 & 41,409 & 4 \\
\hline S-00646 & 16862 & 8875.6 & T. F. & 1.6 & 0 & 4.33 & & & 1 \\
\hline S-00647 & 16862 & 8876.5 & T. F. & 6.0 & 4931 & 3.42 & & 42,502 & 0 \\
\hline
\end{tabular}

Figure 57 is a map illustrating this relationship. The low values in the Rollette County well are not unexpected, since the Bakken in that area is much shallower and has been subjected to less loading. Also, the higher values in the McKenzie County well are not unexpected because this is among the deepest wells in the study area, and the rock exhibits uniformly fine grain size with very low porosity. In other words, the rock in that well is naturally very well compacted and, therefore, can withstand greater compressional forces. If these two wells are removed from the data set, then the Young's modulus and peak strength values tend to cluster fairly closely together (Young's modulus ranging from $3.0 \times 106$ to $4.0 \times 10^{6} \mathrm{psi}$; peak strength ranging from 35,000 to 50,000 psi). 


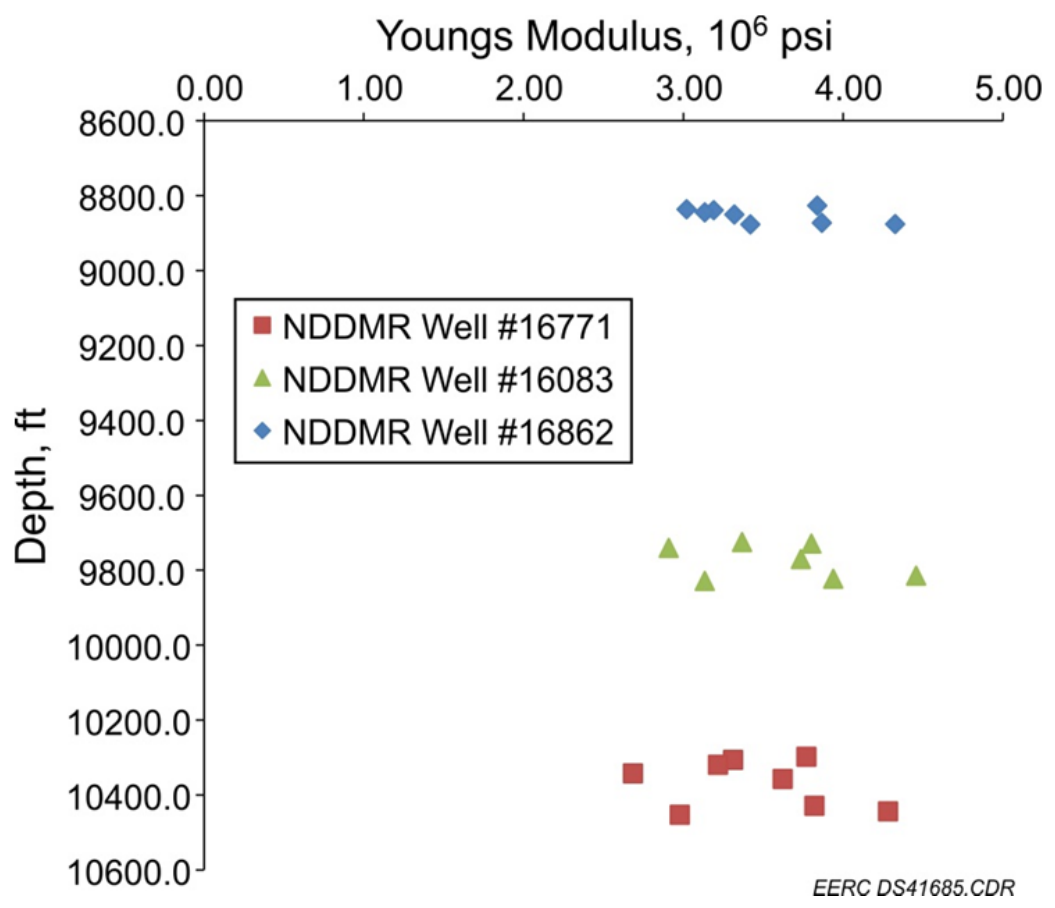

Figure 53. Chart showing the relationship of depth to Young's modulus in vertically sampled wells.

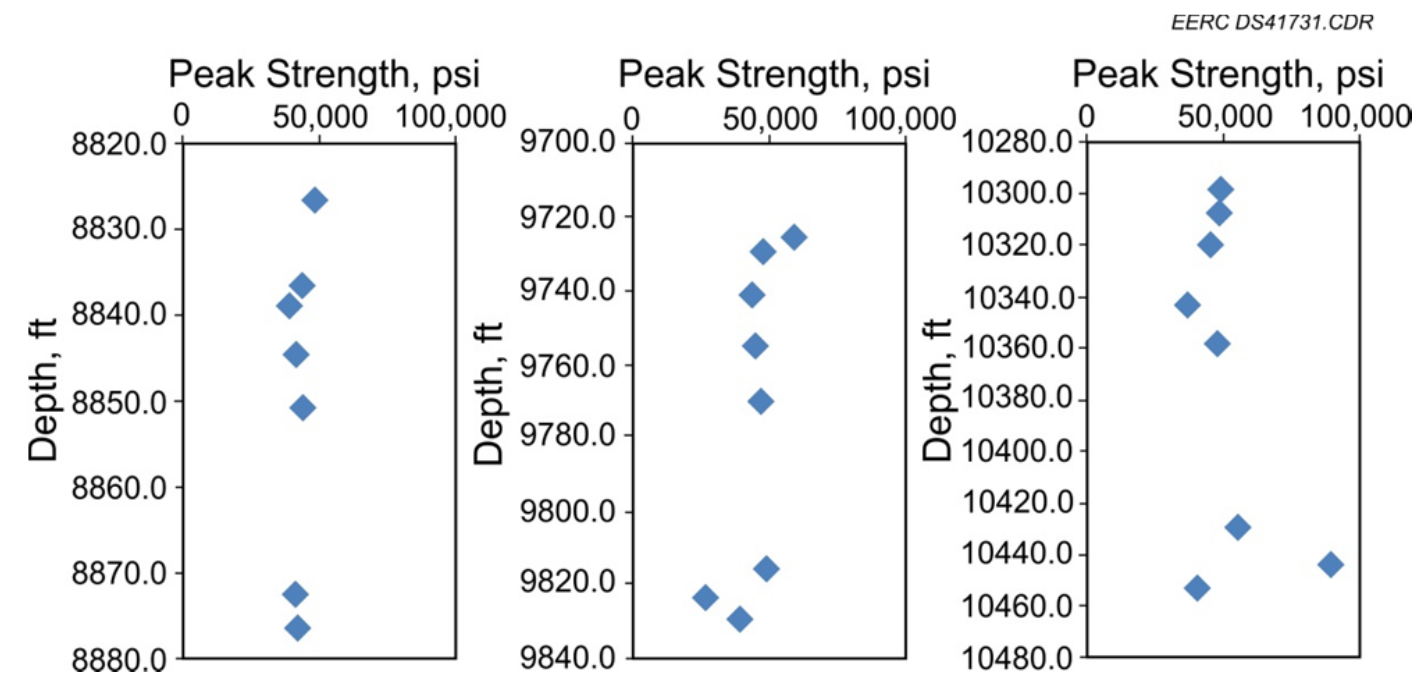

Figure 54. Charts comparing peak strength to depth for vertically sampled wells in the Bakken and Three Forks Formations. 


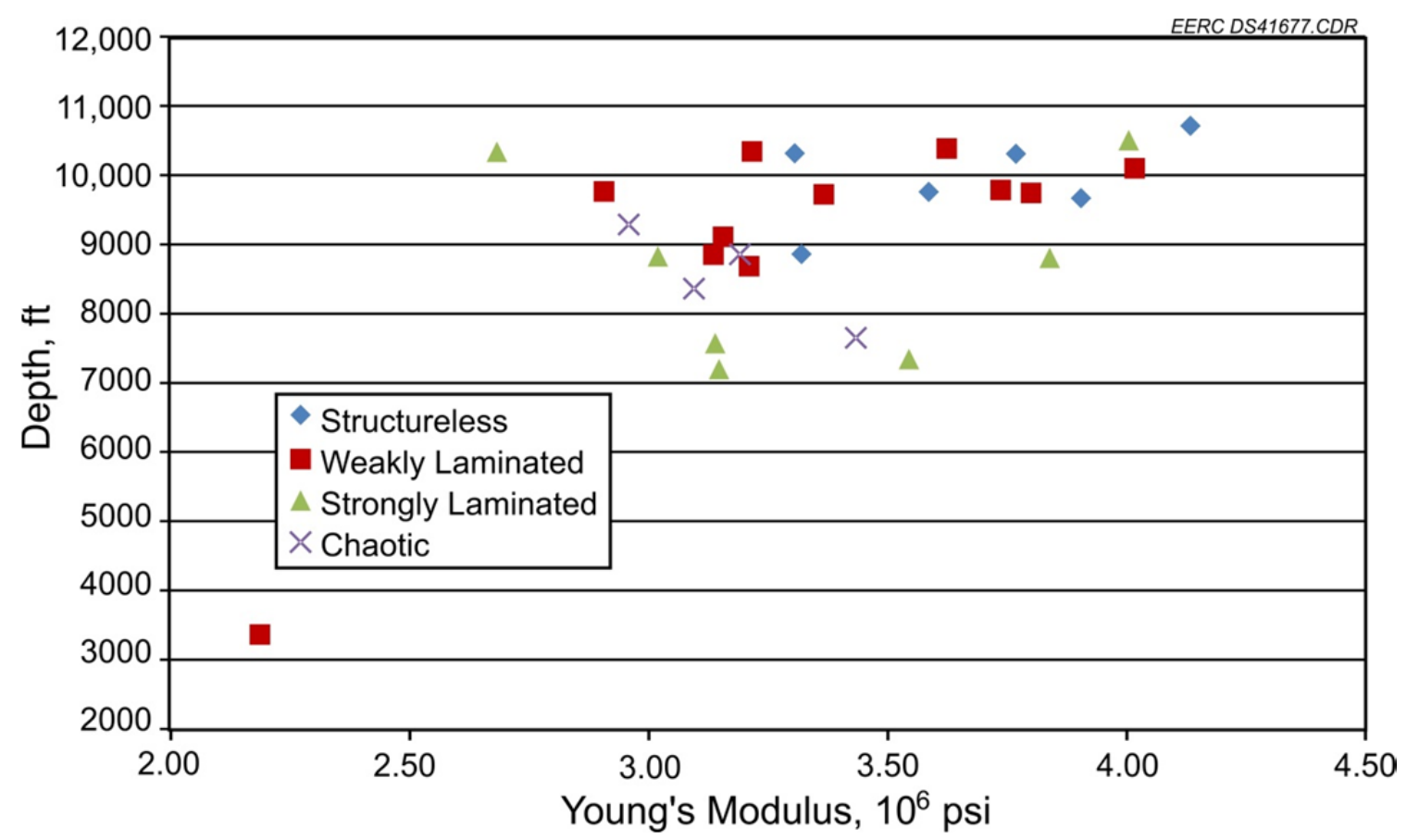

Figure 55. Young's modulus plotted against depth and comparing values with respect to the different classifications of bedding structure (facies).

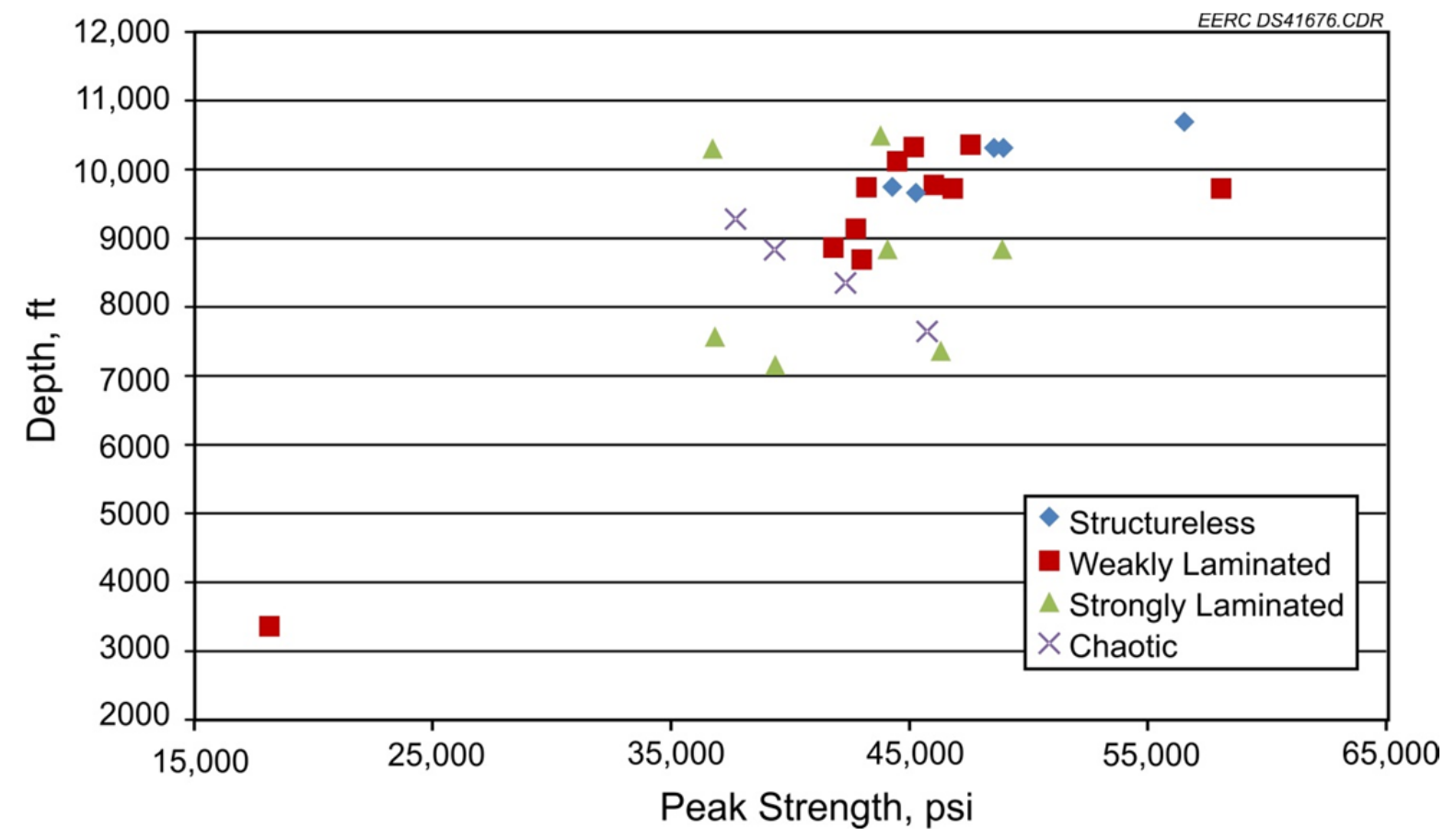

Figure 56. Peak strength values plotted against depth and comparing values with respect to the different classifications of bedding structure (facies). 


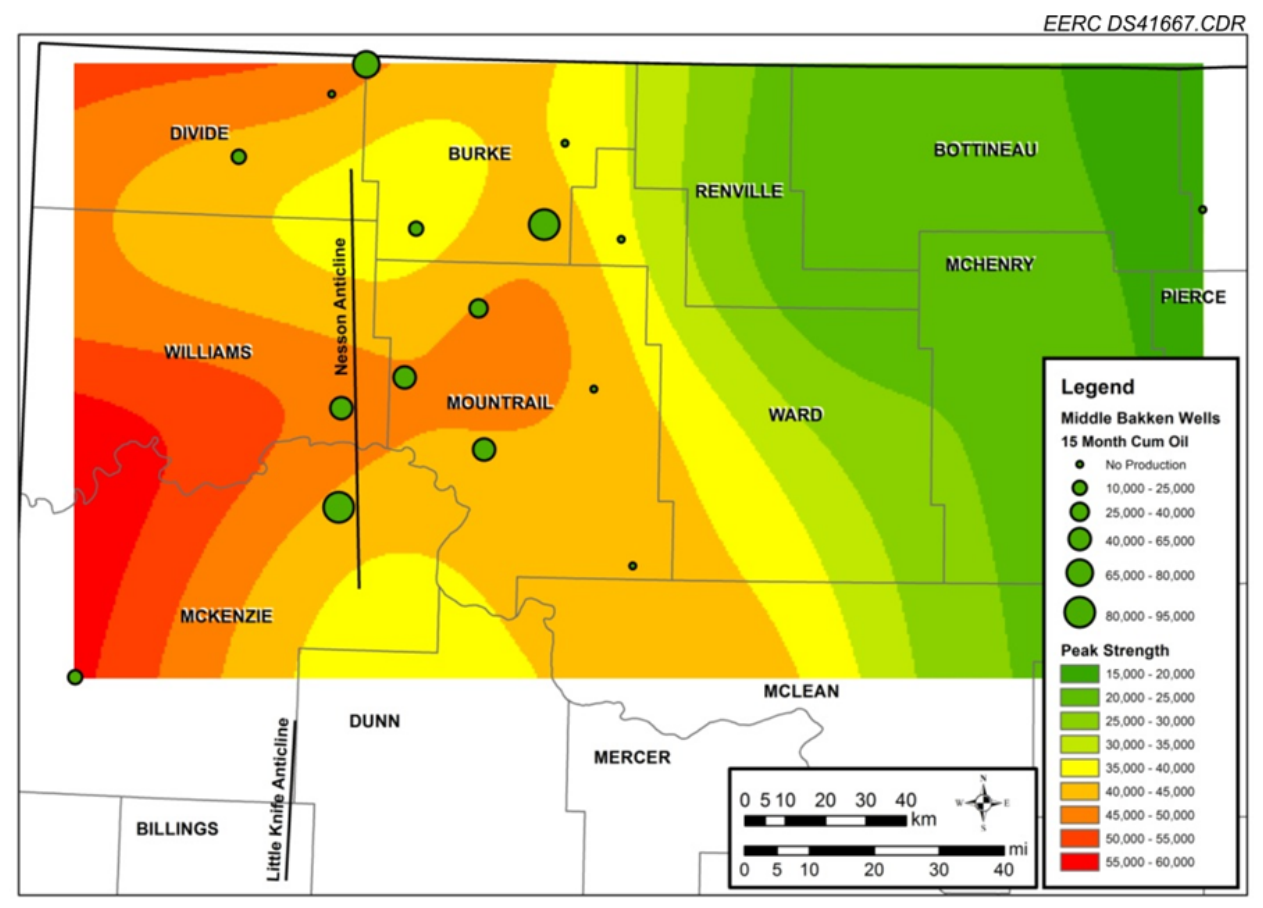

Figure 57. Map illustrating generalized interpretation of the distribution of Young's modulus values for the middle Bakken.

The geomechanical properties of Three Forks Formation samples can be contrasted with the middle Bakken samples in that they display a much wider range of Young's modulus and peak strength values (Young's modulus ranging from $2.2 \times 106$ to $5.5 \times 106$ psi; peak strength ranging from 18,000 to 97,000 psi). Figures 58 and 59 graphically illustrate the Three Forks data. This is likely a function of the typically chaotic to strongly laminated bedding structures that are prevalent in the Three Forks Formation.

There are thirteen samples from the study for which both geomechanical testing and thinsection analyses were conducted. Petrophysical properties such as porosity, microstructure, mineralogy, clay content, and grain size were compared to the geomechanical results. No strong correlations were observed between the petrophysical and geomechanical properties in this data set.

\section{Summary of Geomechanical Key Results}

- Data from the three wells that were sampled to represent multiple vertical zones through both the Bakken and Three Forks showed no significant changes in Young's modulus or peak strength values with depth and/or changes in bedding structure. 


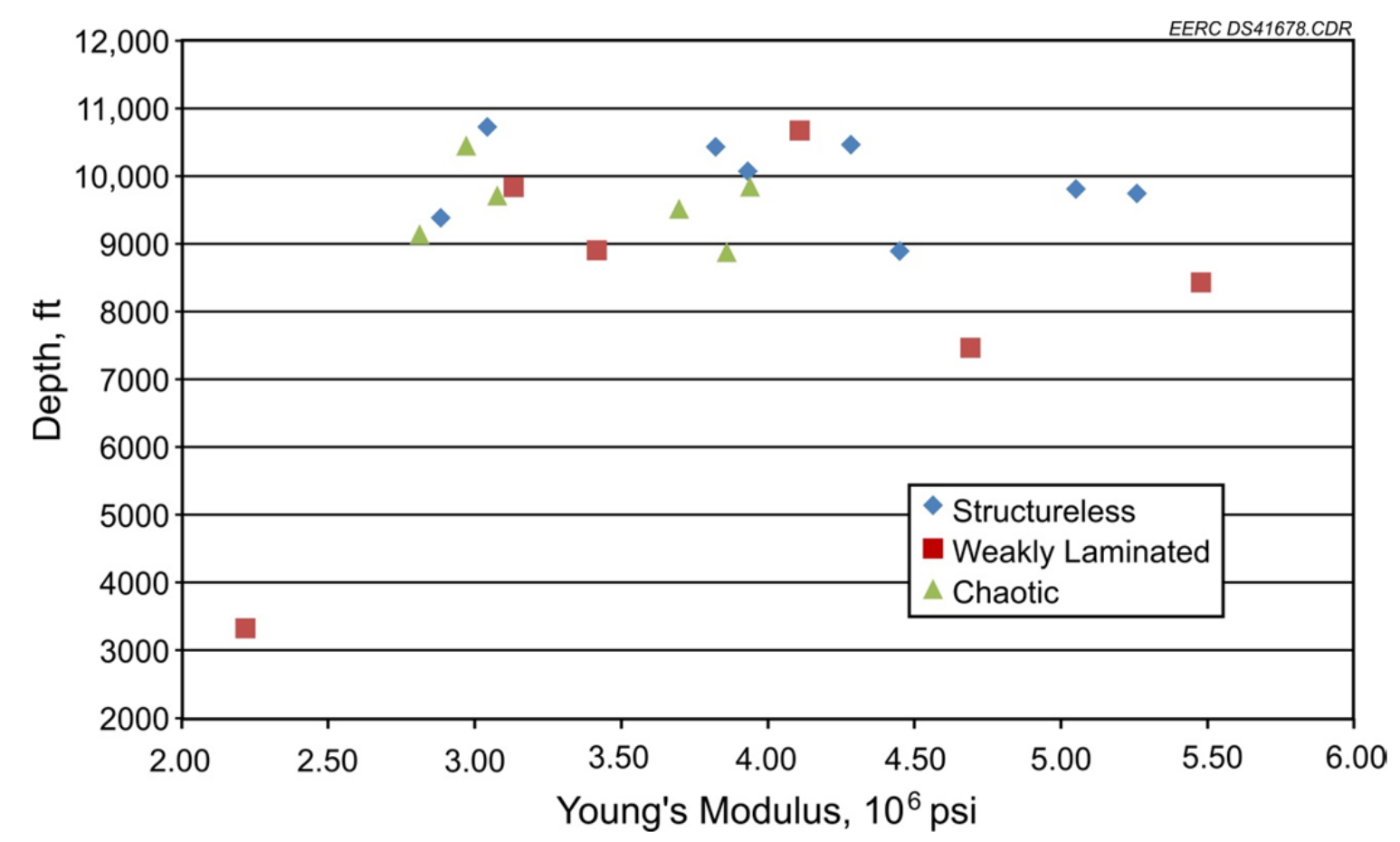

Figure 58. Young's modulus for Three Forks samples plotted against depth and comparing values with respect to the different classifications of bedding structure (facies).

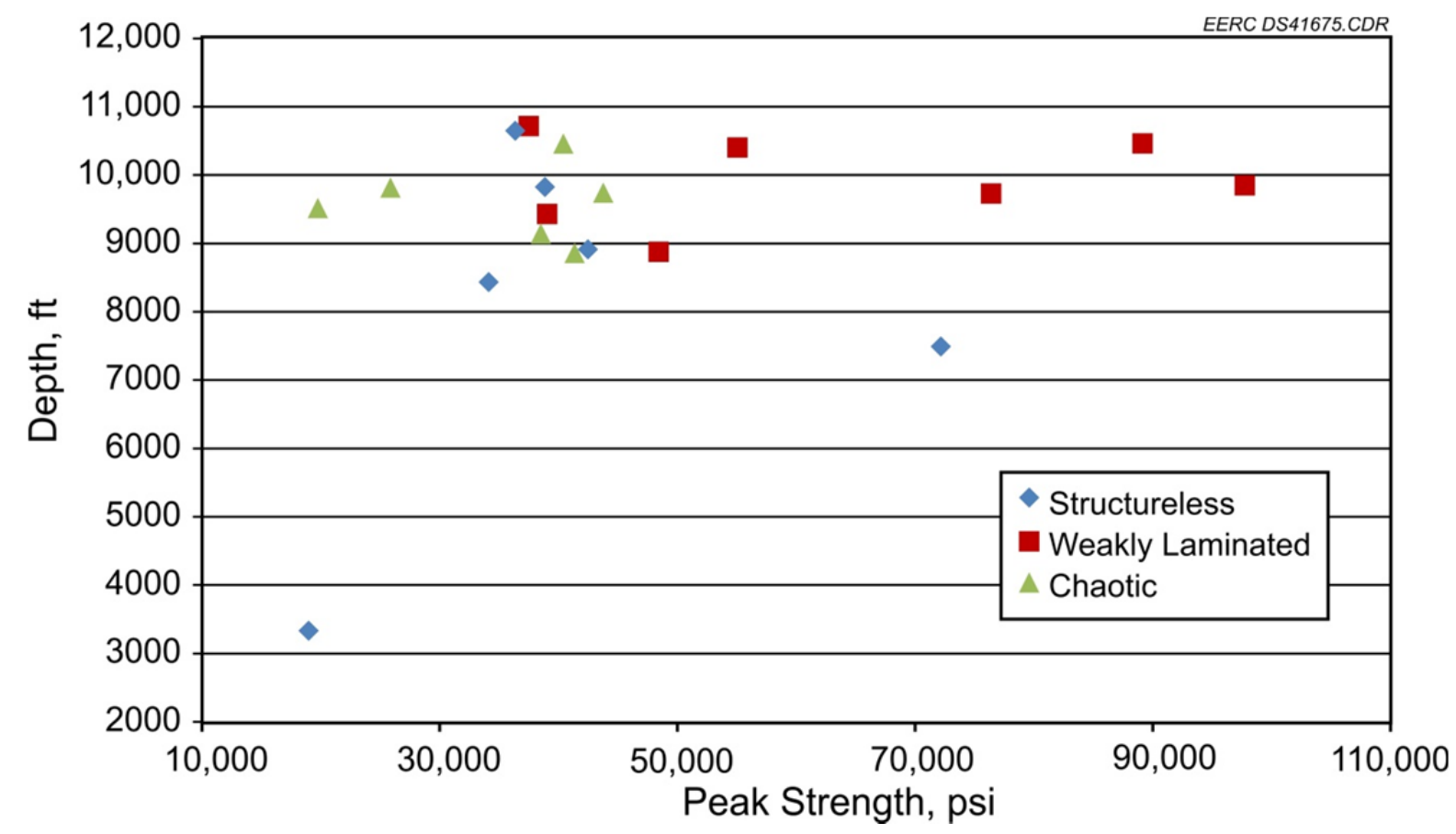

Figure 59. Peak strength values for Three Forks samples plotted against depth and comparing values with respect to the different classifications of bedding structure (facies). 
- With respect to peak strength in the Bakken, sample data consistently fall in the 45,000 psi range (specifically the range was from 18,000 to 58,000 psi); however, minor fluctuations are present, which are likely tied to microstructure and facies.

- Three Forks geomechanical strength tends to be much less predictable, with peak strength ranging from 18,000 to 97,500 psi. This is illustrated nicely in the plot of Young's modulus vs. peak strength (Figure 52).

- For both the Bakken and Three Forks Formation samples, in general, structureless and weakly laminated samples resulted in higher peak strength, whereas strongly laminated or chaotically bedded samples were weaker.

\section{CONCLUSIONS}

Production from the Bakken and Three Forks Formations continues to trend upward as forecasts predict significant production of oil from unconventional resources nationwide. As the U.S. Geological Survey reevaluates the 2008 estimate of 3.65 billion bbl of oil technically recoverable, technological advancements continue to unlock greater unconventional oil resources, and new discoveries continue within North Dakota. It is expected that the play will continue to expand to the southwest, newly develop in the northeastern and northwestern corners of the basin in North Dakota, and fully develop in between. Although not all wells are economical, the success rate has been near $75 \%$ with more than $90 \%$ of the wells finding oil. Currently, only about $15 \%$ of the play has been drilled, and recovery rates are less than $5 \%$, providing a significant future of wells to be drilled and untouched hydrocarbons to pursue through improved stimulation practices or enhanced oil recovery.

This study provides the technical characterizations that are necessary to improve knowledge, provide characterization, validate generalizations, and provide insight relative to hydrocarbon recovery in the Bakken and Three Forks Formations. Oil-saturated rock charged from the Bakken shales and prospective Three Forks can be produced given appropriate stimulation treatments. Highly concentrated fracture stimulations with ceramic- and sand-based proppants appear to be providing the best success for areas outside the Sanish and Parshall Fields. Targeting of specific lithologies can influence production from both natural fracture conductivity and induced. Porosity and permeability are low, but various geological units within the formation are highly saturated and, when targeted with appropriate technology, release economic quantities of hydrocarbons.

\section{TECHNOLOGY TRANSFER}

Technology transfer activity has included the following:

- Publication and presentation - Bremer, J.M., Mibeck, B.A.F., Huffman, B.W., Gorecki, C.D., Sorensen, J.A., Schmidt, D.D., and Harju, J.A., 2010, Mechanical and geochemical assessment of hydraulic fracturing proppants exposed to carbon dioxide 
and hydrogen sulfide: Canadian Society for Unconventional Gas, SPE 136550, October 2010.

- Distribution of Phase I final report to attendees of the Williston Basin Conference in Bismarck, North Dakota, May 2-4, 2010.

- Contributions provided to National Petroleum Council's "Prudent Development of North American Natural Gas and Oil Resources" press release announcement of the study on September 15, 2011. Notable conclusions of the study:

- The potential supply of North American natural gas is far greater than was thought even a few years ago.

- Likely surprising to many, America's oil resources are also proving to be much larger than previously thought.

- Natural gas and oil resources are needed even as efficiency reduces energy demand and alternatives become more economically available on a larger scale.

- Realizing the benefits of natural gas and oil depends on environmentally responsible development.

- New Horizons Oil and Gas Conference, South Dakota School of Mines, Rapid City, South Dakota, October 6-8, 2010.

- Bakken Core Workshop, Federal Center, Lakewood, Colorado, September 23, 2010.

- Presentation of "Evaluation of Key Factors Affecting Successful Oil Production in the Bakken Formation, North Dakota" to the Maximizing Tight Oil in the Bakken Conference, August 2010, Keystone, Colorado, Society of Petroleum Engineers.

- Bakken Cookfest - Industry-led public outreach campaign sponsored by the North Dakota Petroleum Council - July 2010 and July 2011.

- Bakken Consortium, Colorado School of Mines, April 28, 2010, and December 2, 2010.

- Hedberg Conference, "Critical Assessment of Shale Resource Plays," American Association of Petroleum Geologists (AAPG), December 5-10, 2010, Austin, Texas.

- AAPG e-symposium, "The Bakken Petroleum System of the Williston Basin," December 9,2010 - an online webinar attended by the EERC project team.

- American Business Conference on Tight Oil, Denver, Colorado, January 31 February 2, 2011.

- Bakken Hydraulic Fracturing Workshop, Denver, Colorado, February 14-15, 2011. 
- Presentation of "Critical Applied Research for Williston Basin Producers," 19th Williston Basin Petroleum Conference, Regina, Saskatchewan, May 1-3, 2011.

- Presentation at the American Association of State Geologists annual meeting, Dubuque, Iowa, June 13, 2011.

- Presentation of Optimizing Shale Oil and Gas Wells, American Business Conferences, June 28, 2011.

- Hydraulic Fracturing Fundamentals, Workshop held in Grand Forks, North Dakota, July 7, 2011.

- The Rocky Mountain Association of Geologists, "Bakken-Three Forks Petroleum System in the Williston Basin,” Denver, Colorado, September 22, 2011.

\section{REFERENCES}

Bergin, E.M., Bartberger, C.E., and Longman, M., 2011, Defining the updip eastern limit of commercial Bakken oil production, McLean and Dunn Counties, North Dakota: Abstract, Rocky Mountain Association of Geologists Fall Symposium, September 2011.

Besler, M.R., Steele, J.W., Egan, T., and Wagner, J., 2007, Improving well productivity and profitability in the Bakken - a summary of our experiences, drilling, stimulating and operating horizontal wells: SPE 110679.

Bohrer, M., Fried, S., Helms, L., Hicks, B., Juenker, B., McCusker, D., Anderson, F., LeFever, J., Murphy, E., and Nordeng, S., 2008, Bakken Formation Resource Study Project: North Dakota Department of Mineral Resources Report, 23 p.

Crain, E.R., 2011, Crain's petrophysical handbook: www.spec2000.net/12-phires.htm (accessed October 2011).

Donovan, L., 2011, Just getting started: Helms gives stats at Petroleum Council meeting: Bismarck Tribune, September 21, 2011.

Dow, W.G., 1974, Application of oil correlation and source rock data to exploration in Williston Basin: American Association of Petroleum Geologists Bulletin, v. 58, p. 1253-1262.

Farmer, I., 1968, Engineering behavior of rocks: ISBN 041213980.

Flannery, J., and Kraus, J., 2006, Integrated analysis of the Bakken petroleum system, U.S. Williston Basin: American Association of Petroleum Geologists Search and Discovery Article 10105. 
Gidley, J.L., Holditch, S.A., Nierode, D.E., and Veatch, R.W., 1989, Recent advances in hydraulic fracturing: SPE monograph 12.

Grau, A., Sterling, R., Bottjer, R.J., and Dea, P., 2011, Characterization of the Bakken reservoir at Parshall Field and east of the Nesson anticline, North Dakota Chapter 10 of the BakkenThree Forks Petroleum System, in the Williston Basin guidebook: Rocky Mountain Association of Geologists.

Halliburton, 2005, Choosing fracturing sand to optimize permeability achieved vs. cost: H03562, www.Haliburton.com (accessed 2010).

Hoek, E., and Franklin, J.A., 1968, Simple triaxial cell for field or laboratory testing of rock: Transactions of the Institution of Mining and Metallurgy, v. 77A, p. 483-489.

Holditch, S., 2007, "Hydraulic Fracturing" Production and Operations Engineering in Petroleum Engineering Handbook: Society of Petroleum Engineers, 2007.

James, N.P., and Dalrymple, R.W., 2010, Facies models 4: Geological Association of Canada Geotext 6.

Jarvie, D.M., Coskey, R.J., Johnson, M.S., and Leonard, J.E., 2011, The geology and geochemistry of the Parshall area, Mountrail County, North Dakota: Chapter 9 of the Bakken-Three Forks Petroleum System, in the Williston Basin guidebook: Rocky Mountain Association of Geologists.

Johnson, M.S., 2011, Discovery of Parshall Field, North Dakota: Chapter 16 of the BakkenThree Forks Petroleum System, in the Williston Basin guidebook: Rocky Mountain Association of Geologists.

Johnson, M.S., 2010, Parshal Field Bakken shale discovery: Presentation at the American Association of Petroleum Geologists Geochemistry Short Course on Unconventional Shale Resource Plays, April 2010.

Jones, J.R., and Britt, L.K., 2009, Design and appraisal of hydraulic fractures: Society of Petroleum Engineers, ISBN 978-1-55563-143-7.

LeFever, J.A., 2007, Lithofacies of the middle Bakken member, North Dakota: North Dakota Geological Survey Geologic Investigations No. 45.

Meissner, F.F., and Banks, R.B., 2000, Computer simulation of hydrocarbon generation, migration, and accumulation under hydrodynamic conditions - examples from the Williston and San Juan Basins, USA: American Association of Petroleum Geologists Search and Discovery Article 40179. 
Meissner, F.F., 1984, Petroleum geology of the Bakken Formation, Williston Basin, North Dakota and Montana, in G. Demaison and R.J. Murris, eds., Petroleum geochemistry and basin evaluation: AAPG Memoir 35, p. 159-179.

Miller, B., and Paneitz, J., 2008, Unlocking tight oil-selective multi-stage fracturing in the Bakken shale: Society of Petroleum Engineers, SPE 116105.

New England Research, 2011, Elastic constants and strength of berea sandstone: http://ner.com/pdf/NER_tn_berea.pdf (accessed April, 2011).

North Dakota Industrial Commission (NDIC) well file \#16089, "Core Analysis Results from Nordstog 14-23-161-98H Well” June 22, 2006.

Olsen, T.N., Gomez, E., McCrady, D., Forrest, G., Perakis, A., and Kaufman, P., 2009, Stimulation results and completion implications from the consortium multiwell project in the North Dakota Bakken Shale: Society of Petroleum Engineers, SPE 2009.

Pittman, J.K., Price, L.C., and LeFever, J.A., 2001, Diagenesis and fracture development in the Bakken Formation, Williston Basin-implications for reservoir quality in the middle member: U.S. Geological Survey Professional Paper 1653.

Prats, M., 1961, Effect of vertical fractures on reservoir behavior incompressible fluid case: Society of Petroleum Engineers Journal, Vol. 1, 2, 105-118, Trans AIME, 222. SPE-1575-G. DOI: $10.2118 / 1575-G$.

Price, L.C., 1999. Origins and characteristics of the basin-centered continuous-reservoir unconventional oil resource base of the Bakken source system, Williston Basin: Unpublished manuscript, www.undeerc.org/Price (accessed January 2010).

Rankin, R., Thibodeau, M., Vincent, M.C., and Palisch, T.T., 2010, Improved production and profitability achieved with superior completions in horizontal wells - a Bakken/Three Forks case history: Society of Petroleum Engineers, SPE 134595.

Sandberg, C.A., 1962, Stratigraphic section of type Three Forks and Jefferson Formations at Logan, Montana, in Billings Geological Society 13th Annual Field Conference: Proceedings, p. $47-50$.

Schmoker, J.W., and Hester, T.C., 1983, Organic carbon in the Bakken Formation, United States portion of Williston Basin: American Association of Petroleum Geologists Bulletin, v. 67, no. 12 , p. $2165-2174$.

Simenson, A., 2010, Depositional facies and petrophysical analysis of the Bakken Formation, Parshall Field, Mountrail County, North Dakota: Master's thesis, Colorado School of Mines, Golden, Colorado. 
Sneddon, I.N., and Elliot, A.A., 1946, The opening of a griffith crack under internal pressure, Quarterly of Applied Mathematics, Vol. 4, p. 262-267.

Sorensen, J.A. Schmidt, D.D., Smith, S.A., Bailey, T.P., Mibeck, B.A.F., and Harju, J.A., 2010, Subtask 1.2 - Evaluation of key factors affecting successful oil production in the Bakken Formation, North Dakota: Final Report (October 1, 2008-March 30, 2010) report for U.S. Department of Energy Cooperative Agreement No. DE-FC26-08NT4329.1, Grand Forks, North Dakota, Energy \& Environmental Research Center, March.

U.S. Geological Survey, 2008, Assessment of undiscovered oil resources in the DevonianMississippian Bakken Formation, Williston Basin province, Montana and North Dakota, 2008: U.S. Geological Survey Fact Sheet 2008-3021, April, 2 p.

Vincent, M.C., 2011, Restimulation of unconventional reservoirs: when are refracs beneficial?: Journal of Canadian Petroleum Technology, Society of Petroleum Engineers, SPE-136757PA-P.

Webster, R.L., 1982, Analysis of petroleum source rocks of the Bakken Formation (Devonian and Mississippian) in North Dakota: Master's Thesis, University of North Dakota, Grand Forks, North Dakota, $150 \mathrm{p}$. 
APPENDIX A

GEOMECHANICAL TESTING TECHNIQUES 


\section{GEOMECHANICAL TESTING TECHNIQUES}

Triaxial compression tests are specific for underground rock in which in situ conditions are simulated. Generally, the procedures are as follows. A rock core specimen is cut to length, and the ends are machined flat. The specimen is placed in a chamber used to provide confining pressure, and the chamber is placed in a loading frame for applying axial load. Axial load is increased continuously on the specimen, and deformation is measured as a function of load until peak failure is obtained. The data are used to calculate compressive strength, Young's modulus, Poisson's ratio, angle of internal friction, and cohesion intercept.

The test apparatus (Figure A-1) includes the load frame, confining chamber, and data acquisition instrumentation. The load frame used in this evaluation is a modified Forney universal compression machine capable of exerting axial loads as high as 400,000 pounds of force. The load cell records the applied axial forces up to 225,000 pounds of force and communicates values to the data acquisition system.

The device used to provide a confining pressure is known as a Hoek cell (Figure A-2). The test specimen is inserted into a cylindrical hole running axially through the chamber, containing a nonpermeable gasket, and confining pressure is created by pumping hydraulic fluid into a void space that surrounds the test specimen (Figure A-3). Platens are used to contact the test specimen axially and are constructed according to specified standards. The platens are normally hardened steel and are equal or greater than the diameter of the test specimen. Strain is measured in the axial and vertical directions by adhering gauges to the midheight of the specimen and allowing wires to protrude from the Hoek cell.

The preparation of samples has been performed according to the described ASTM International (ASTM) and International Society of Rock Mechanics (ISRM) methods. Specifically, high-concentration diamond bits have been acquired to meet standard core size of 1.185-inch diameter. Although less than the standard 1.85-inch diameter specified by ASTM, the smaller diameter is accepted practice for plugs cut from oil and gas well cores for laboratory testing. Most importantly, the sample cores have a length-to-diameter ratio of at least 2:1, which is required to confine induced shear fractures within the length of the specimen. A high-quality machinist drill press was used to produce sample specimens. Similar ISRM procedures recommend that the ends are ground perpendicular to the specimen to a tolerance of $0.001 \mathrm{in}$. Generally, end caps are not permitted except for circumstances where it is physically impossible to end-grind the material flat. Figure A-4 shows a sample as-received and prepared for insertion into the Hoek cell sleeve for testing. 


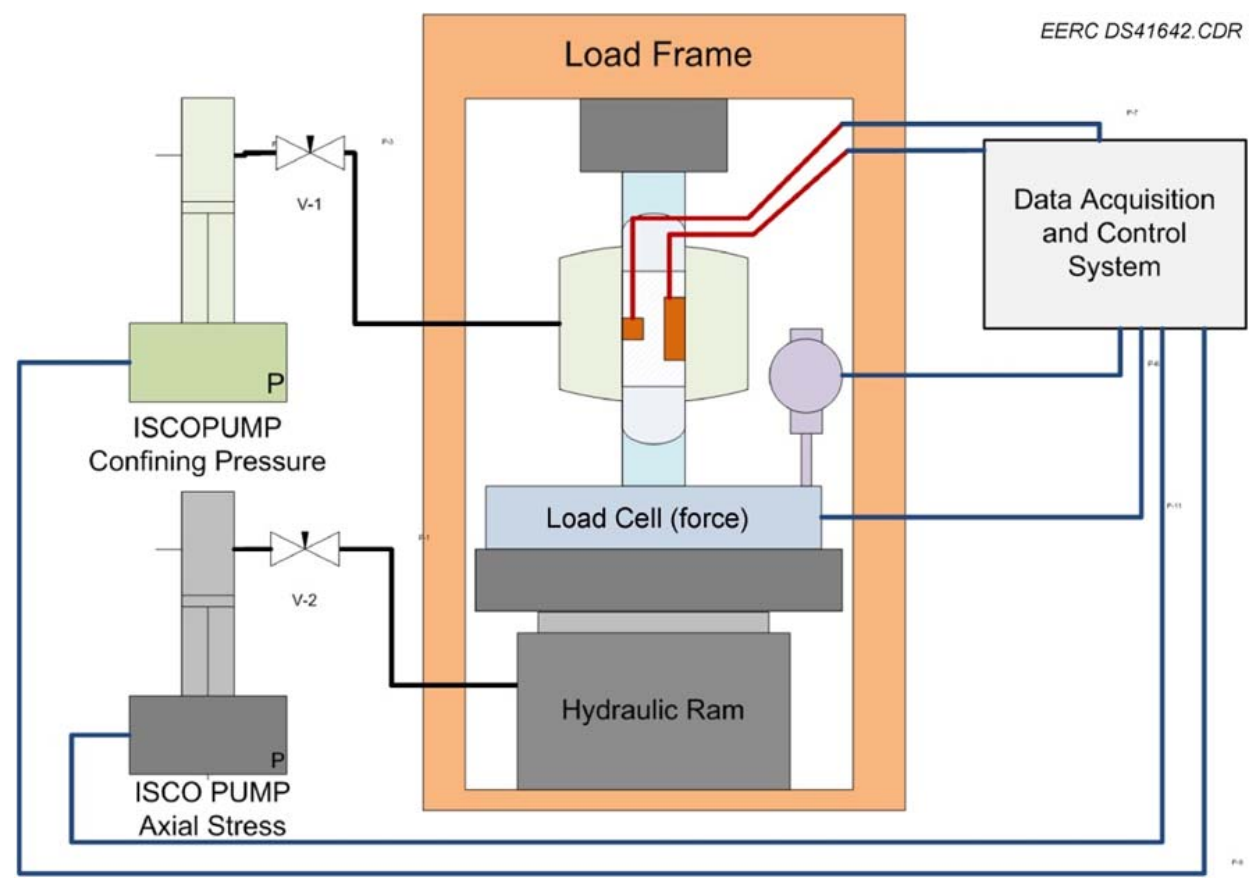

Figure A-1. Diagram showing load frame utilized to conduct multistage triaxial testing.

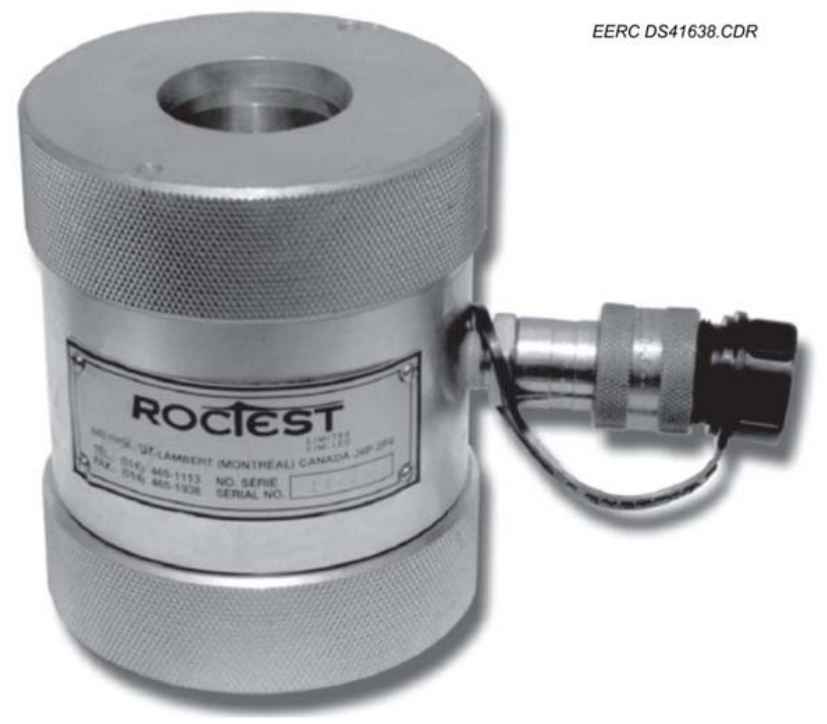

Figure A-2. Hoek cell used for applying confining pressure for triaxial testing. 


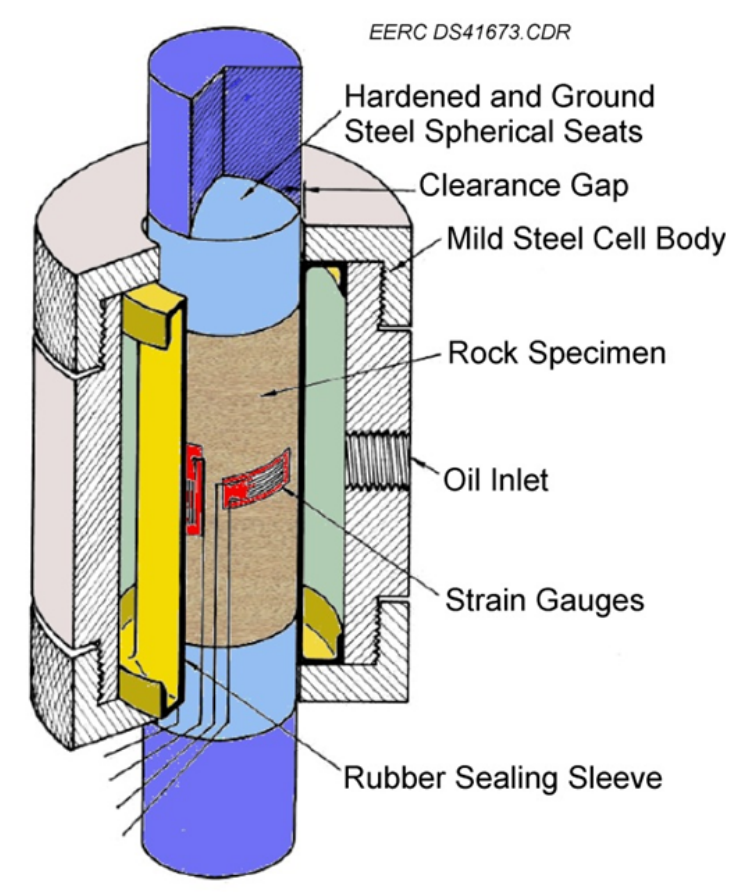

Figure A-3. Diagram illustrating configuration of sample, strain gauges, and Hoek cell as prepared for triaxial testing (modified from Hoek and Franklin [1968].
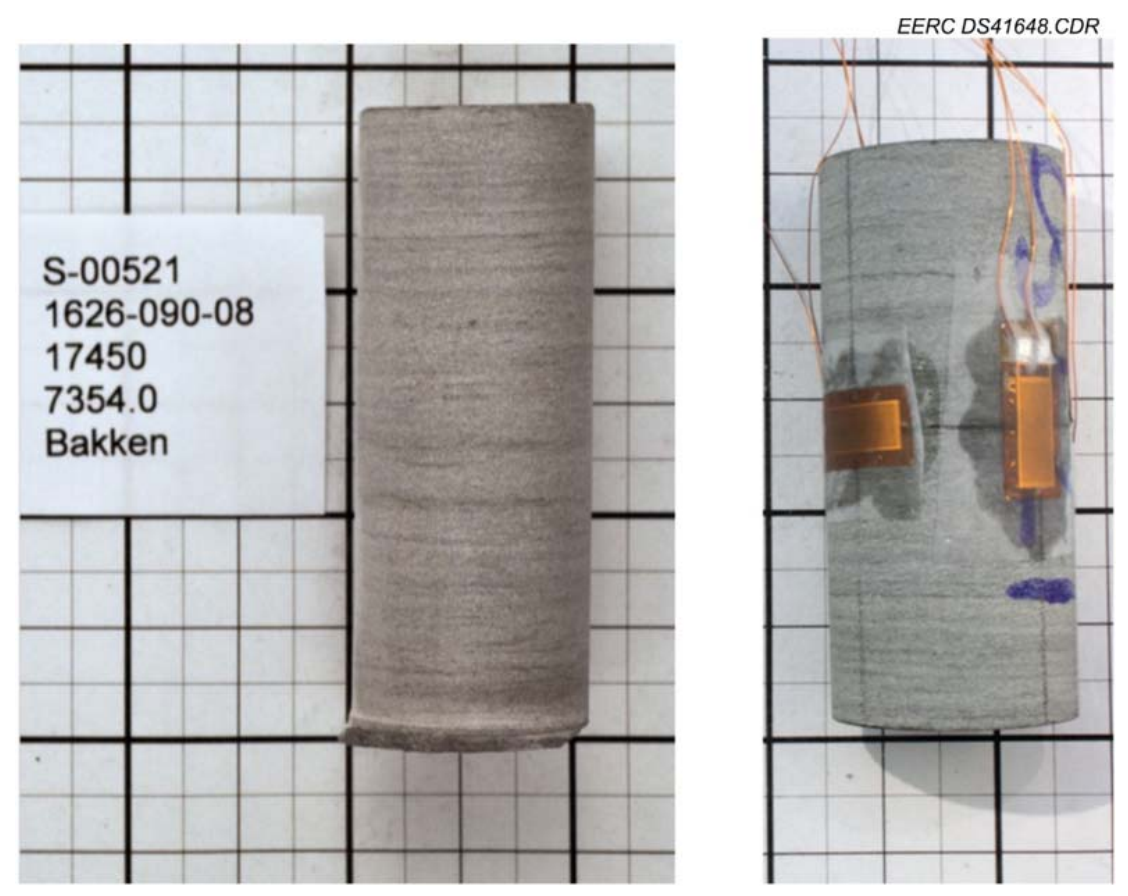

Figure A-4. Sample as-received (left) and prepared for triaxial testing with ends milled and strain gauges applied (right). 
The test method included a nondestructive loading/unloading portion followed by a destructive multistage test for determining the peak strength at different confining pressures. The first portion of testing consists of three loading/unloading cycles, each at a different confining pressure. Unloading (rebound) was initiated before any observed yielding of the sample. This portion of the test allows the most accurate determination of elastic parameters as a result of performing these measurements before damage occurs to the sample. After the rebound portion, the sample is then subjected to an ISRM Type 2 multistage triaxial test (Figure A-5). The results of this test include the determination of a peak strength envelope and Mohr-Coulomb criterion and observation of residual strength. Axial load is applied continuously without shock for a constant stress rate of $72.5-145 \mathrm{psi} / \mathrm{s}$. Yield of the specimen is expected between 2 and 15 minutes for each stage. Continuous data collection is maintained.

The test is performed at three predetermined confining pressures at less than the ultimate strength. The confining pressure is increased to a predetermined level followed by an increase in axial load until the peak strength at the given confining pressure is realized on the stress-strain curve. In most cases, a yield is observed corresponding to deflection of the stress-strain curve of $0.1 \%$. The confining pressure is then raised again to a predetermined level, and axial loading is repeated in the same manner. A final confining pressure is then selected and applied, and axial loading continues until ultimate strength of the specimen is achieved.

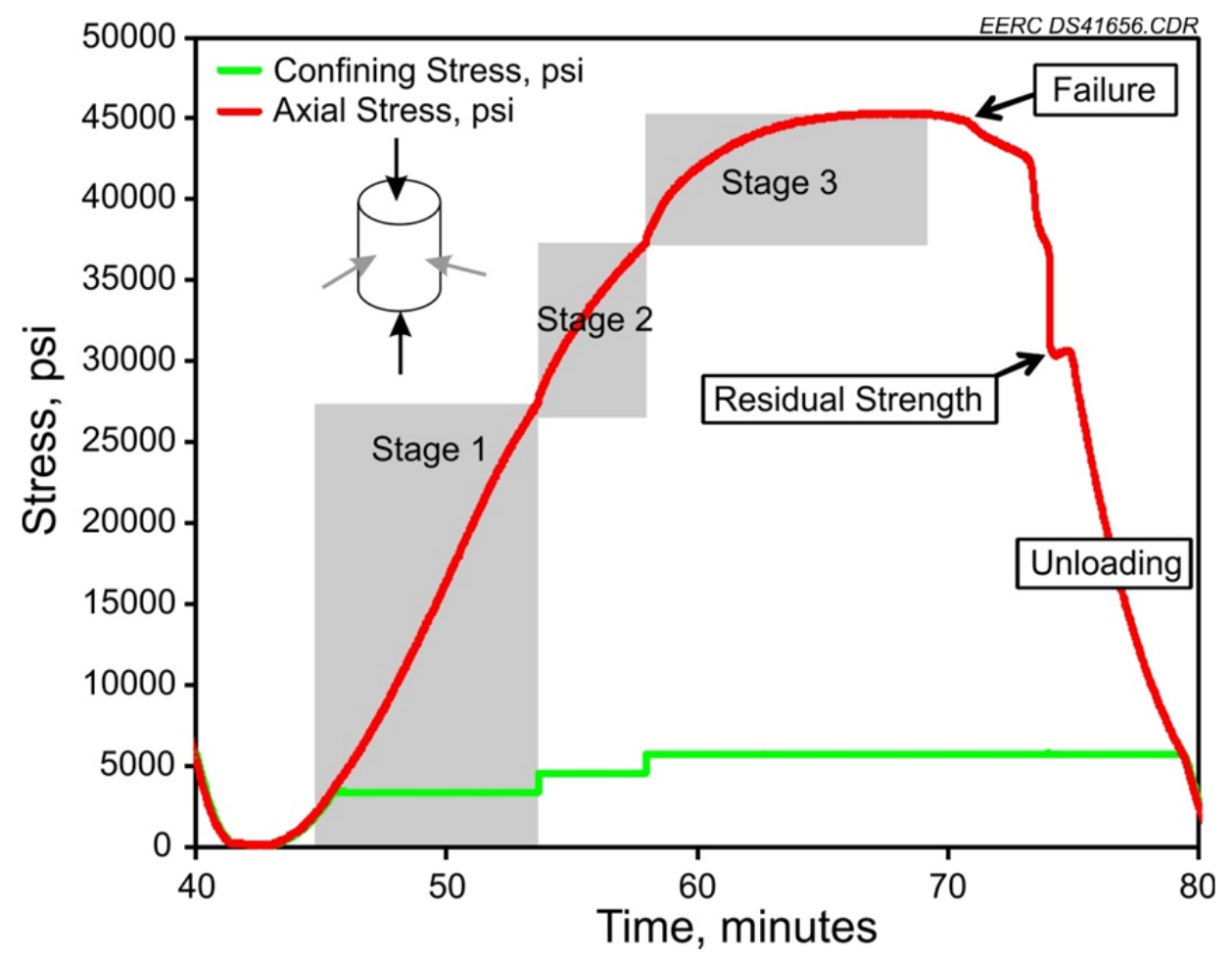

Figure A-5. Example of ISRM Type 2 multistage triaxial test. 


\section{YOUNG'S MODULUS}

Young's modulus, also called the elastic or tensile modulus, quantifies the degree of stiffness of a solid material. Stiffness is the resistance to deformation a material exhibits when under load. Measurements of axial strain (the percent linear deflection) are used in comparison to an applied force (stress) on a sample with known cross-sectional area to determine Young's modulus. The linear relationship between stress and strain is used to compute Young's modulus at three different confining pressures. Data for this calculation are chosen to be in the elastic region of the stress vs. strain curve, after grain compaction occurs but before damage begins in the plastic region. An illustration of the rebound portion of the curve is depicted in Figure A-6. Note that each of the three rebound curves is shown in a different color.

Data highlighted in red indicate the 100 data points for Rebound 1 that would be used for the computation. These data are fitted with a straight line, the slope of which is Young's modulus. A similar region is chosen for Rebound 2 and for Rebound 3.

\section{POISSON'S RATIO}

Poisson's ratio describes how the dimension perpendicular to the applied force is distorted relative to the dimension in parallel with the applied force. Poisson's ratio together with Young' modulus describe the volumetric behavior of a sample under load.

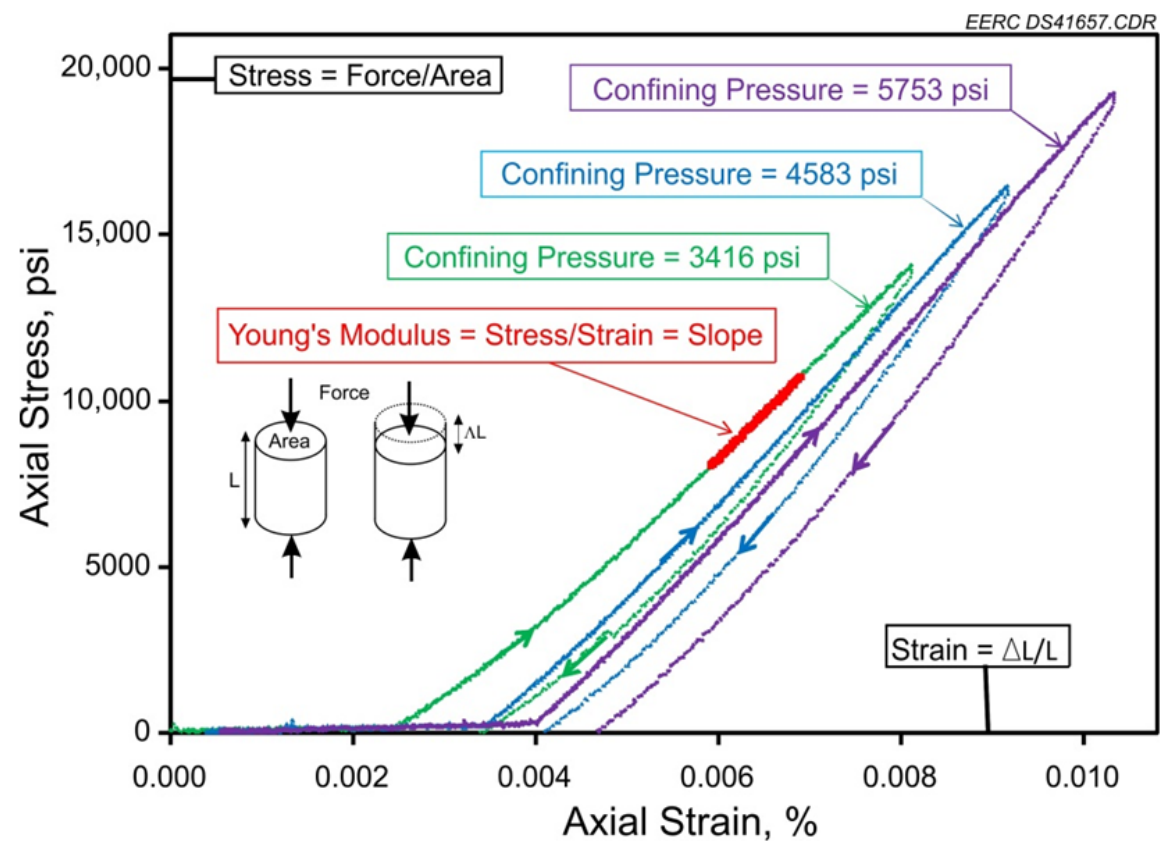

Figure A-6. Figure showing the relationships between deformation and applied force and the data used to derive Young's modulus. 
Axial strain and radial strain measurements are made using variable resistance gauges fixed directly to the sample. When stretched, these gauges increase in resistance. This change is detected using a Wheatstone bridge circuit. Resistance strain gauges are delicate and susceptible to damage during testing. The value recorded during the test is $\mathrm{V}_{\mathrm{r}}$, which is equal to $\left(\mathrm{V}_{\text {out }}{ }^{-}\right.$ $\left.\mathrm{V}_{\text {zero }}\right) / \mathrm{V}_{\text {in }}$ where $\mathrm{V}_{\text {out }}$ is the instantaneous reading from the data acquisition, $\mathrm{V}_{\text {zero }}$ is the value recorded at the beginning of the test (no load applied) and $V_{\text {in }}$ is the excitation voltage. Strain is calculated for each gauge using:

$$
\varepsilon=\frac{-4 V_{r}}{G F\left(1+2 V_{r}\right)} \cdot\left(1+\frac{R_{\text {line }}}{R_{\text {gauge }}}\right)
$$

Where $G F$ is the gauge factor (a correction factor provided by the vendor for batch-to-batch differences), $R_{\text {line }}$ is the electrical resistance in ohms of the connection between the gauge and the bridge completion circuit, and $R_{\text {gauge }}$ is the unstrained resistance of the gauge. It is worth noting that while the horizontal resistance strain gauge is technically measuring the circumferential strain, this value is equal to the radial strain:

$$
\frac{\Delta C}{C_{0}}=\frac{2 \pi(\Delta r)}{2 \pi r_{0}}=\frac{\Delta r}{r_{0}}
$$

Finally, Poisson's ratio is determined from:

$$
\varepsilon_{\text {radial }}=-v \cdot \varepsilon_{\text {axial }}
$$

Which is simply the slope of a line plotted using $\varepsilon_{\text {radial }}$ on the y-axis and $\varepsilon_{\text {axial }}$ on the x-axis (see Figure A-7).

\section{VOLUMETRIC STRAIN}

Volumetric strain is also found using the internal resistance strain gauges and is related to axial and radial strain. An approximation is made here for strains $<<1 \%$; the volumetric strain is determined to be:

$$
\frac{\Delta V}{V_{0}} \cong \varepsilon_{\text {axial }}+2 \varepsilon_{\text {radial }}=\varepsilon_{\text {axial }}(1-2 v)
$$




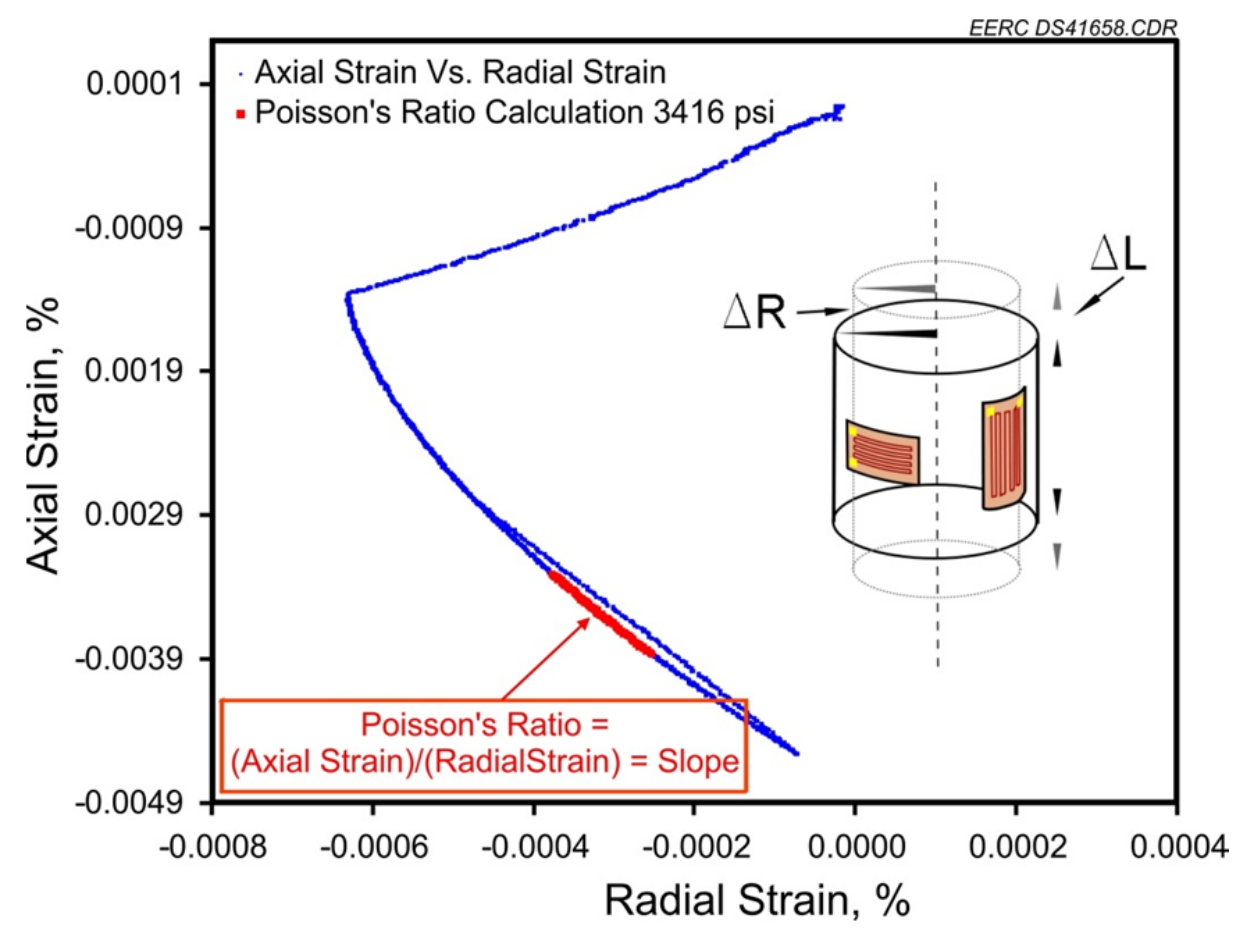

Figure A-7. Relation between resistance strain gauges and the deformation that occurs during testing (exaggerated in inset diagram). Poisson's ratio is defined as the slope (ratio) between the axial strain and radial strain.

\section{PEAK STRENGTH}

Peak strength is found using data from the ISRM Type 2 test. This is clearly seen in the axial stress vs. radial stress curve. Points are chosen at the end of each ISRM stage corresponding to either yield strength or zero tangent point, depending on how the test was conducted. The point is highlighted by the analysis program on the plot of confining pressure vs. axial stress. The peak strength envelope is the linear fit of the peak strengths chosen during this operation (Figure A-8).

\section{RESIDUAL STRENGTH ENVELOPE}

The residual strength is the stress which occurs after rock failure and before controlled release of stress on the sample. An example of residual strength is shown in Figure A-9 on the stress-strain curve. 


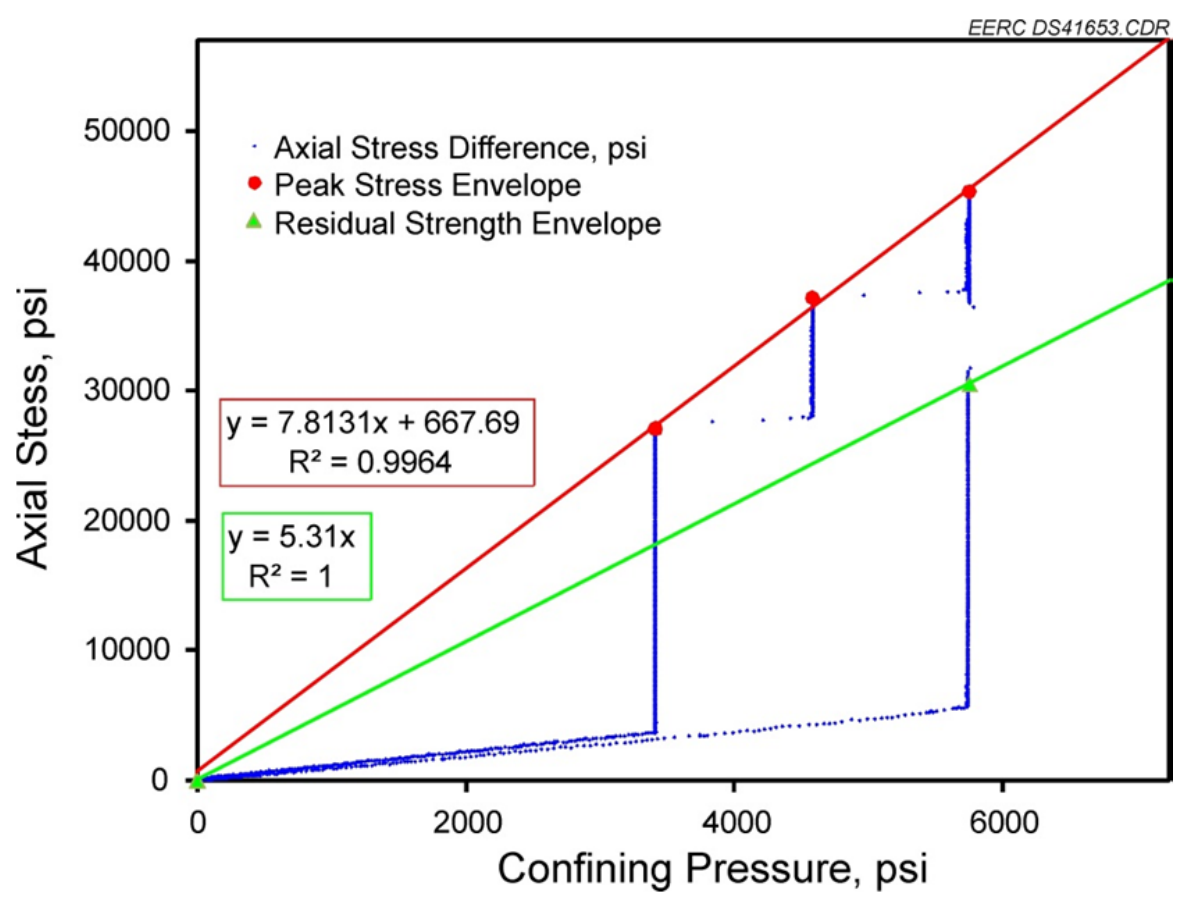

Figure A-8. Plot with peak strength envelope (red) and residual strength envelope (green) shown.

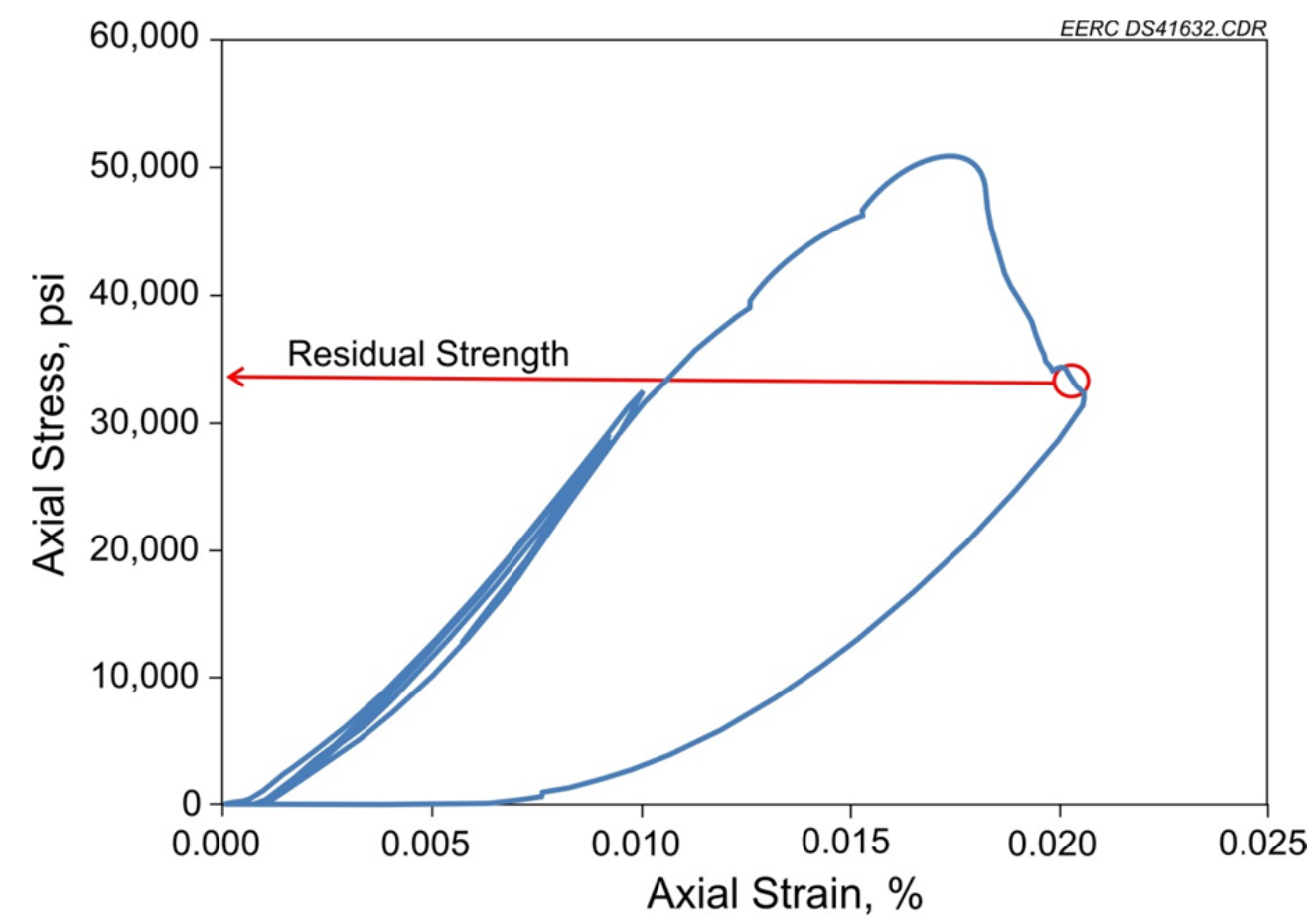

Figure A-9. Residual strength shown in relation to the axial stress vs. strain curve. 


\section{MOHR-COULOMB CRITERION}

Rock fails when it can no longer maintain its internal structure. This occurs when the shear stress in a plane exceeds the normal stress in the same plane. These internal stresses are caused by the combination of applied axial and radial stress. The point at which failure occurs depends on the frictional forces in between the surfaces on each side of the fracture.

A Mohr circle is a collection of points that relate the shear and normal stresses for any plane passing through the rock mass at angle $\theta$. For $\theta=0$, the shear stress is 0 and the normal stress satisfied by either the confining pressure $\left(s_{3}\right)$ or the axial stress $\left(s_{1}\right)$. In other words, the Mohr circle intersects the normal stress axis at the confining pressure $\left(\mathrm{s}_{3}\right)$ and peak strength of $\left(\mathrm{s}_{1}\right)$ as observed for each stage of a multistage triaxial test (Figure A-10). The line tangent to all circles is the Mohr-Coulomb failure criterion and represents the conditions, in terms of $s_{n}$ and $t$, needed to produce a failure plane in the rock. A failure is the point at which the shear stress $t$ exceeds the normal stress $\mathrm{s}_{\mathrm{n}}$. The physical significance of the slope (equal to $\tan [\varphi]$ ) of the Mohr-Coulomb criterion is that rock maintains stability for planes below the friction angle $\varphi$ (Figure A-11).

Each Mohr circle represents a stage of the multistage triaxial test and is defined as a circle, centered on the x-axis of a shear stress vs. normal stress plot. The Mohr-Coulomb criterion is approximated by a line that is tangent to all Mohr circles. This line is given by:

$$
\tau=S_{i}+\sigma \tan \phi
$$

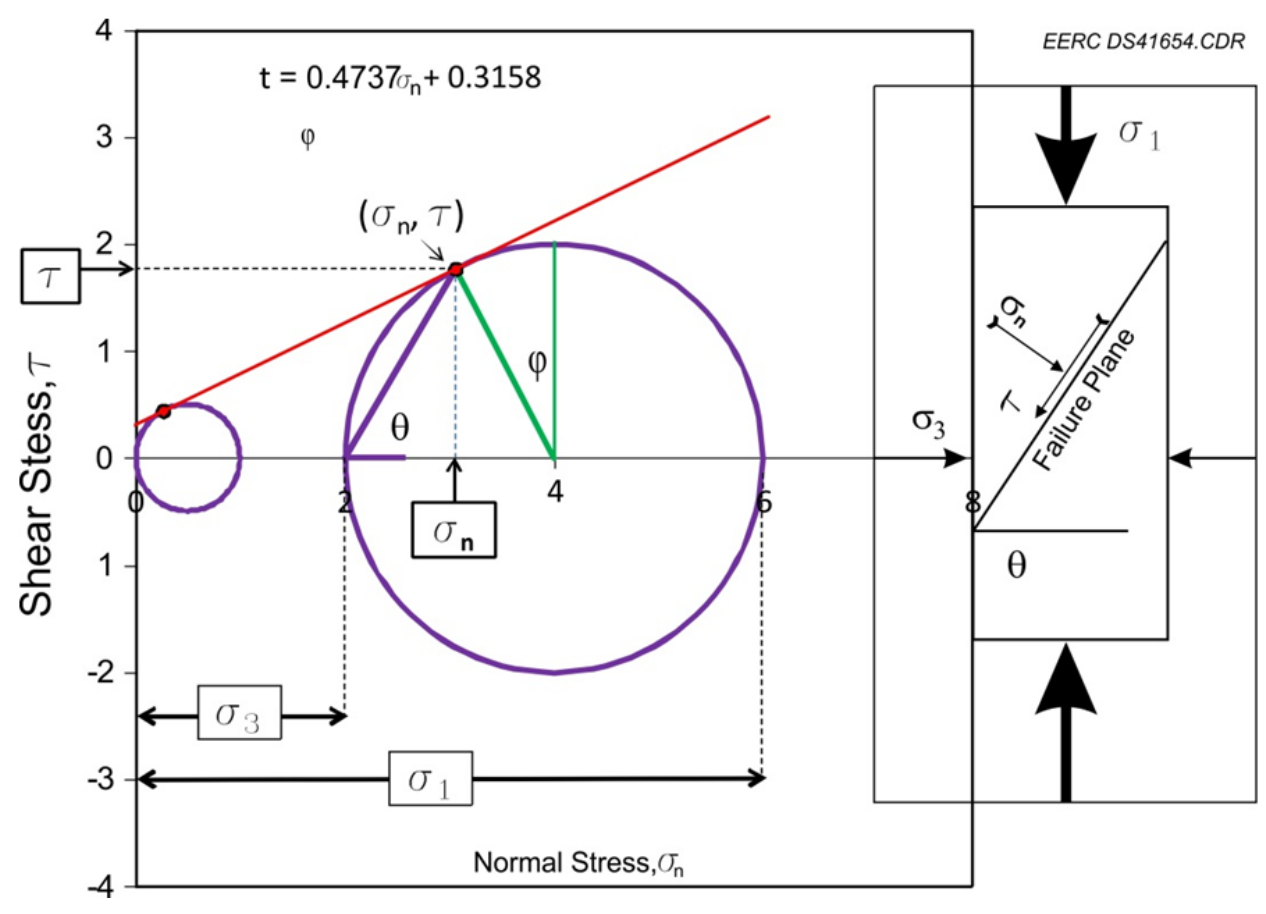

Figure A-10. Assembly of the Mohr circles in the determination of the Mohr-Coulomb failure criterion. 


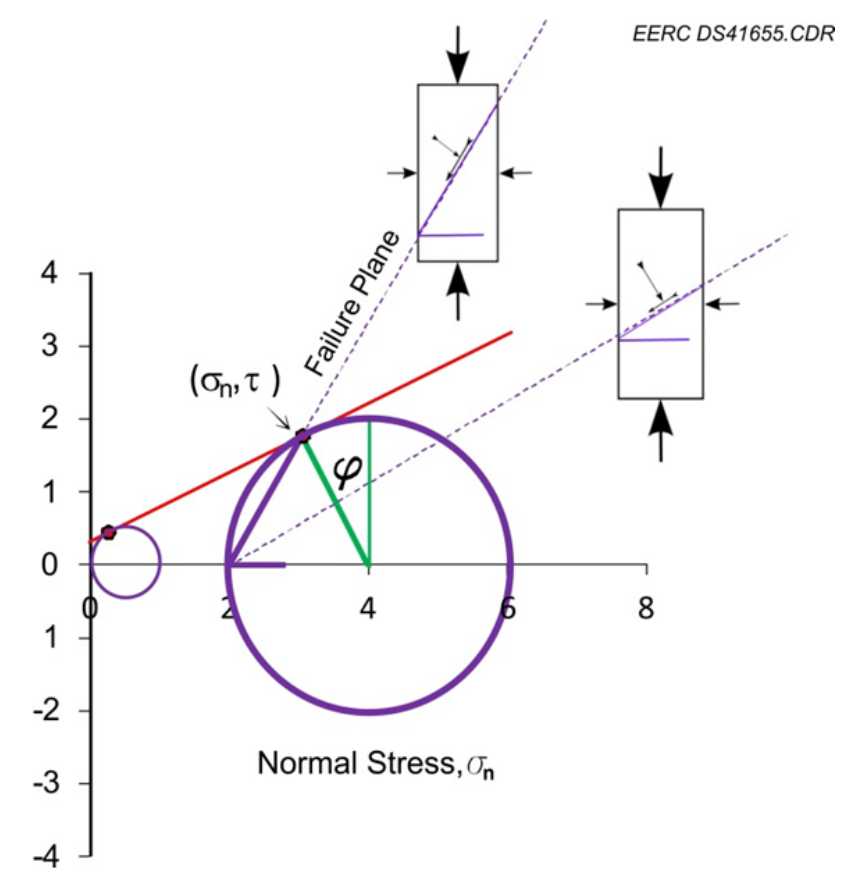

Figure A-11. The physical significance of the Mohr-Coulomb failure criterion. For planes in the rock that are below $\theta$, the normal stress $\sigma_{\mathrm{n}}$ is less than the shear stress $\tau$. At values of $\theta$, a failure plane develops. The angle of internal friction $\varphi$ is related to angle $\theta$.

Where $\tau$ is the shear stress, $\sigma$ is the normal stress, $S_{i}$ is the shear intercept (also called cohesion), and $\varphi$ is the angle of internal friction. The value of $\tan (\varphi)$ is the slope of the line representing the Mohr-Coulomb criterion.

The circles are centered at normal stresses according to $\sigma_{c}=\left(\sigma_{3}+\sigma_{1}\right) / 2$ and have a radius $r=\sigma_{3}-\sigma_{c}$. It follows from trigonometry that points $\left(\sigma_{n}, \tau_{n}\right)$ on the circle for stage $\mathrm{n}$ are closest to the Mohr-Coulomb criterion when:

$$
\begin{aligned}
& \sigma_{n}=\frac{\left(\sigma_{1}+\sigma_{3}\right)}{2}+\frac{\left(\sigma_{1}-\sigma_{3}\right)}{2} \cos 2 \theta \\
& \tau_{n}=\frac{\left(\sigma_{1}-\sigma_{3}\right)}{2} \sin 2 \theta \\
& \tau_{n}=S_{i}+\sigma_{n} \tan \phi \\
& \phi=\arctan (m) \\
& \theta=1 / 4 \pi+1 / 2 \phi
\end{aligned}
$$


The method for determining these points lends itself to an iterative calculation. First, a value for $\theta$ is "guessed" to be $\pi / 2$ and for each stage, Equations 6 and 7 are used to find a candidate point $(\sigma, \tau)$. A line is fitted to these points and is used to determine $\varphi$ using the slope $\mathrm{m}$ (Equation 9). Equation 10 is used to determine $\theta$ from $\varphi$. The resulting $\theta$ from Equation 10 is closer to the true value than the original guess. The result is input to Equation 10 and the process repeated until an acceptable closure is reached. At this point, $\varphi$ is the correct angle of internal friction and $S_{i}$ is the correct shear intercept (cohesion).

\section{REFERENCE}

Hoek, E., and Franklin, J.A., 1968, Simple triaxial cell for field or laboratory testing of rock: Transactions of the Institution of Mining and Metallurgy, v. 77A, p. 483-489. 